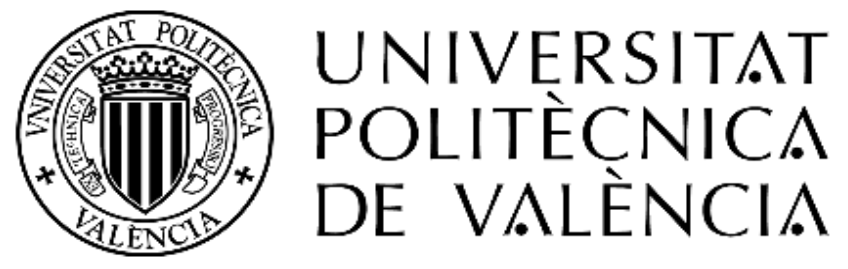

\title{
Biotechnological application of potyvirus-based vectors in cucurbit plants
}

\author{
Fakhreddine Houhou
}

September 2021

Director: Prof. José Antonio Darós Arnau 


\section{Biotechnological application of potyvirus-based vectors in cucurbit plants}

A Thesis presented by

\section{Fakhreddine Houhou}

to obtain the degree of Doctor of Philosophy in Biotechnology

September 2021

Universitat Politècnica de València

DIRECTOR:

Prof. José Antonio Darós Arnau 
Dr. José-Antonio Daròs, Research Professor at Agencia Estatal Consejo Superior de Investigaciones Científicas (CSIC), in Instituto de Biología Molecular y Celular de Plantas (IBMCP), joint center between CSIC and Universitat Politècnica de València

\section{CERTIFIES:}

That FAKHREDDINE HOUHOU, master in Plant Biotechnology, has performed under his direction the work entitled "Biotechnological application of potyvirusbased vectors in cucurbit plants", and authorizes its presentation to qualify for the degree of Philosophical Doctor (Ph.D.).

And for the record, I issue and sign this certificate in Valencia, October 7th, 2021.

José-Antonio Daròs 

TABLE OF CONTENT 


\section{TABLE OF CONTENT}

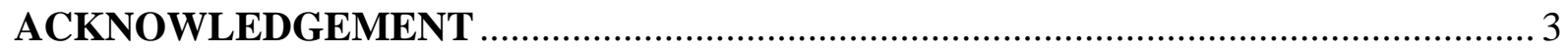

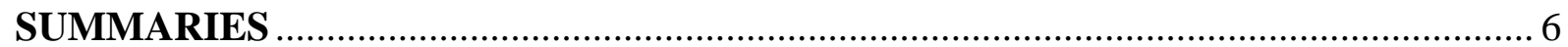

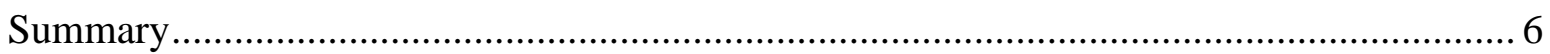

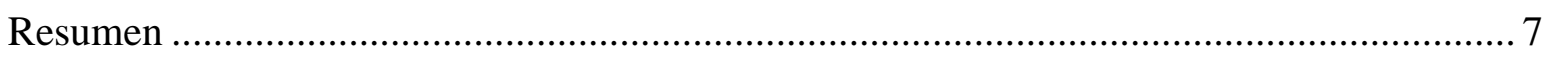

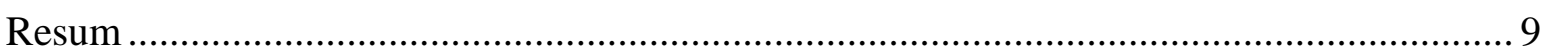

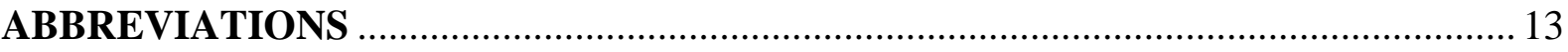

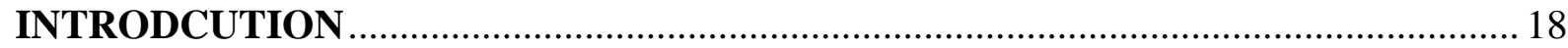

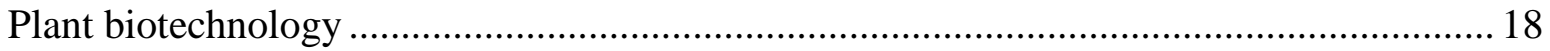

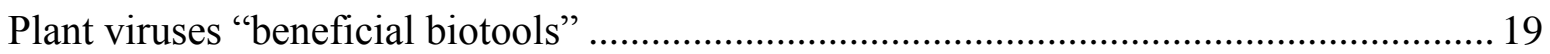

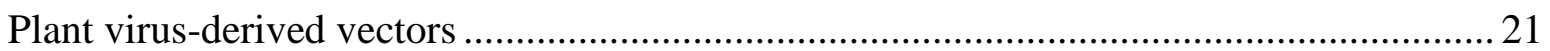

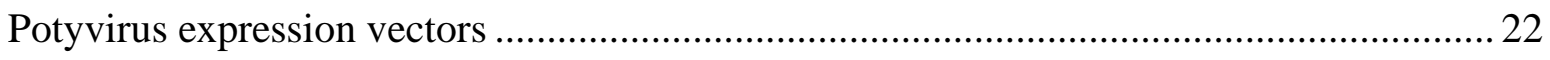

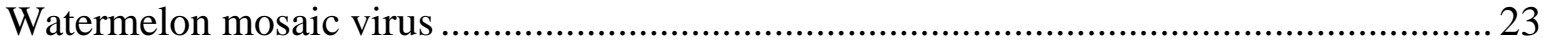

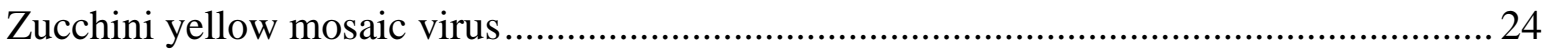

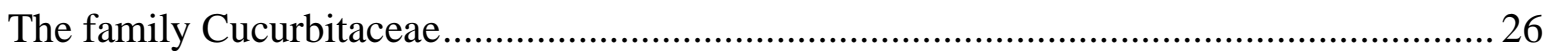

Virus-induced gene silencing and the dynamic process of systemic silencing ...................26

Carotenoids biosynthesis and advances in metabolic engineering ..................................... 31

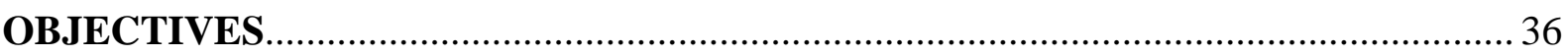

CHAPTER I

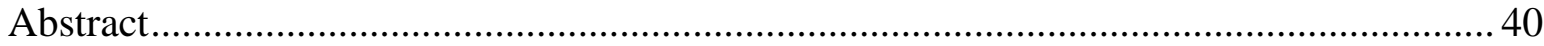

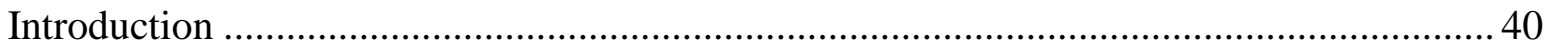

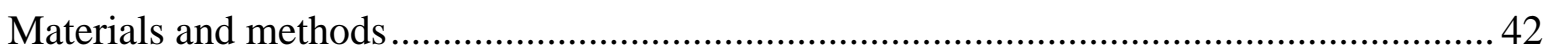

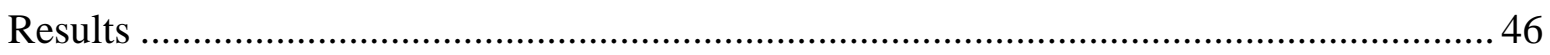

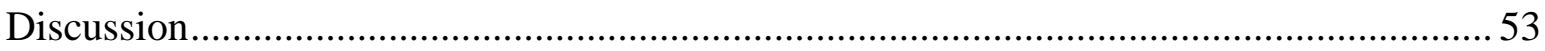

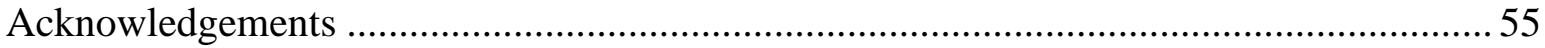

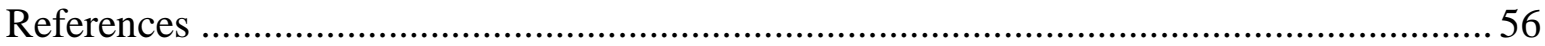

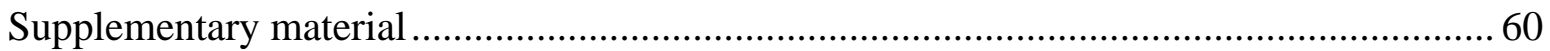

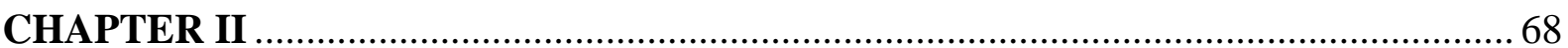

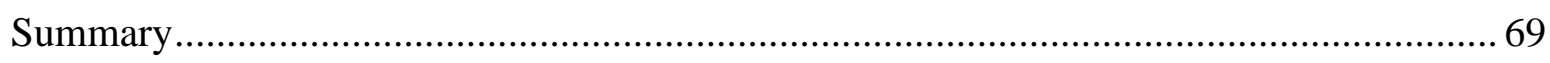

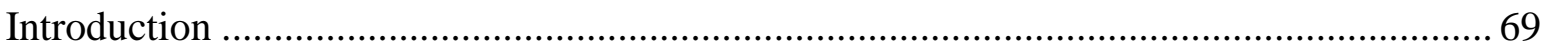

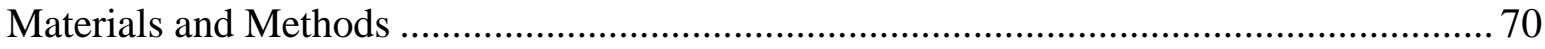

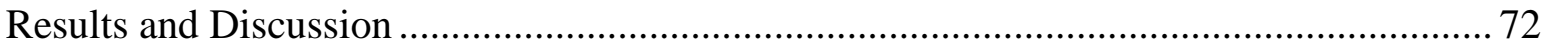




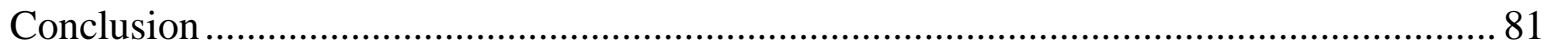

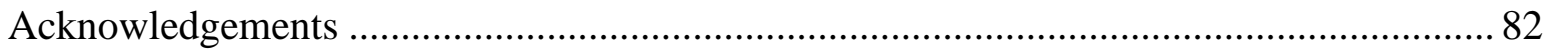

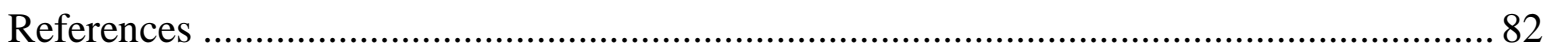

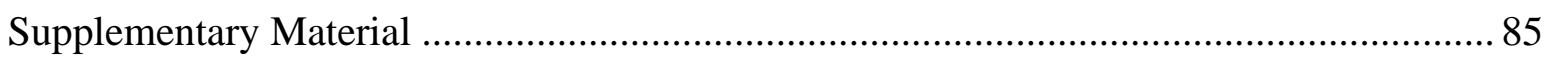

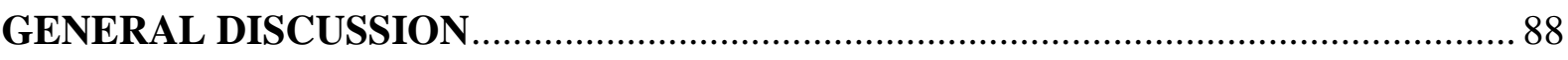

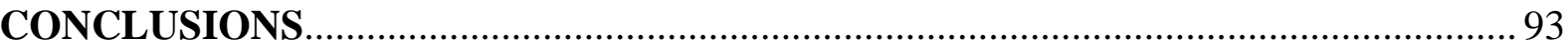

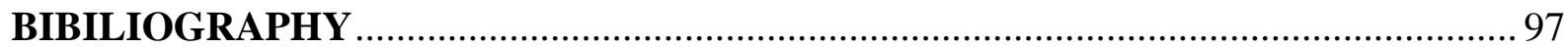



ACKNOWLEDGEMENTS 


\section{ACKNOWLEDGEMENT}

First and foremost, i am extremely grateful to my director dr. José Antonio Daròs, who has guided me along this journey with his constructive advices, continuous support, and patience during my phd study. Thank you for to let me part of the plant virus biotechnology lab where I gained valuable knowledge and technical experience.

My sincere gratitude to prof. Carmelo López del Rincón, my tutor for his inestimable encouragement and continual supervision in all the administrative steps.

A special thanks to dr. Belén Picó for her precious assistance at every stage of the VIGS project.

I want to thank my labmates who were of great company and support during these four years not only as colleagues but also as friends with whom I have shared nice memories, a special thanks to Verónica Aragonés, Teresa Cordero, Mari Carmen Martí, Beltrán Ortolá, María Nicolau, Alexandra Spada, Mireia Uranga. A warm thank to my friends of the institute Meriem, Miguel and Facu.

I dedicate this work to my big family, a special feeling of gratitude to my loving parents Mohammed Rabie and Hafiza Rakia who have been a source of motivation and empowerment for me during this Phd, I thank my uncles Mohammed Tahar and Tarek who were always be by my side, as well as my brothers; Daha, Labib, Rostom, Arkam, Anase and my sister Nedjla who have been encouraging me in every aspect of life. Big thanks to my small family; to my wife Amina and my daughter Saja for their endless love and support. 

SUMMARIES 


\section{SUMMARIES}

\section{Summary}

Nowadays, plant viruses are not only perceived as pathogens, but also able to build a beneficial partnership with their hosts and co-work together from a biotechnological view. The virus, as a vector, can be a tool to introduce heterologous genes into the plant, which will process together with the viral information and produce valuable recombinant proteins, metabolites or nanoparticles. Viral vectors are also able to interfere with plant silencing machinery giving priority to the viral genes.

Potyviruses are plant RNA viruses, mainly encoding a polyprotein of about ten mature proteins with different functions, from which the responsible of silencing suppression are helpercomponent proteinase (HC-Pro) and the viral protein genome-linked (VPg). In the first part of this work, we used a mild isolate of Watermelon mosaic virus (WMV; genus Potyvirus, family Potyviridae) to build a vector for virus induced gene silencing (VIGS) in melon plants. Using this virus as a vector, we expressed a fragment of melon Phytoene desaturase (PDS) mRNA in sense, antisense, and hairpin modalities to investigate the effect of the viral construct on gene silencing. The results showed a stable expression of the inserted sequence fragment in the plant in both sense and antisense orientations, whereas in the hairpin modality the insert was soon lost. Yet, all three constructs induced silencing of the endogenous PDS gene. The usefulness of the WMV for reverse genetic analysis in melon was confirmed expressing a fragment of Magnesium chelatase subunit I (CHLI). Overall, our results supported that the WMV vector is useful to apply the VIGS technology in melon and, possibly, other cucurbits.

In the second part of this work, with the aim to fortify edible fruits with health promoting metabolites, a viral RNA vector derived from Zucchini yellow mosaic virus (ZYMV; genus Potyvirus, family Potyviridae) was used to express a bacterial phytoene synthase (crtB) in zucchini (Cucurbita pepo L.) fruits. This enzyme catalyzes the first committed step of carotenoid biosynthesis. The crtB expression mediated by ZYMV resulted in the overaccumulation of a range of carotenoids and tocopherols metabolites, namely $\alpha$ - and $\beta$ carotene (pro-vitamin A), lutein and phytoene, as well as $\alpha$ - and $\gamma$-tocopherol (vitamin E), in both zucchini rind and flesh. This result illustrates how edible fruits can be metabolically fortified using viral vectors without plant genome modification. 


\section{Resumen}

Hoy en día, los virus de las plantas no sólo se perciben como patógenos, sino que también son capaces de establecer una asociación beneficiosa con sus huéspedes y colaborar desde un punto de vista biotecnológico. El virus, como vector, puede ser una herramienta para introducir genes heterólogos en la planta, que se procesarán junto con la información viral y producirán valiosas proteínas recombinantes, metabolitos o nanopartículas. Los vectores virales también son capaces de interferir con la maquinaria de silenciamiento de la planta dando prioridad a los genes virales.

Los potyvirus son virus de ARN de plantas, que codifican principalmente una poliproteína con unas diez proteínas maduras con diferentes funciones, de las cuales las responsables de la supresión del silenciamiento son la proteína componente auxiliar (HC-Pro) y la proteína viral ligada al genoma (VPg). En la primera parte de este trabajo, utilizamos un aislado suave del virus del mosaico de la sandía (WMV; género Potyvirus, familia Potyviridae) para construir un vector para el silenciamiento génico inducido por virus (VIGS) en plantas de melón. Utilizando este virus como vector, expresamos un fragmento de ARNm de la Fitoeno desaturasa (PDS) de melón en las modalidades sentido, antisentido y horquilla para investigar el efecto de la construcción viral en el silenciamiento génico. Los resultados mostraron una expresión estable del fragmento de secuencia insertado en la planta en ambas orientaciones, sentido y antisentido, mientras que en la modalidad de horquilla el inserto se perdió pronto. Sin embargo, las tres construcciones indujeron el silenciamiento del gen $P D S$ endógeno. Se confirmó la utilidad del WMV para el análisis genético inverso en melón expresando un fragmento de la subunidad I de la quelatasa de magnesio $(C H L I)$. En general, nuestros resultados apoyaron que el vector WMV es útil para aplicar la tecnología VIGS en melón y, posiblemente, en otras cucurbitáceas.

En la segunda parte de este trabajo, con el objetivo de fortificar las frutas comestibles con metabolitos promotores de la salud, se utilizó un vector de ARN viral derivado del virus del mosaico amarillo del calabacín (ZYMV; género Potyvirus, familia Potyviridae) para expresar una fitoeno sintasa bacteriana (crtB) en los frutos del calabacín (Cucurbita pepo L.). Esta enzima cataliza el primer paso de la biosíntesis de carotenoides. La expresión de la crtB mediada por el ZYMV dio lugar a la sobreacumulación de una serie de metabolitos de carotenoides y tocoferoles, concretamente $\alpha$ - y $\beta$-caroteno (provitamina A), luteína y fitoeno, así como $\alpha$ - y $\gamma$-tocoferol (vitamina E), tanto en la piel como en la pulpa del calabacín. Este 
resultado ilustra cómo se pueden enriquecer metabólicamente las frutas comestibles utilizando vectores virales sin modificar el genoma de la planta. 


\section{Resum}

A dia de hui, els virus de les plantes no sols es perceben com a patògens, sinó que també són capaços d'establir una associació beneficiosa amb els seus hostes i col-laborar des d'un punt de vista biotecnològic. El virus, com a vector, pot ser una eina per a introduir gens heteròlegs en la planta, que es processaran juntament amb la informació viral i produiran valuoses proteïnes recombinants, metabòlits o nanopartícules. Els vectors virals també són capaços d'interferir amb la maquinària de silenciament de la planta donant prioritat als gens virals.

Els potyvirus són virus d'ARN de plantes, que codifiquen principalment una poliproteïna d'unes deu proteïnes madures amb diferents funcions, de les quals les responsables de la supressió del silenciament són la proteïna component auxiliar (HC-Pro) i la proteïna viral lligada al genoma (VPg). En la primera part d'aquest treball, utilitzem un aïllat suau del virus del mosaic del meló d'Alger (WMV; gènere Potyvirus, família Potyviridae) per a construir un vector per al silenciament gènic induït per virus (VIGS) en plantes de meló. Utilitzant aquest virus com a vector, expressem un fragment d'ARNm de la Fitoeno desaturasa (PDS) del meló en les modalitats de sentit, antisentit i forqueta per a investigar l'efecte de la construcció viral en el silenciament gènic. Els resultats van mostrar una expressió estable del fragment de sequiència inserit en la planta en totes dues orientacions, sentit i antisentit, mentre que en la modalitat de forqueta l'inserit es va perdre prompte. No obstant això, les tres construccions van induir el silenciament del gen PDS endogen. Es va confirmar la utilitat de la WMV per a l'anàlisi genètica inversa en meló expressant un fragment de la Subunitat I de la quelatasa de magnesi (CHLI). En general, els nostres resultats van secundar que el vector WMV és útil per a aplicar la tecnologia VIGS en meló i, possiblement, en altres cucurbitáceas.

En la segona part d'aquest treball, amb l'objectiu de fortificar les fruites comestibles amb metabòlits promotors de la salut, es va utilitzar un vector d'ARN viral derivat del virus del mosaic groc de la carabasseta (ZYMV; gènere Potyvirus, família Potyviridae) per a expressar una fitoeno sintasa bacteriana (crtB) en els fruits de la carabasseta (Cucurbita pepo L.). Aquest enzim catalitza el primer pas compromés de la biosíntesi de carotenoides. L'expressió de la crtB mediada pel ZYMV va donar lloc a la sobreacumulación d'una sèrie de metabòlits de carotenoides i tocoferoles, concretament $\alpha$ - i $\beta$-caroté (provitamina A), luteïna i fitoeno, així com $\alpha$ - i $\gamma$-tocoferol (vitamina E), tant en la pell com en la polpa de la carabasseta. Aquest 
resultat il·lustra com es poden enriquir metabólicamente les fruites comestibles utilitzant vectors virals sense modificar el genoma de la planta. 

ABBREVIATIONS 


\section{ABBREVIATIONS}

AGO, Argonaute

ALSV, Apple latent spherical virus

bp, base pair

CaMV, Cauliflower mosaic virus

CCD2L, carotenoid cleavage dioxygenase $2 \mathrm{~L}$

cDNA, complementary DNA

CGMMV, Cucumber green mottle mosaic virus

CHLI, Magnesium chelatase subunit I

$\mathrm{CI}$, cilindrical inclusion

CMV, Cucumber mosaic virus

$\mathrm{CP}$, capsid protein

CPMV, Cowpea mosaic virus

crtB, phytoene synthase

crtE/GGPPS, GGPP synthase

crtI, phytoene desaturase

$\mathrm{Ct}$, cycle threshold

DCL, Dicer-like

DGI, dark green island

DMAPP, dimethylallyl diphosphate

DNA, deoxyribonucleic acid

dsRNA, double-stranded RNA

dpi, days post-inoculation

EDTA, ethylenediaminetetraacetic acid

GAP, glyceraldehyde-3-phosphate

GFP, green fluorescent protein

GGPP geranylgeranyl diphosphate

GOI, gene of interest

GUS, $\beta$-glucuronidase

HC-Pro, helper component protease

HPLC, high-performance liquid chromatography

IPP, isopentenyl diphosphate

LB, Luria-Bertani 
MEP, methylerythriol 4-phosphate

$\mathrm{MP}$, movement protein

mRNA, messenger RNA

NIa, nuclear inclusion a

NIaPro, nuclear inclusion a protease

$\mathrm{NIb}$, nuclear inclusion $\mathrm{b}$

nt, nucleotide

OD, optic density

ORF, open reading frame

$\mathrm{P} 1$, protein 1

$\mathrm{P} 3$, protein 3

PD, plasmodesmata

Pdk, Piruvate orthophosphate dikinase

PDS, phytoene desaturase

PIPO, pretty interesting Potyviridae ORF

PSY, phytoene synthase

PTGS, post-transcriptional gene silencing

PVX, Potato virus $X$

qPCR, quantitative polymerase chain reaction

RdRp, RNA-dependent RNA polymerase

RISC, RNA-induced silencing complex

RNA, ribonucleic acid

$\mathrm{RT}$, reverse transcription

siRNAs, small interfering RNAs

ssRNA+, single stranded positive-sense RNA

TAE, Tris-acetate-EDTA

T-DNA, transferred DNA

TEV, Tobacco etch virus

TMV, Tobacco mosaic virus

TRV, Tobacco rattle virus

TuMV, Turnip mosaic virus

VIGS, Virus-induced gene silencing

VPg, viral protein genome-linked

WMV, Watermelon mosaic virus 
ZYMV, Zucchini yellow mosaic virus 



\section{INTRODUCTION}




\section{INTRODCUTION}

\section{Plant biotechnology}

Throughout history, plants played an essential part in mankind life, domesticated principally as food supply, building material and in medicinal use. Plants are also natural bioreactors with a powerful biosynthetic capacity to utilize light source (photosynthesis) and convert it to biomass and protein accumulation (Xu et al., 2012). In fact, new techniques have been applied to metabolic engineering to upgrade plant genome with a greater faculty to produce higher amounts of specific plant secondary compounds that ultimately will be directed in pharmaceutical and biopharmaceutical industries (Hidalgo et al., 2018). Therefore, new approaches have emerged over the last decades to enhance plant agronomical values with the application of genetic engineering techniques known as plant biotechnology that are developed on the principles of cellular totipotency and genetic transformation (Vasil, 2008).

Plant biotechnology has experienced exponential progress after the breakthrough of agrobacterium-mediated gene transfer reported in the early 1980s, which was facilitated by the capacity of Agrobacterium tumefaciens to transfer DNA fragments into plant cells and generate transgenic plants (Grimsley et al., 1986; Szeto et al., 1977). With such molecular tools, plants have been manipulated to overproduce endogenous or foreign product of interest, like recombinant proteins and other secondary metabolites used in pharmaceutical industries, to produce vaccines, or in food industry to develop plants with higher nutritional values (Canto, 2016). More recently, plants are being used in biotechnology as leading expression platforms for antibody production thanks to their efficient post-transcriptional modifications (PTMs) that enable the assembly of complex proteins and the production of diagnostic and therapeutic proteins (Rybicki, 2020). The application of plants as biofactories of recombinant proteins are referred to as "Molecular Farming" (Shanmugaraj et al., 2020; Wang et al., 2021).

Given the long process behind the development of transgenic plants and the instability of seed lines, as well as the difficulties with consistency in expression due to gene silencing and positioning effects, more research in the field of plant biotechnology is still required. On the other hand, transient expression methods in plants can be more advantageous in time and efficiency (Pogue et al., 2002). Transient delivery systems, including biolistic bombardment, A. tumefaciens-mediated transfer of T-DNA fragments into plant, and the use of plant viruses 
as expression vectors, are successful alternatives to plant stable transformation. Viruses have the attribute of prioritize the productions of their own proteins in the host cells, which usually results in a high expression levels that are rarely reached by inducible or constitutive expression of transgenes (Porta and Lomonossoff, 2002).

\section{Plant viruses "beneficial biotools"}

In present time, the perception of viruses has changed; they are not regarded only as pathogens but they can also be beneficial biotechnological tools (Hefferon, 2012; Wang et al., 2020). During these recent decades, plant virology has contributed to biology and biotechnology with the discovery of viral elements such as promoters, terminators, translational enhancers and various cis-regulatory sequences to understand fundamental concepts of modern biology (Lico et al., 2008). The most important breakthrough being the pioneering discovery of Tobacco mosaic virus in the late nineteenth century (Mayer, 1886), which has made a great impact on the science of virology and plant pathology (Lomonossoff and Wege, 2018).

To survive and propagate, viruses usually rely on arthropods, nematodes, or fungal vectors to transport them to their host plants, where they must pass a series of natural barriers to replicate. Virus entry into the host cell can also be facilitated through mechanically-induced wounds or A. tumefaciens-mediated transmission (Carbonell et al., 2016; Sanfaçon, 2017). After replication, viral movement from cell to cell is performed through channels of plasmodesmata (PD), with the coordination of virus-encoded movement proteins (MP), and then long-distance usually through the phloem (Heinlein, 2015; Lucas, 2006).

There are more than 6500 species of plant viruses described to date, which are identified and classified in several distinct taxa according to the latest report of the International Committee on Taxonomy of Viruses. One of the largest families of plant viruses is the family Potyviridae, which includes 12 genera and 228 species (Wylie et al., 2017). They have a broad geographical distribution and can cause severe damages in a wide range of mono- and dicotyledonous plant species. Hence, as RNA viruses, they are well known for having high mutation rates, short generation times, and large population sizes. They have a high evolutionary potential and are typical emerging and re-emerging viruses that threaten valuable crop cultivations (Elena and Sanjuán, 2007). Viewed as significant pathogens, potyviruses affect several important crops of great economical interest when presented alone or in synergy with other viruses leading to great 
loss in cultivations. The genus Potyvirus is one of the 12 genera of the family Potyviridae. Genera are differentiated in terms of their host range, transmission vector, genomic features and phylogeny (Ivanov et al., 2014; Mäkinen, 2020; Wylie et al., 2017).

Due to the number of species, potyviruses (genus Potyvirus) are studied at a greater extent than other viruses belonging to the other genera within the family. These studies brought to light important aspect of plant virology which includes, functional characterization of viral proteins, molecular interaction with hosts and vectors, structure, taxonomy, evolution, epidemiology, and diagnosis (Revers and García, 2015). Considering that potyviruses are spread by aphids in a non-persistent manner, and that each potyvirus may be spread by several aphid species, and each aphid species may transmit many potyviruses, control and prevention of the infection is arduous to manage for farmers. Agricultural crops provide suitable environment for aphids to proliferate rapidly, with their parthenogenetical capacity to adapt and reproduce on woody winter hosts, and herbaceous summer host species successively producing large migrant populations (Von Dohlen et al., 2006; Gibbs et al., 2008). Seed transmission is another plausible mode of propagation in some species (Zamora et al., 2017).

The genome of potyviruses consists of a single-stranded, positive-sense RNA with a flexuous filamentous particle. Its 5' end is covalently linked to a viral protein genome-linked (VPg), and its 3' terminus is polyadenylated. It encodes a main open reading frame (ORF) expressed as a polyprotein precursor processed into ten smaller proteins: protein 1 (P1), helper component protease (HC-Pro), protein 3 (P3), cylindrical inclusion (CI), nuclear inclusion a (NIa; further split in VPg and protease domains), nuclear inclusion b (NIb), capsid protein (CP) and two small proteins $6 \mathrm{~K} 1$ and $6 \mathrm{~K} 2$. There is an additional protein, P3N-PIPO, separately synthesized through a transcriptional slippery mechanism in the P3 region, which was found to be present in all potyviral members (Figure 1) (Chung et al., 2008; Majer et al., 2015; Revers and García, 2015). Exceptionally, another short ORF termed PISPO (pretty interesting sweet potato potyviral ORF) was recently discovered within the P1 coding sequence of Sweet potato feathery mottle virus (SPFMV), The P1N-PISPO was found to be involved in counteracting the RNA silencing-based plant defense to viral infection (Mingot et al., 2016). Nonetheless, one of the major property of potyviruses, in terms of biotechnology, is the elongated virion that permits large insertions of foreign genetic material (Bedoya et al., 2010). 


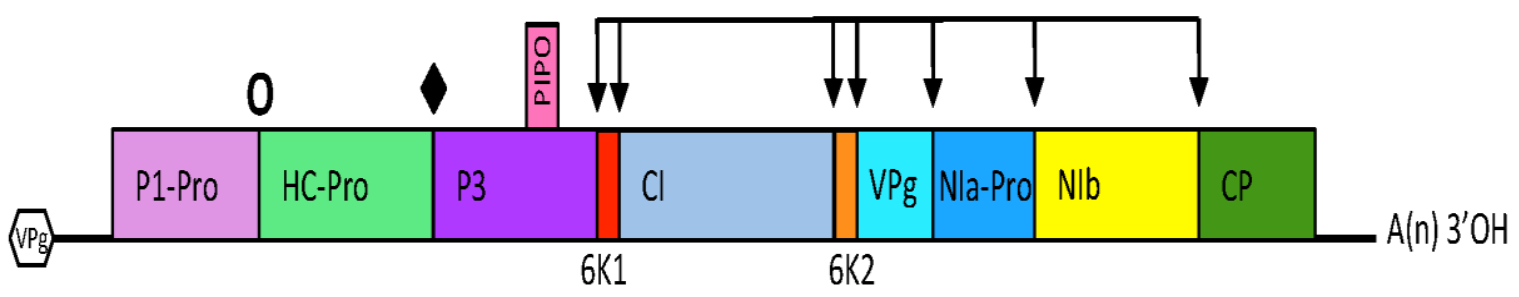

Figure 1. Schematic illustration of a model member of the genus Potyvirus. P1-Pro (protein 1 protease), HC-Pro (helper-component protease) P3 (protein 3), PIPO (pretty interesting Potyviridae ORF), 6K (six kilodalton peptide), CI (cylindrical inclusion). VPg (viral protein genome-linked), NIa-Pro (nuclear inclusion a protease). NIb (nuclear inclusion b), CP (coat protein). Cleavage sites of P1-Pro (O), HCPro $(\diamond)$ and NIa-Pro $(\downarrow)$ are indicated. Figure taken from Wylie et al. (2017).

\section{Plant virus-derived vectors}

Nowadays, viruses are being extensively applied in plant biotechnology as potent tools to produce valuable recombinant proteins. This bioproduction systems are development for the benefit of food, industrial and pharma sectors, for their velocity, and cost-effective performance. Plant viruses are exploited in different approaches. For example, they are used as RNA silencing vectors for gene functional studies by identifying a loss-of-function phenotype for a gene of interest (Dommes et al., 2019). Moreover, plant viral vectors have been engineered to over-express endogenous and/or foreign genes for the production of vaccines and health beneficial molecules (Wang et al., 2020). In contrast to systems based on bacteria, yeast or animal cells, the production of proteins in plants arises as an affordable and safer alternative with low contamination risks, in addition to the ability of certain plants to produce large amounts of biomass in a short span (Kusnadi et al., 1997; Peyret and Lomonossoff, 2015).

The first plant virus expression vector developed was a double stranded DNA vector derived from Cauliflower mosaic virus (CaMV), from family Caulimoviridae (Howell and Hull, 1978; Szeto et al., 1977), although applications faced limitation in the packaging capacity affecting essential functions of viral DNA (Lico et al., 2008). Since this initial vector, many more strategies using DNA and RNA plant viruses have been developed to date (Wang et al., 2020). In the case of RNA virus-based vectors, new techniques have also been elaborated to express viral RNA in plant cells. A successful system widely used in transient expression is the Gramnegative bacterium A. tumefaciens that harbors a functional plasmid named Ti (tumor- 
inducing), where it is possible to integrate genes of interest (GOI) in a section of this plasmid (the transfer DNA, T-DNA) (Chilton et al., 1977). Subsequently, viruses will be introduced to plant leaves by agroinoculation aiming to hijack the transcriptional and processing machineries of the plant cell to replicate and proliferate systematically.

\section{Potyvirus expression vectors}

Potyvirus-based vectors, which were firstly developed based on Tobacco etch virus (TEV), allowed the expression of proteins that released from the viral polyprotein (Dolja et al., 1992). The main features of potyviruses as viral vectors is their ability to produce foreign heterologous proteins in an equimolar amount as most of the other viral proteins, in addition to the filamentous shape of the virus, which offers no major restrictions for the length of the genome to be encapsidated (Guo et al., 2001). They have the ability of coexpressing several heterologous proteins in different insertion sites from a single vector (Kelloniemi et al., 2008; Majer et al., 2015). Furthermore, potyviruses are a large virus group with many species able to infect a wide range of host plants (Nigam et al., 2019).

Proteases play a crucial role in processing genetic information in potyvirus biology. When a heterologous protein is flanked by the recognition sequences of a viral protease, it will efficiently contribute to its release from the polyprotein (Carrington et al., 1993). An important viral component in potyviral protein regulation is VPg and its fusion partner, NIaPro. They work together, so that NIa fusion slowly releases VPg, which is required for the infectivity of TEV (Schaad et al., 1996). Moreover, the interaction of VPg domain with the NIaPro domain increases the pathogenicity in Pepper vein banding virus (PVBV) (Mathur et al., 2012).

To prevent the instability of plasmid vectors encoding a potyvirus such as Pea seedborne mosaic virus (PSBMV) and to facilitate cdna amplification in escherichia coli, introns were inserted into cloned cdna as a way to manipulate and amplify unstable cdna fragments that can be toxic to the host bacteria. This strategy cancels expression of undesired viral proteins in bacteria without interfering with further proteins expression in the host plant (Johansen, 1996) 


\section{Watermelon mosaic virus}

Watermelon mosaic virus (WMV) is classified within genus Potyvirus of the family Potyviridae. It is distributed worldwide mainly in tropical and Mediterranean areas, and it is reported to have an important variability in host range and symptomatology. WMV has a wide host range compared to other potyviruses (Desbiez and Lecoq, 2004; Zamora et al., 2017). A recent approach was developed using a WMV clone tagged with the yellow visual maker phytoene synthase (crtB) from the bacteria Pantoea ananatis in order to investigate WMV infection in cucurbits. Some isolates of this virus cause mild symptoms, which makes difficult to manage the virus in field cultivations and monitor breeding programs aiming for genetic resistance in cultivars (Aragonés et al., 2019). The procedure mentioned utilized WMV as a vector to express $P$. ananatis crtB, which induces an accumulation of a yellow pigments in infected tissues that are clearly visible. For that, an infectious WMV clone was constructed by amplifying a cDNA from an RNA preparation of an infected melon. crtB cDNA from $P$. ananatis was inserted between NIb and CP cistrons of WMV. The whole cDNA was flanked by CaMV 35S promoter and terminator in a basic cloning vector, which was used to transform A. tumefaciens. Transformed bacteria were used to agroinoculate both $N$. benthamiana and melon plants (cultivar Piñonet Piel de Sapo) (Figure 2). The results showed plants with mild symptoms that were pigmented with a yellow color highlighting infected tissue. The work finally concluded that crtB marker was an efficient tool to score infectivity by visual diagnosis in melon breeding programs (Aragonés et al., 2019). 


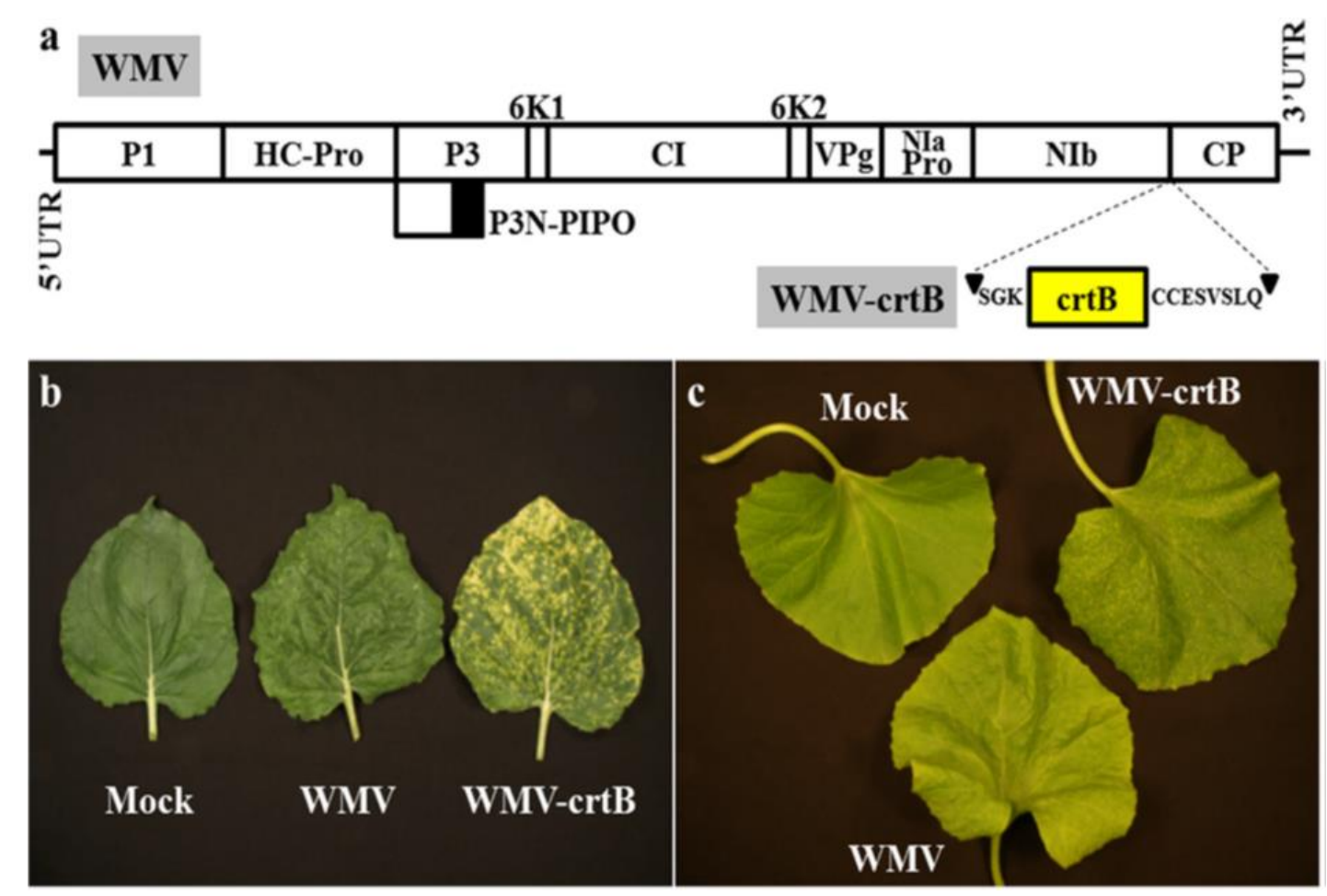

Figure 2. Pictures of $N$. benthamiana and Piñonet Piel de Sapo melon plants showing WMV-Vera and WMV-crtB symptoms. (a) Genomic organization of WMV-crtB vector. As indicated, crtB is inserted in $\mathrm{NIb} / \mathrm{CP}$ intercistronic site. (b) Pictures of $N$. benthamiana upper leaves infected with WMV and WMVcrtB. (c) Pictures of melon upper leaves infected with WMV and WMV-crtB. Pictures were taken at 28 dpi. Figure taken from Aragonés et al. (2019).

\section{Zucchini yellow mosaic virus}

Zucchini yellow mosaic virus (ZYMV; genus Potyvirus, family Potyviridae) was initially detected in Italy in 1981 (Lecoq et al., 1981). Since then, it has rapidly spread to all parts of the world. ZYMV is a significant damaging pathogen to cucurbits, which lowers significantly yield production, mainly transmitted non-persistently by aphids and, at a lower extend, through seeds (Desbiez and Lecoq, 1997; Lecoq et al., 2009). Like other potyviruses, it has a filamentous rod shape structure that enclose an RNA genome allowing the expression of foreign proteins as part of the viral polyprotein, if properly inserted. An attenuated ZYMV (AG) viral vector was developed as a non-pathogenic expression vector in cucurbits which does not provoke severe symptoms of viral infection in plants in contrast to the wild-type virus (Arazi et al., 2001). This was possible by engineering a single amino acid in the HC-Pro cistron to attenuate the virulence and block the aphid-transmission pathway by inducing a mutation in Asp8, Ala9 and Gly10 (DAG) motif involved in transmission by aphids. A site-directed mutagenesis was performed 
to switch Ala to Thr which eventually suppresses ZYMV transmission by aphids (Gal-On et $a l .$, 1992). Next, an insertion site between NIb and CP genes was constructed, after the insertion site between P1 and HC-Pro genes failed to express Cucumber mosaic virus (CMV) $\mathrm{CP}$ in plants, suggesting that the position between $\mathrm{NIb}$ and $\mathrm{CP}$ genes is more appropriate for efficient expression. The stable vector named AGII was also studied to characterize and localize inserted GOI in planta using reporter genes; jellyfish green fluorescent protein (GFP; $0.8 \mathrm{~kb}$ ) and $\beta$ glucuronidase (uidA; GUS; $1.8 \mathrm{~kb}$ ). Both reporter proteins were highly accumulated suggesting that long insertions between P1 and HC-Pro are more susceptible to recombination, and that foreign insert size is not the only factor that affect virus titer (Arazi et al., 2001; Dolja et al., 1992; Simon and Bujaraski, 1994).

Furthermore, a human interferon-alpha 2, which is an important human anti-viral drug, was expressed using the AGII-IFN vector. This protein was mainly concentrated in squash and cucumber fruit embryonic tissue, indicating that foreign gene expression depends on viral distribution (Arazi et al., 2001). This expression vector was successful to overexpress multiple GOIs in cucurbits, such as the herbicide resistance gene "bar", which has been tested in field where infected plants have also developed a cross-protection against ZYMV (Shiboleth et al., 2001). The expression system was also proved to express structural proteins that augment production of specific antibodies (Chen et al., 2005). In addition, the ZYMV has been successfully used for therapeutic proteins expression (Arazi et al., 2002).

In a recent study, an infectious full-length cDNA clone of ZYMV was engineered to express two reporter genes, GFP and bar (Kang et al., 2016). The first step in construction was to amplify fully ZYMV cDNA and insert it in a modified binary vector to create plasmid pZYMVPA. This plasmid was transmitted by rub inoculation using carborundum into zucchini leaves to assess the infectivity of the ZYMV clone. The second step was to insert cloning sites (ApaI, SpeI and SalI) and a NIaPro cleavage site into the polyprotein ORF between the NIb and CP cistrons. The NIb region was then amplified and subcloned into an intermediate clone. Then, a fragment of the CP region was also amplified. Finally, ZYMV NIb/CP region harboring the cloning sites and a NIaPro cleavage site was cut out and inserted into pZYMV-PA. The final constructs were designated as pZYMV-GFP and pZYMV-Bar, and successfully inoculated onto the cotyledons of zucchini seedlings by direct rub-inoculation (Kang et al., 2016). 


\section{The family Cucurbitaceae}

The Cucurbitaceae is a prominent horticultural plant family, which includes plants known as cucurbits. It is ranked second after the Solanaceae for its economic importance worldwide. Cucurbits are significantly appreciated for their dietary source rich in minerals, vitamins and fibers (Rolnik and Olas, 2020), as well as, for their medical and cultural significance in many civilizations. The origin of the family name, Cucurbitaceae, rooted from Latin, where the word "corbis" means "basket" or "bottle" (Lebeda et al., 2006). Within this family, watermelon (Citrullus lanatus), melon (Cucumis melo), cucumber (Cucumis sativus), zucchini (Cucurbita pepo) and bottle gourd (Lagenaria siceraria) represent the major cucurbits commercially produced. In consequence, over the last decades, molecular and genetic technologies have focused on cucurbit crops to identify, characterize, and understand cucurbit growth, development and adaptation to their environments (Grumet et al., 2017).

One of cucurbits assets is their vast diversity comprising nearly 1000 species, which facilitates their adaptation to various agricultural systems in different environments. However, the center of origin of cucurbit species are traced back to tropical and sub-tropical regions, but they have spread out to all parts of the world where they are produced extensively (Renner and Shaefer, 2016). Genetic transformation of cucurbits is laborious and takes a long time to deliver notable results. Advances in transient transformation facilitates rapid and efficient understanding of gene function. One of this transient expression strategies is the so called virus-induced gene silencing (VIGS) (Liu et al., 2019).

\section{Virus-induced gene silencing and the dynamic process of systemic silencing}

The term VIGS was first used by A. van Kammen to depict post-transcriptional gene silencing (PTGS) in transgenic plants and the phenomena of recovery from virus infection (Van Kammen, 1997). In fact, VIGS is a remarkable technique used in reverse genetic analysis to determine gene function and enable comparison between genes of the same species, by diminishing the expression of a gene, which is similar to producing a mutant that fails to encode a functional protein. To achieve this, a short sequence of a targeted plant gene is introduced into a viral expression vector. The vector will be used to infect a plant. In consequence, a rapid response from the natural defense mechanism of the plant will be triggered to suppress virus 
replication leading to degradation of homologous endogenous mRNAs, which is responsible for silencing (Burch-Smith et al., 2004).

RNA silencing in plants serves, among other roles, as a defensive shield against viral attacks. Cleavage of double stranded RNA (dsRNA) via Dicer-like (DCL) enzymes produce small interfering molecules (siRNAs) of about 21-24 nt, which will be embodied into a multi-subunit complex, the RNA-induced silencing complex (RISC). Guided by the siRNA, the protein complex binds to mRNA and degrade it in a sequence-specific manner. siRNAs are also involved in RNA-directed DNA methylation (RdDM) (Wassenegger et al., 1994). Hence, one important factor in gene silencing mechanism of plants is the activity of RNA-dependent RNA polymerases (RDRs), especially RDR6, which are required to amplify the silencing signal through production of secondary siRNAs (Vaistij and Jones, 2009).

VIGS approach is, therefore, suited to investigate essential genes that exhibit lethal phenotypes in mutant or transgenic plants (Ruiz et al., 1998). As a matter of fact, this technique is widely used for its many advantages as a partial gene sequence is sufficient for gene silencing or easy to use with rapid phenotype detection. Stable plant transformation is not required, which renders the technique highly consistent and cost-effective (Dinesh-Kumar et al., 2003). Consequently, VIGS systems have been extensively studied during the past decades mainly with the aim to characterize important plant genes involved in plant growth, disease resistance, metabolic regulation, and cell-to-cell signaling (Purkayastha et al., 2010; Zhao et al., 2016).

Many plant viruses were modified to serve as VIGS vectors, which are majorly RNA viruses. However, not all RNA virus-derived vectors make functional VIGS (Robertson, 2004). For an expression vector to be efficient in VIGS, it should infect the plant and propagate in a homogeneous manner towards the meristematic regions of the plant. The viral vector should not generate strong silencing suppressors, which could interfere with the host silencing machinery (Dinesh-Kumar et al., 2003). Some of the most popular VIGS vectors derived from TMV (Kumagai et al., 1995), Potato virus X (PVX) (Faivre-Rampant et al., 2004) and, particularly, Tobacco rattle virus (TRV) (Valentine et al., 2004). An interesting aspect of VIGS is the ability to suppress host gene expression despite viral proteins directed for suppression of RNA silencing. In fact, the first RNA-silencing suppression (RSS) protein discovered is the potyviral HC-Pro. Therefore, potyviruses were not favored as VIGS vectors due to the strong 
activity of HC-Pro that mitigate silencing of overexpressed genes in the plant (Johansen \& Carrington, 2001).

VIGS has also been applied to cultivated plants, such as cucurbits, to better understand the wide genetic baggage of these crops. One of the successful VIGS systems was demonstrated by means of a transient expression of the PDS gene using a Tobacco ringspot virus (TRSV)-based vector (Figure 3) (Zhao et al., 2016). Silencing of PDS gene was induced in different cucurbit species, such as melon, oriental melon and cucumber. Inoculation triggered a partial photobleaching phenotype in silenced plants, developing almost completely white new leaves, petioles, petals, sepals and even tendrils. Subsequently, silencing recovery started to show in both melon and oriental melon prior to fruit development whereas cucumber plants did not recover from TRSV-mediated VIGS. Therefore, the presence of the nepovirus expressing a fragment of PDS was demonstrated to be helpful to study the recovery pathway mechanism (Zhao et al., 2016).
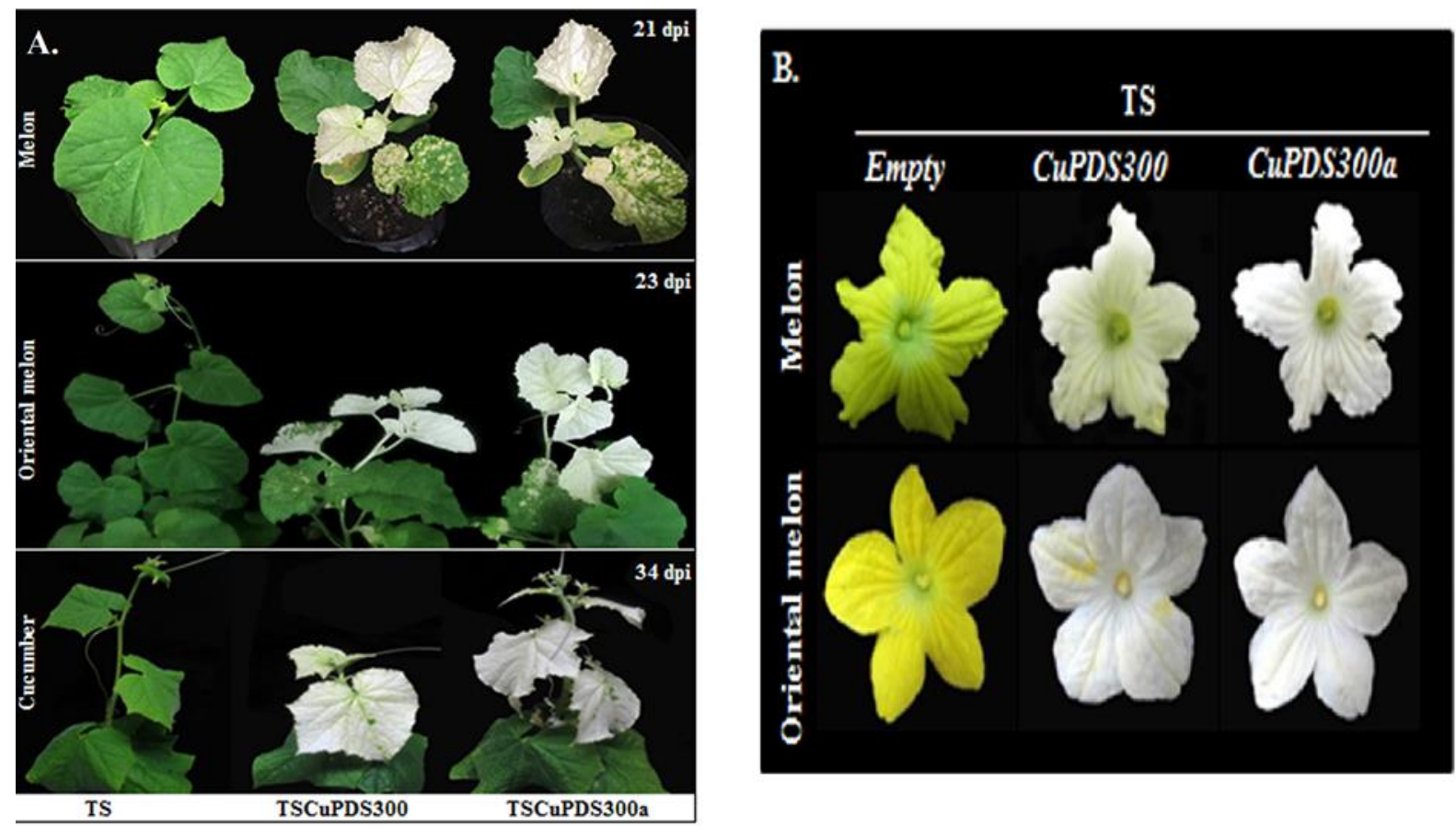

Figure 3. PDS gene silencing in melon, Oriental melon and cucumber plants using a TRSV-derived vector. (A) Symptoms induced by agroinfiltration of the indicated vectors in melon at 21 dpi (top row), oriental melon at $23 \mathrm{dpi}$ (middle row) and cucumber 34 dpi (bottom row). (B) Agroinoculation of melon (upper row) and oriental melon (lower row) with different TRSV-derived constructs. Figure taken from Zhao et al. (2016). 
Likewise, potyviruses were also adopted as potential VIGS vectors. This is the case of Potato virus A (PVA) (Gammelgård et al., 2007). N. benthamiana is a model system for RNA silencing and VIGS, valued for its dynamic output. The transgenic $N$. benthamiana $16 \mathrm{c}$ line exhibits strong constitutive expression of GFP. It was inoculated with chimeric PVA-GFP viral construct, carrying the GFP gene. Inoculation caused mild symptoms that could be the result of low RSS efficiency, which add a favorable point to the utilization of potyviruses for VIGS, despite of the potyviral strong silencing suppressor protein, HC-Pro. PVA-GFP was silenced and virus-specific siRNA were accumulated. In systematic infected leaves, viral deletion mutants missing GFP insert were observed as well as a regressive silencing of the GFP transgene in some part of the plants (Gammelgård et al., 2007).

Interestingly, GFP silencing was maintained in newly developed leaves even in the absence of PVA-GFP, which let to deduce that systemic silencing signals ascended from the lower infected leaves and that HC-Pro was not hindering the process. The results showed a complete loss of visible GFP fluorescence of leaves numbered from 7 to 12 dpi (Figure 4). However, signals for GFP mRNA were still present on the leaves, yet silencing was proficient to produce a radical phenotypic change in GFP expression. A new phase was detected with insert-less mutants and reverse silencing in the last upper leaves, displaying green fluorescence spots induced from the gradual decrease of PVA-GFP RNA and the proportional increase of deletions mutants, in which the RSS functions of HC-Pro regained its influence and overpower the local silencing. A mosaic-like red-green pattern was observed under UV light. The red tissue coincided with dark green island under visible light, which proved the presence of localized areas which are virus-free tissues, and are known to develop only on leaves in active division and are highly resistant to super-infection of the same virus (Gammelgård et al., 2007; Moore et al., 2001). 

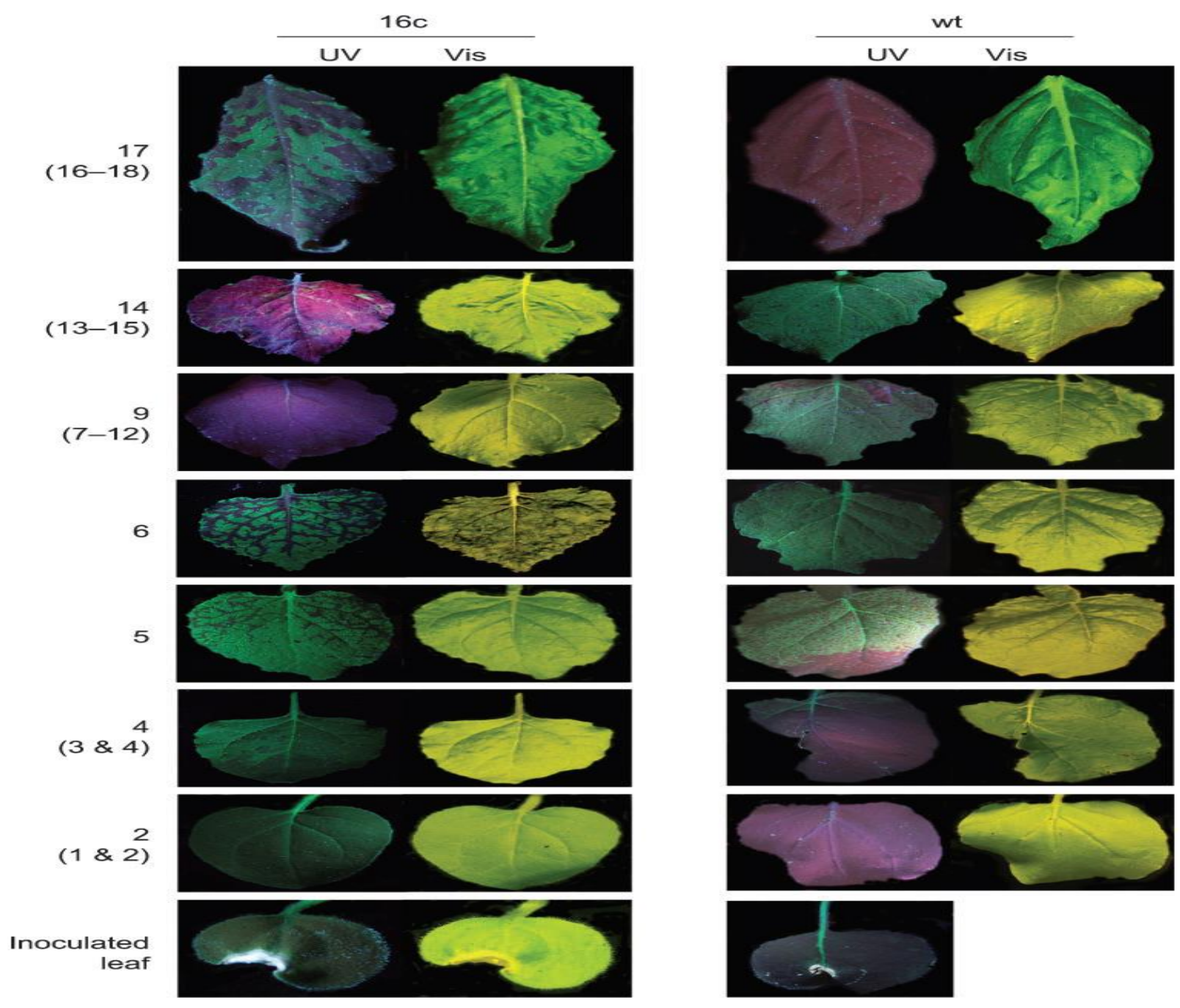

Figure 4. Systemic infection with PVA-GFP of GFP-transgenic (line 16c) and non-transgenic (wt) $N$. benthamiana plants. GFP expression was captured under UV. In wt plants, green fluorescence is caused by the GFP-containing PVA chimera in the mid vein and petiole of inoculated leaf. However, in line $16 \mathrm{c}$, green fluorescence is due to GFP transgene, PVA chimera or both. In leaf 5 of wt plant, the loss of GFP fluorescence from veins and adjacent tissues is explained by the discharge of PVA-GFP in contrast to 16c plant were GFP fluorescence start to be visible. Dark green areas are observed in the upper leaves (position 17) of line 16c, presented in red under UV light and perceptible under visible light. Figure taken from Gammelgård et al. (2007).

Similarly, VIGS vectors that target PDS of $N$. benthamiana were described using PVX as vector. They expressed PDS fragments (PVX-PDS) in both sense and antisense orientation. The results showed a photo-bleaching where the PDS mRNA was targeted by VIGS in all green tissues of the infected plant without having an impact on the PVX-PDS construct (Figure 5). On the other hand, PVX-GFP construct was affected. At first, the GFP was expressed in all green tissues, though, after 30 dpi the newly emerging leaves did not express GFP, whereas in 
the previous initiated leaves the expression was maintained. This suggested that VIGS is a posttranscriptional and cytoplasmic mechanism directed against cytoplasmic RNA targeting exons rather than introns, and against viral RNAs (Ruiz et al., 1998).

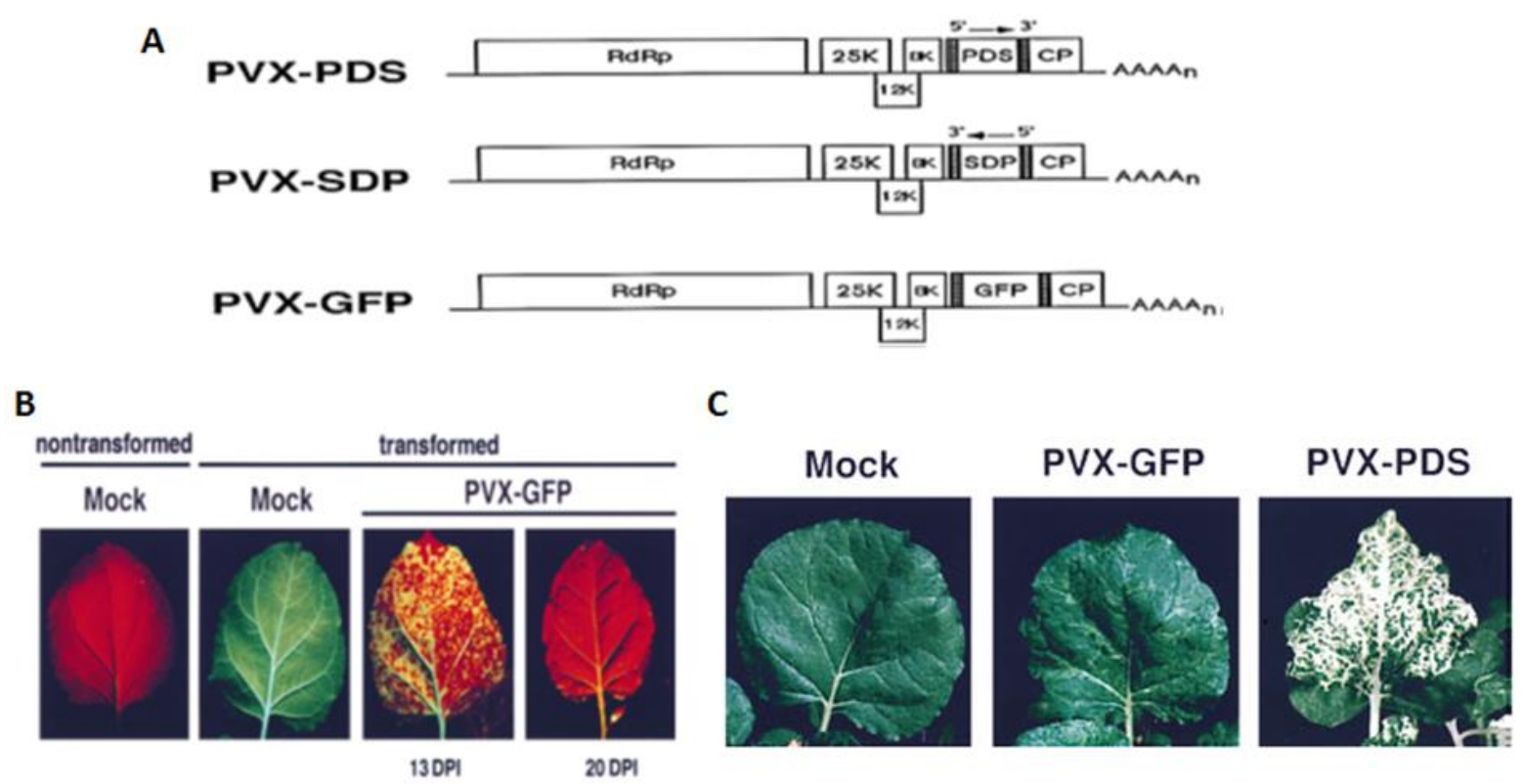

Figure 5. PVX vector used in VIGS of PDS. (A) Illustration of PVX genomic organization is presented as follow; RdRp (RNA dependent RNA polymerase), 25K (25 kDa protein), 12K (12 kDa protein), 8K ( $8 \mathrm{kDa}$ protein), and $\mathrm{CP}$ (coat protein). The inserts were placed between $8 \mathrm{~K} / \mathrm{CP}$ site in different configurations; in sense (PDS), and antisense (SDP) orientation, in addition to a GFP control construct (PVX-GFP). (B) Uppermost leaves of mock inoculated and PVX-GFP inoculated plants photographed under UV light at 13 and 20 dpi. (C) Systemic leaves of mock inoculated, PVX-GFP and PVX-PDS inoculated plants were photographed at 24 dpi. Figure taken from Ruiz et al. (1998).

\section{Carotenoids biosynthesis and advances in metabolic engineering}

With their universal photosynthetic capacity to transform sunlight into organic molecules, plants produce a myriad of primary and secondary metabolites that are biosynthesized through a cascade of chemical reactions, producing nutritional elements such as carbohydrates, lipids and proteins, which are primary metabolites. Secondary metabolites usually mediate interactions between plants and their environment (Lau et al., 2014). 
Carotenoids are isoprenoid molecules that are widely present in nature. They usually consist of red, orange, and yellow pigments produced by photosynthetic organisms. Carotenoids take part in important plant processes; they are indispensable for light capture and photoprotection, they are produced in correlation with chlorophylls in plant leaves where they are particularly conserved in higher plants. Carotenoids are also greatly accumulated as secondary metabolites in fruits and flowers as a mean to captivate pollinators and seed disseminators (Meier et al., 2011). Besides, they have a valuable role in human and animal dietary uptake, for example $\beta$ carotene, which is an efficient precursor in the production of vitamin A. They are also valorized for their health benefits to potentially palliate age-related diseases in humans. This is the case of phytoene, lycopene and lutein that are phytonutrients found in colorful fruits (Fraser and Bramley, 2004; Rodriguez-Concepcion et al., 2018). Another type of carotenoids, such as astaxanthin and canthaxanthin, which are not present in plants in their natural state, were largely used by pharmaceutical, cosmetic, forage and alimentation industries; hence, drawing the attention of biotechnological applications for their versatile importance in many aspects of biotechnology (Majer et al., 2017; Wurtzel, 2019).

Due to the great value found in carotenoids for their chemical, physiological and metabolic properties, efforts have been put forward to understand their metabolic pathway and biosynthetic regulations processes. Metabolic engineering was developed as a tool to target their accumulation and augment their content in plants by genetic manipulation. Carotenoids genes have been cloned and deeply studied to enhance nutritional value of edible fruits. The natural carotenoid pathway starts with the first independent reaction catalyzed by the enzyme phytoene synthase (PSY), producing phytoene that goes through desaturation and isomerization reactions activated by other enzymes that lead to the transformation of the non-colored phytoene molecule into lycopene, colored in red. Subsequently, lycopene generates two distinctive carotenoids molecules $\beta$-carotene that derives in xanthophylls, and lutein (Majer et al., 2017).

To achieve a high level of carotenoid biosynthesis, plant engineering methods has confronted numerous constraints due to the complexity of regulation pathways of plant metabolism. However, advances in molecular engineering provides important steps forward to transcend regulative constraints by using viral vectors. For example, researchers used a vector derived from TEV to express an engineered metabolic pathway of lycopene (Figure 6) (Majer et al., 2014). This compound is not present in non-infected tobacco tissue. With the insertion of a 
cassette expressing phytoene synthase (crtB) that is derived from the soil bacteria $P$. ananatis, resulting in a boost of $10 \%$ of carotenoids content made of lycopene in the infected tobacco leaves in addition to a clear diminution in chlorophylls and the appearance of a bright yellow pigmentation in infected tissues, which was considered as a potential carotenoid-based reporter to visually track infection solely or in combination with other visual reporter such as the transcription factors Rosea1 (Majer et al., 2017).

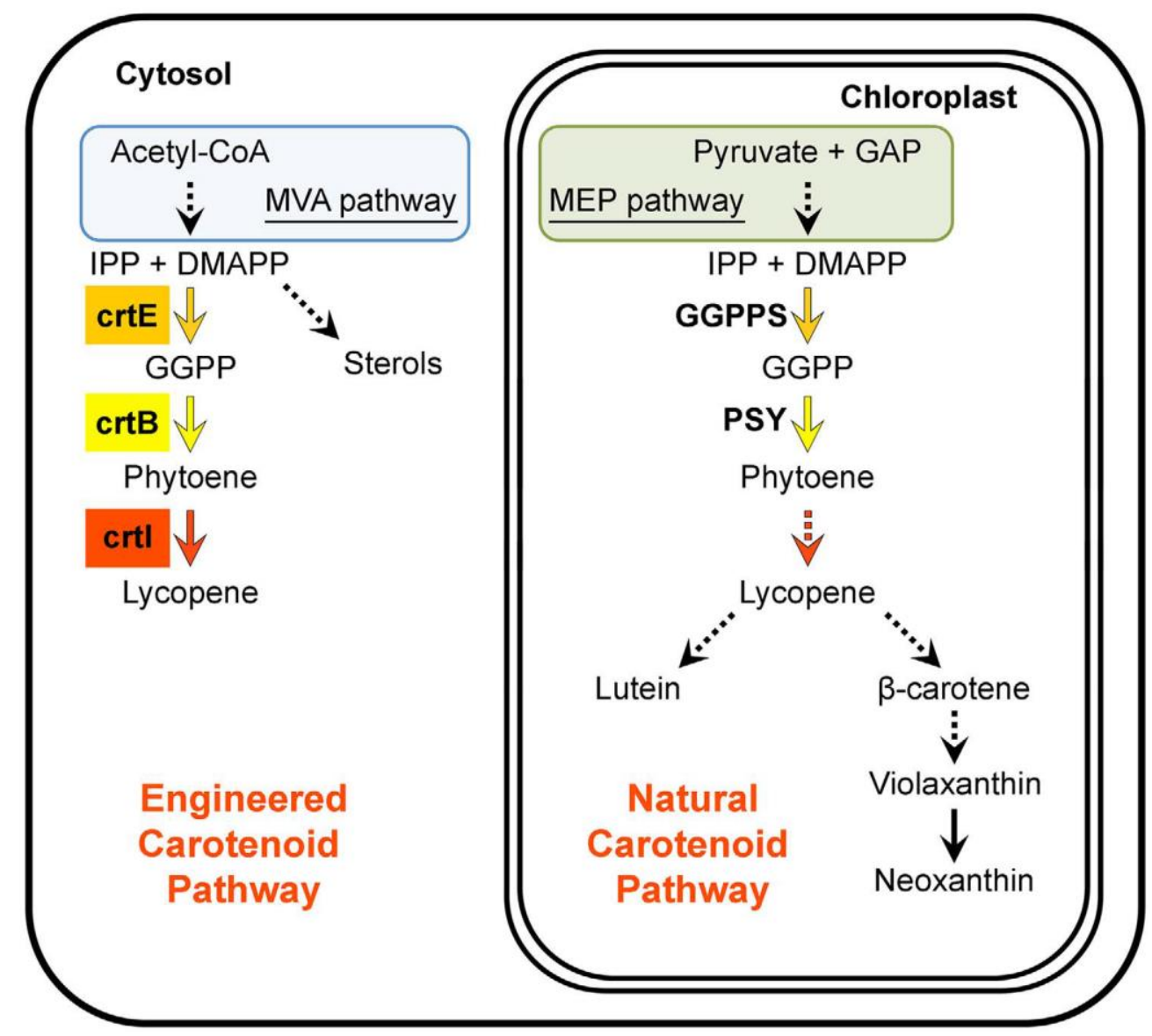

Figure 6. Comparative schemes between the endogenous plant isoprenoid pathways and the virusenabled metabolic engineering approach applied by Majer et al. (2017). MEP and carotenoid pathways naturally take place in the plant chloroplast whereas both endogenous MVA pathway and the engineered carotenoid biosynthetic pathway were localized in the cytosol. Solid arrows represent single enzymatic steps, dashed arrows represent multiple enzymatic steps. The catalytic steps activated by Pantoea ananatis crtE, crtB and crtI were marked as follow; GAP, glyceraldehyde-3-phosphate; IPP, isopentenyl diphosphate; DMAPP, dimethylallyl diphosphate; GGPP, geranylgeranyl diphosphate; crtE/GGPPS, GGPP synthase; crtB/PSY, phytoene synthase; crtI, phytoene desaturase. Figure taken from Majer et al. (2017). 

OBJECTIVES 


\section{OBJECTIVES}

Cucurbits constitute an important family of cultivated plants. However, breeding is timeconsuming and genetic manipulation labor-intensive and resource consuming. In this work, we have explored the use of potyvirus-based vectors for different biotechnological applications in cucurbit plants. More specifically, the goals of this work were:

1. To build an efficient virus-induced gene silencing (VIGS) vector for cucurbits based on a potyvirus isolate.

2. To induce accumulation of health-valuable metabolites into commercial cucurbits fruits with the help of a potyvirus-derived vector. 

CHAPTER I 


\section{CHAPTER I}

\section{A virus-induced gene-silencing vector based on a mild isolate of Watermelon mosaic virus for reverse genetic analyses in cucurbits}

Fakhreddine Houhou ${ }^{1}$, Verónica Aragonés ${ }^{1}$, Anamarija Butković ${ }^{1}$, Cristina Sáez ${ }^{2}$, Belén Picó $^{2}$, Carmelo López ${ }^{2}$, José-Antonio Daròs ${ }^{1}$

${ }^{1}$ Instituto de Biología Molecular y Celular de Plantas (Consejo Superior de Investigaciones Científicas-Universitat Politècnica de València), Avenida de los Naranjos s/n, 46022 Valencia, Spain

${ }^{2}$ Instituto de Conservación y Mejora de la Agrodiversidad Valenciana, Universitat Politècnica de València, Avenida de los Naranjos s/n, 46022 Valencia, Spain 


\section{Abstract}

As a response to viral infections, host plants trigger an RNA-mediated gene silencing defense, to which viruses respond with the expression of viral-encoded RNA silencing suppressors. If virus clones are manipulated to include sequences homologous to host endogenous genes, these are also targeted by the plant RNA silencing machinery. This so-called virus-induced gene silencing (VIGS) has become a powerful technique for reverse genetic analyses in plants, as an alternative to labor-intensive genome transformation. We show that a mild isolate of Watermelon mosaic virus (WMV, genus Potyvirus) can be used as a VIGS vector for reverse genetic analyses in melon. Recombinant WMV clones - in which fragments of the melon Phytoene desaturase (PDS) mRNA were inserted in sense, antisense, and hairpin modalitiesinduced a distinctive phenotype and significant silencing of the endogenous gene. While the foreign fragments in sense and antisense orientations were stable in the viral progeny, the hairpin was quickly lost. Nevertheless, the hairpin construct triggered a maintained silencing effect comparable to those of the sense and antisense constructs. The suitability of WMV as a VIGS vector was further confirmed targeting melon Magnesium chelatase subunit I (CHLI). These results also support that, although potyviruses express a strong silencing suppressor that usually precludes VIGS, mild isolates of this kind of viruses can be used as VIGS vectors. Finally, to facilitate the use of this new tool by cucurbit geneticists, we describe plasmid pGWMV-VIGS that allows easy cloning fragments of the genes of interest in a single Gibson assembly reaction.

\section{Introduction}

In most eukaryotic organisms, multiple pathways of RNA-induced gene silencing contribute to crucial biological functions such as development regulation, genome integrity, or responses to biotic and abiotic stresses. In plants, among these relevant roles, RNA silencing has been revealed as a foremost antiviral mechanism, since virtually all plant viruses encode one or more RNA silencing suppressors in their small genomes to accomplish infection (Csorba et al. 2015). Double-stranded RNA (dsRNA) replication intermediates from RNA viruses, as well as structured or overlapping transcripts from both RNA and DNA viruses, are recognized by the host plant Dicer-like (DCL) RNase III enzymes, which produce duplex small interfering RNAs (siRNAs) of approximately 20-24 nucleotides (nt). A single siRNA strand is loaded by an 
Argonaute (AGO) RNase $\mathrm{H}$ enzyme to form the RNA-induced silencing complex (RISC), which inactivates the viral nucleic acids - usually by cleavage, but also by translation arrest or DNA hypermethylation. Importantly, in plants, primary siRNAs can also serve as primers for the host RNA-dependent RNA polymerases to amplify the silencing signal by producing new viral dsRNAs that are subsequently processed by DCLs to generate to systemic signaling of infection. This mechanism of antiviral RNA silencing implies that, if a sequence fragment homologous to a plant gene is artificially inserted into the viral genome, the host antiviral machinery will produce siRNAs that will also target the endogenous gene. Therefore, in reverse genetic analyses to study gene function, a relatively-simply built recombinant virus infectious clone can be used as an alternative to cumbersome plant genome transformation (Baulcombe 1999) — provided that the virus-encoded RNA silencing suppressors do not fully dismantle the host antiviral response, which is why viruses with mild or weak RNA silencing suppressors are preferred. This so-called virus-induced gene silencing (VIGS) was demonstrated more than two decades ago using both RNA and DNA plant viruses. Since then, it has been extensively applied to both model species (Lindbo et al. 1993; Kumagai et al. 1995; Kjemtrup et al. 1998; Teresa Ruiz et al. 1998; Jones et al. 1998). Since then, it has been extensively applied to both model species (Liu et al. 2002b; Burch-Smith et al. 2006) and cultivars of agronomical interest (Holzberg et al. 2002; Liu et al. 2002a; Fofana et al. 2004). Recent reviews have comprehensively overviewed the more-than-fifty VIGS vector systems that have been developed to date, as well as the dicot and monocot species to which they can be applied (Kant and Dasgupta 2019; Dommes et al. 2019; Courdavault et al. 2020). However, despite the numerous currently available VIGS vectors, no universal system exists, since each plant virus (or even each virus strain) exhibits a particular host range and other biological peculiarities; therefore, novel systems are still required to efficiently target various plant species and families.

Potyviruses (genus Potyvirus, family Potyviridae) are the largest group of plant RNA viruses, with approximately 200 species currently recognized (Wylie et al. 2017). However, relatively few VIGS vectors have been derived from potyviruses (Lindbo et al. 1993; Gammelgård et al. 2007). This is possibly because potyviruses express a strong RNA-silencing suppressor: the helper-component protease (HC-Pro), which efficiently inhibits the host RNA-based antiviral response (Valli et al. 2018). In addition, the approximately 10,000-nt potyvirus RNA genome encodes a large polyprotein that, after translation, is processed in a regulated cascade by three virus-encoded proteases: P1 protease, HC-Pro, and the nuclear inclusion a (NIa) protease (NIaPro) ) (Revers and García 2015). Shorter polyprotein versions are also produced by 
transcriptional slippage mechanisms (Olspert et al. 2016). This genome organization, based on a nearly genome-long open reading frame (ORF), may have also hindered the development of VIGS vectors from potyviruses, since care must be taken to avoid interrupting the viral polyprotein with stop codons from exogenous sequences.

We have recently characterized a Watermelon mosaic virus (WMV, genus Potyvirus) isolate that induces mild symptoms in melon (Cucumis melo L.) and other cucurbits (Aragonés et al. 2019). WMV is one of the most prevalent viruses on cucurbits worldwide and exhibits a wide host range (Bertin et al. 2020; Desbiez et al. 2020). We investigated whether an infectious clone derived from this mild WMV isolate could be useful as a VIGS vector. (Weng et al. 2020); it includes at least ten species considered major crops worldwide and more than twenty additional of local commercial importance (Chomicki et al. 2020). Again, few VIGS vectors have been developed for reverse genetics analyses in cucurbits (Igarashi et al. 2009; Zhao et al. 2016; Liu et al. 2020). In this work, we aim to derive a VIGS vector from a mild isolate of the potyvirus WMV for application in genetic analyses in cucurbits and for illuminating how fragments of host genes can be inserted into a potyvirus vector to efficiently induce gene silencing. In this way, we sought to not only add a new VIGS vector for cucurbits, but also to contribute to the incorporation of the highly diverse group of potyviruses into VIGS technology.

\section{Materials and methods}

\section{Plasmid construction}

Plasmid pGWMV-Vera (Fig. S1) contains an infectious clone of the WMV Vera isolate (GenBank accession number MH469650) inserted in the binary plasmid pG35Z (Cordero et al. 2017), under the control of the CaMV 35S promoter and terminator (Aragonés et al. 2019). We amplified a fragment of this plasmid by the polymerase chain reaction (PCR) using primers P1 and $\mathrm{P} 2$, which contained flanking $B s a \mathrm{I}$ restriction sites; this fragment was ligated to a basic cloning vector using T4 DNA ligase (Thermo Scientific). All PCRs for cloning purposes consisted of 30 cycles and were performed with Phusion high-fidelity DNA polymerase in buffer HF (Thermo Scientific). The sequences of the resulting plasmids were confirmed experimentally. The sequences of all primers used in our study are given in Table S1. The resulting plasmid, with a fragment of pGWMV-Vera, was linearized by PCR using primers P3 
and P4 with extended 5' regions, in order to introduce the artificial NIaPro cleavage site at the $\mathrm{NIb} / \mathrm{CP}$ intercistronic site. The PCR product was ligated to a linker consisting of two unique NheI and SpeI restriction sites flanking a LacZ' blue/white selection marker. We named the resulting intermediate plasmid pMWMV-Z (Fig. S1). Plasmids pGWMV-sPDS, pGWMVaPDS, pGWMV-hPDS, and pGWMV-sCHLI (Fig. S1) were constructed by two consecutive Gibson assembly reactions (Gibson et al., 2009), using the NEBuilder HiFi DNA assembly master mix (New England Biolabs). We amplified fragments of the melon (Cucumis melo L., cv. Piñonet Piel de Sapo) Phytoene desaturase (PDS; Cucurbit Genomics Database MELO3C017772.2), Magnesium chelatase subunit I (CHLI; MELO3C007233.2) genes by PCR using primers P5-P10 and P13-P16 (Table S1). The Tetrahymena thermophila 26S rRNA group-I self-splicing intron with 10-nt flanking exons (from positions 43 through 475 of GenBank accession no. V01416.1) was amplified with primers P11 and P12 from a cDNA template obtained by gene synthesis. The resulting intermediate plasmids were digested with BsaI (BsaI-HFv2, New England Biolabs); the inserts were transferred to pGWMV-Vera digested with Bpu1102I and ApaI (Thermo Scientific) by means of a second Gibson assembly reaction. We created pGWMV-VIGS (Fig. S1) in a similar way, albeit by using primers P17 and P18.

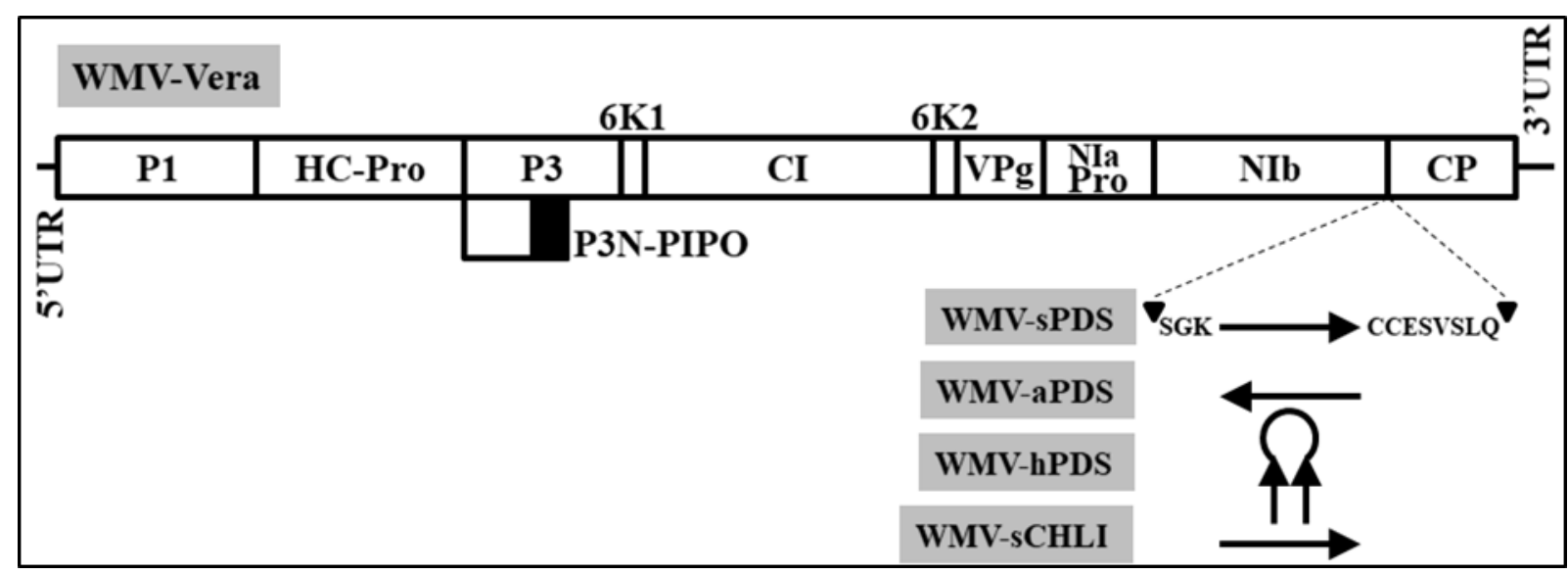

Fig. 1. Schematic representation of the WMV genome. Lines and boxes represent the 5' and 3' UTRs and protein coding cistrons, as indicated. In pMWMV-Z and pGMWV-VIGS an artificial NIaPro cleavage site was inserted at the $\mathrm{NIb} / \mathrm{CP}$ intercistronic site. Both the amino acid and the nucleotide sequences are indicated. The exogenous sequences inserted in WMV-sPDS, WMV-aPDS, WMV-hPDS and WMV-sCHLI are also schematically represented. 


\section{Plant inoculation}

Fifteen-day-old melon plants of the Piñonet Piel de Sapo cultivar were inoculated in the first true leaf with preparations of Agrobacterium tumefaciens $\mathrm{C} 58 \mathrm{C} 1$ bearing the various WMV constructs. A. tumefaciens were previously transformed with helper plasmid pCLEAN-S48 (Thole et al. 2007). Transformed A. tumefaciens were selected at $28^{\circ} \mathrm{C}$ in plates with $50 \mu \mathrm{g} / \mathrm{l}$ rifampicin, $7.5 \mu \mathrm{g} / \mathrm{l}$ tetracycline, and $50 \mu \mathrm{g} / \mathrm{l}$ kanamycin. Single colonies were then grown at $28^{\circ} \mathrm{C}$ in liquid Luria-Bertani (LB) cultures containing, as a selection antibiotic, only $50 \mu \mathrm{g} / \mathrm{l}$ kanamycin. The various $A$. tumefaciens clones were harvested by centrifugation at an optic density at $600 \mathrm{~nm}\left(\mathrm{OD}_{600}\right)$ between 0.5 and 2. The bacteria were resuspended in inoculation

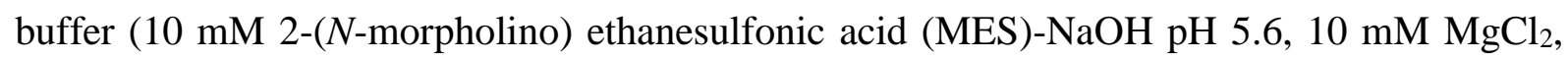
and $150 \mu \mathrm{M}$ acetosyringone) at $\mathrm{OD}_{600} 0.5$. Virulence genes were induced by incubation for $3 \mathrm{~h}$ at $28^{\circ} \mathrm{C}$. Finally, induced bacteria were infiltrated in the abaxial side of the first true leaf of melon plants, using a needle-less $1 \mathrm{ml}$ syringe. The plants were cultivated in a greenhouse at $25^{\circ} \mathrm{C}$ with a 16 -hour day and an 8 -hour night photoperiod.

\section{RNA analyses}

At the indicated days post-inoculation (dpi), RNA was purified from systemic non-inoculated leaf tissue samples. Frozen leaf samples (approximately $50 \mathrm{mg}$ ) were ground in 2-ml Eppendorf tubes, using a bead mill homogenizer (VWR) with 4-mm diameter stainless steel balls for 1 min at $30 \mathrm{~s}^{-1}$. Aliquots of $1 \mathrm{ml}$ of extraction buffer ( $4 \mathrm{M}$ guanidine thiocyanate, $0.1 \mathrm{M}$ sodium acetate, $\mathrm{pH}$ 5.5, $10 \mathrm{mM}$ ethylenediaminetetraacetic acid -EDTA-, and $0.1 \mathrm{M} 2-$ mercaptoethanol) were added to the tubes, which were vortexed intensively. The extracts were clarified by centrifugation for $5 \mathrm{~min}$. We mixed $0.6 \mathrm{ml}$ of the supernatant with $0.39 \mathrm{ml}$ of $96 \%$ ethanol. After 1 mine of centrifugation, we loaded $0.7 \mathrm{ml}$ of the supernatant on silica gel spin columns (Zymo-Spin I column, Zymo Research). The spin columns were washed twice with $0.5 \mathrm{ml}$ of washing buffer (70\% ethanol, $10 \mathrm{mM}$ sodium acetate, $\mathrm{pH}$ 5.5); the RNA samples were eluted with $10 \mu \mathrm{l}$ of $20 \mathrm{mM}$ Tris-HCl, $\mathrm{pH} 8.5$.

We performed WMV diagnosis using reverse transcription (RT)-PCR amplification followed by electrophoretic separation of the amplified products. Aliquots of $1 \mu \mathrm{l}$ of RNA were subjected to RT with RevertAid reverse transcriptase (Thermo Scientific) using primer P19. Aliquots of $1 \mu 1$ of the RT products were amplified by PCR for 30 cycles with Thermus thermophilus DNA 
polymerase (Biotools), using $1 \mu \mathrm{M}$ primers $\mathrm{P} 20$ and $\mathrm{P} 21$ in $75 \mathrm{mM}$ Tris- $\mathrm{HCl}, \mathrm{pH} 9.0,2 \mathrm{mM}$ $\mathrm{MgCl}_{2}, 50 \mathrm{mM} \mathrm{KCl}, 20 \mathrm{mM}\left(\mathrm{NH}_{4}\right)_{2} \mathrm{SO}_{4}$, and $0.2 \mathrm{mM}$ dNTPs. We electrophoresed the PCR products through a $1 \%$ agarose gel in buffer TAE $(40 \mathrm{mM}$ Tris, $20 \mathrm{mM}$ sodium acetate, and 1 mM EDTA, $\mathrm{pH}$ 7.2). The gels were stained by shaking for $15 \mathrm{~min}$ in $0.5 \mu \mathrm{g} / \mathrm{ml}$ ethidium bromide. Viral progeny analysis at the NIb/CP intercistronic site was also performed by RTPCR, followed by electrophoresis. RT was performed as explained above, albeit with primer P22. The PCR products were obtained with Phusion high-fidelity DNA polymerase, using primers P23 and P24, and analyzed by electrophoresis as explained above.

\section{mRNA quantification}

We quantified $P D S$ and $C H L I$ mRNAs using RT-quantitative PCR (qPCR). RNA was purified from leaf samples using Extrazol (BLIRT) and quantified using a NanoDrop 1000 spectrophotometer (Thermo Scientific). Remains of DNA were further removed using Perfecta DNase I (Qantabio). We analyzed three biological replicates and two technical replicates for each virus inoculum, using a LightCycler 480 system (Roche). The RT reactions were performed as explained above using an oligo(dT) primer. Aliquots of $1.5 \mu 1$ of the RT products were used in the qPCR reactions in a final volume of $15 \mu \mathrm{l}$. We used $7.5 \mu \mathrm{l}$ of $2 \times$ FastStart Essential DNA Green Master (Roche), $1.5 \mu 1100 \mathrm{nM}$ each primer and $1.5 \mu 1$ of $\mathrm{H}_{2} \mathrm{O}$. We used primers P25-P26, P27-P28, and P29-P30 to amplify, respectively, fragments of PDS, CHLI, and the housekeeping gene (Cyclophilin CYP7; MELO3C025848.2) (Gonzalez-Ibeas et al. 2007). The conditions consisted of an incubation for $5 \mathrm{~min}$ at $95^{\circ} \mathrm{C}$ followed by 40 cycles of 5 $\mathrm{s}$ at $95^{\circ} \mathrm{C}, 30 \mathrm{~s}$ at $60^{\circ} \mathrm{C}$, and $15 \mathrm{~s}$ at $72^{\circ} \mathrm{C}$. Relative mRNA levels were calculated using the $2^{-}$ $\Delta \Delta \mathrm{Ct}$ method (Livak and Schmittgen 2001), where $\Delta \Delta \mathrm{Ct}$ is the difference between the $\Delta \mathrm{Ct}$ of each sample $(\Delta \mathrm{Ct}$ sample $=\mathrm{Ct}$ viral target gene $-\mathrm{Ct}$ housekeeping gene $)$ and the $\Delta \mathrm{Ct}$ of the reference sample ( $\Delta \mathrm{Ct}$ calibrator). The sample with lower $\Delta \mathrm{Ct}$ was used as the reference in both assays. 


\section{Results}

\section{Construction of a VIGS vector for reverse genetics analyses in cucurbits from a mild isolate of $W M V$}

The Vera isolate of WMV (GenBank accession number MH469650) induces mild symptoms in commercial melon varieties, such as the Mediterranean elite Piel de Sapo cultivars (Aragonés et al. 2019). To study the potential use of this virus isolate for analyzing gene function in melon and other cucurbits, we used an infectious clone of this virus isolate as a vector to express fragments of the melon Phytoene desaturase (PDS). PDS is the second enzyme in the carotenoid biosynthesis pathway; its silencing is usually easily observed as a visual photobleaching phenotype. We expressed PDS mRNA fragments between the WMV nuclear inclusion $b(\mathrm{NIb})$ and coat protein (CP) cistrons (Fig. 1), as this is a typical position to express foreign genes using potyvirus vector (Choi et al. 2000). To avoid potential interference with virus infection, we also flanked the exogenous sequence with the two parts of an artificial NIaPro cleavage site to ultimately release the foreign fragment from the viral polyprotein (Fig. 1). Finally, to study the effect of the insertion on gene silencing, but also on vector stability, we expressed the PDS fragment in sense, antisense, and hairpin modalities (Fig. 1). In the latter case, we placed the inverted repeats that would produce both hairpin strands separated by the Tetrahymena thermophila rRNA group-I self-splicing intron, flanked by two 10-nt exon fragments-because it is well-known that DNA inverted repeats are highly unstable during plasmid amplification in Escherichia coli, unless they are separated with a spacer (Lai et al. 2016). Of course, our designs avoided the introduction of stop codons in the open reading frame of WMV polyprotein.

To prepare the vector system, beginning with the cloned WMV-Vera cDNA in plasmid pGWMV-Vera (Fig. S1), we transferred the final fragment of the WMV cDNA-including part of NIb, the entire CP, and 3' UTR, as well as the 35S Cauliflower mosaic virus (CaMV) terminator-to a basic cloning vector. This DNA fragment was flanked by two BsaI restriction sites to facilitate subsequent restoration, after manipulation, in pGWMV-Vera. Next, between the NIb and CP cistrons, we inserted the artificial NIaPro cleavage site, interrupted by a polylinker for cloning purposes. We named this intermediate plasmid pMWMV-Z (Fig. S1). The inserted artificial $(-8 /+3)$ NIaPro cleavage site corresponded to the native NIb/CP cleavage 
site, although it included silent mutations to avoid long sequence repetitions that would facilitate recombination during virus replication (Fig. 1 and Fig. S1). Next, we built the three intermediate plasmids to express fragments of the melon PDS: (i) the 5' 201-nt of the ORF in a sense orientation; (ii) the 5' 200-nt of the ORF in an antisense orientation, plus an additional $\mathrm{T}$ (we moved the reading frame +1 to avoid stop codons; and (iii) the 5, 102-nt of the ORF in a sense orientation, followed by the T. thermophila rRNA group-I intron and the 5' $101-\mathrm{nt}$ of the ORF in an antisense-orientation, plus an additional $\mathrm{T}$; again, we moved the ORF +1 to avoid stop codons (Fig. S2). Finally, these manipulated fragments of the WMV genome were transferred to pGWMV-Vera to create pGWMV-sPDS, pGWMV-aPDS, and pGWMV-hPDS (Fig. 1 and Fig. S1), in order to express PDS fragments in sense, antisense, and hairpin modalities, respectively.

\section{Gene silencing of melon marker genes using the WMV vector}

Triplicate young melon plants were agroinoculated in the first true leaves to express WMVsPDS, WMV-aPDS, and WMV-hPDS. As controls, plants were also inoculated with Agrobacterium tumefaciens transformed with pG35Z (Supplementary Fig. S1) - the empty plasmid - and with pGWMV-Vera, the wild-type virus. Two weeks after inoculation, all melon plants, except those mock-inoculated with the empty plasmid, showed symptoms of infection. Interestingly, while plants inoculated with the WMV-Vera control exhibited the mild symptoms previously observed, plants inoculated with WMV-sPDS, WMV-aPDS, and WMV-hPDS exhibited a photobleaching phenotype compatible with PDS silencing (Fig. 2). 


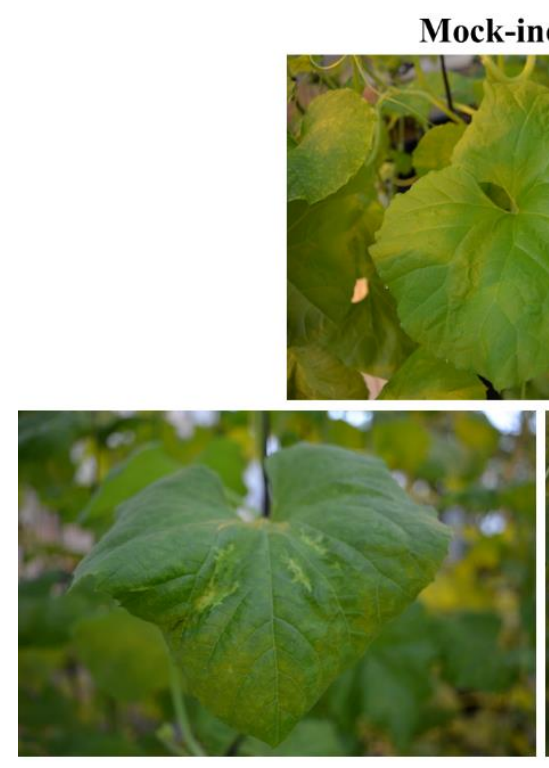

WMV-sPDS

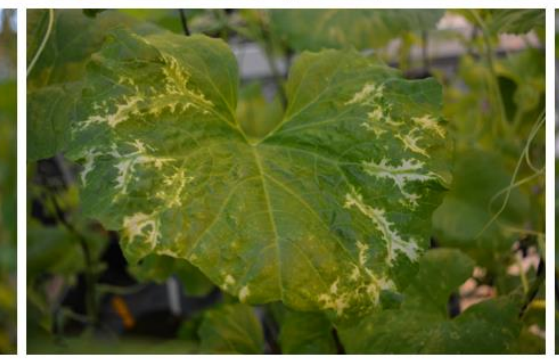

WMV-aPDS
WMV-Vera
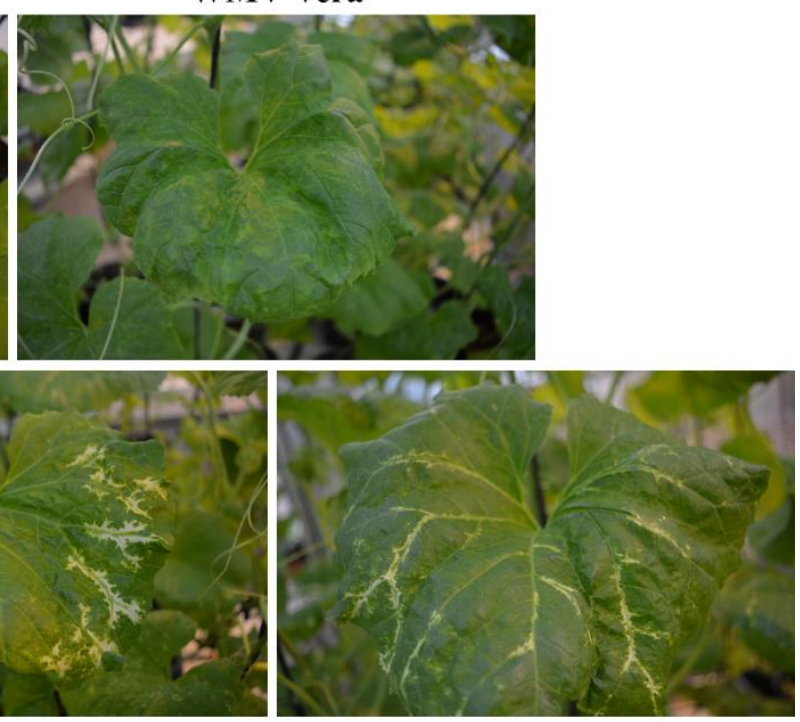

WMV-hPDS

Fig. 2. Photographs of representative leaves of melon plants mock-inoculated or inoculated with WMV-Vera, WMV-sPDS, WMV-aPDS and WMV-hPDS, as indicated. Leaves correspond to systemic non-inoculated leaves and photographs were taken $28 \mathrm{dpi}$.

Three weeks after inoculation, leaf samples were taken for RNA analyses. Reverse transcription (RT)-polymerase chain reaction (PCR) amplification of the viral CP cistron, followed by electrophoretic analysis of the products, confirmed the presence of the virus in all agroinoculated plants, except for those mock-inoculated (Fig. 3A). RT-PCR analysis encompassing the $\mathrm{NIb} / \mathrm{CP}$ intercistronic site, in which the exogenous cDNA was inserted, indicated that, while the sense and antisense PDS fragments were stable in the viral progeny, the hairpin was lost (Fig. 3B). 

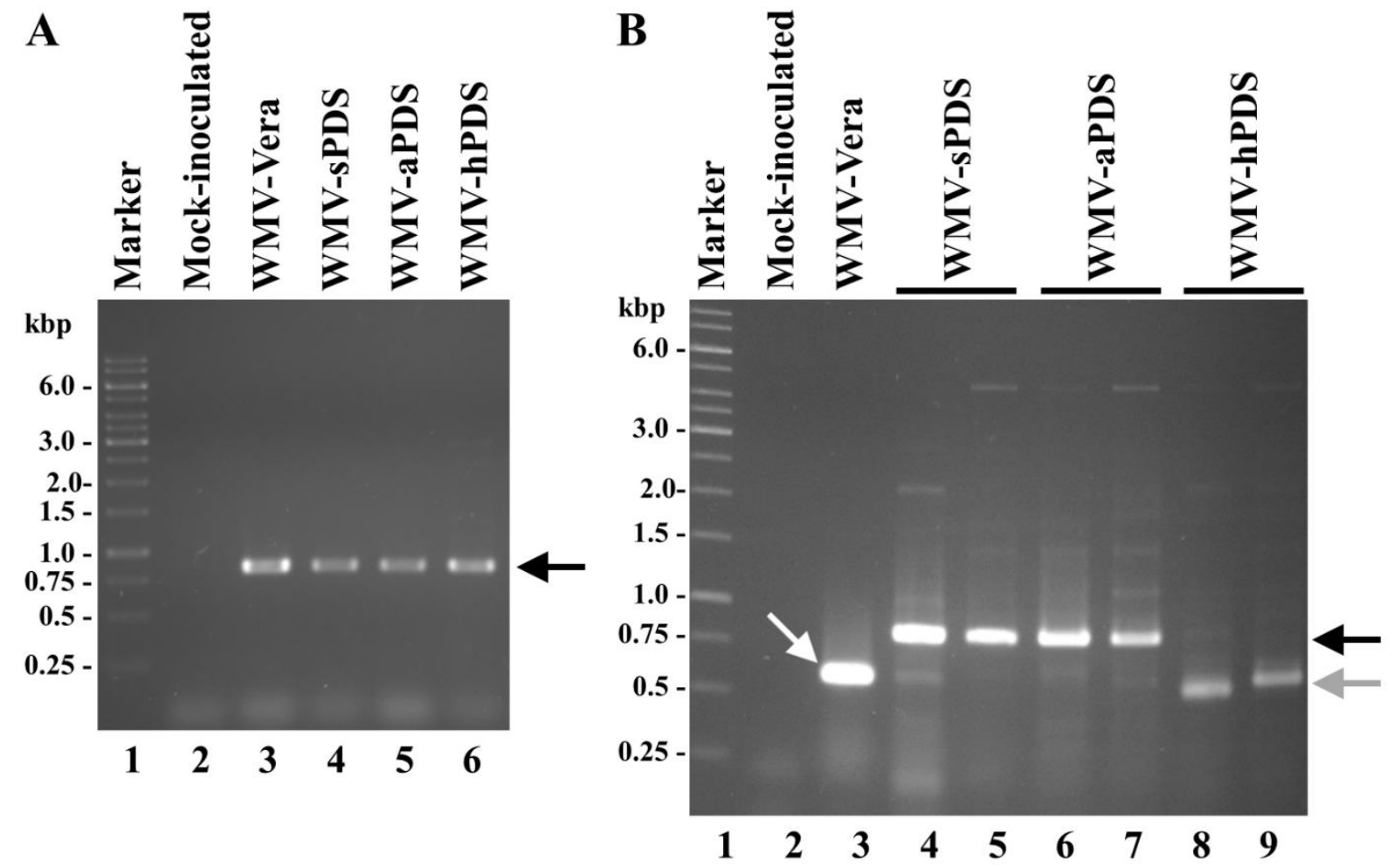

Fig. 3. RT-PCR analysis of the viral progeny. (A) Infection diagnosis by RT-PCR amplification of the CP cistron 15 dpi. (B) RT-PCR analysis of the inserted exogenous sequence 21 dpi. RNA preparations from systemic non-inoculated leaves were subjected to RT-PCR amplification and the products separated by electrophoreses in agarose gels that were stained with ethidium bromide. (A and $\mathbf{B}$ ) Lanes 1, DNA marker with the sizes (in $\mathrm{kbp}$ ) of some of the standards on the left; lanes 2 and 3, single representative plants mock-inoculated and inoculated with WMV-Vera, respectively. (A) Lanes 4 to 6 , single representative plants inoculated with WMV-sPDS, WMV-aPDS and WMV-hPDS, respectively. Black arrow points to the WMV CP cistron cDNA product. (B) Lanes 4 to 9, two representative plants inoculated with WMV-sPDS (lanes 4 and 5), WMV-aPDS (lanes 6 and 7) and WMV-hPDS (lanes 8 and 9). White, black and gray arrows point to cDNA products with no exogenous sequence, that keep the sequence and that lost the sequence, respectively.

Sequence analysis of the progenies accumulating in plants infected by WMV-hPDS indicated nearly full deletion of the inserted sequences in the progeny, as a consequence of different recombination events. One of these events is outlined, as an example, in Fig. 4. 


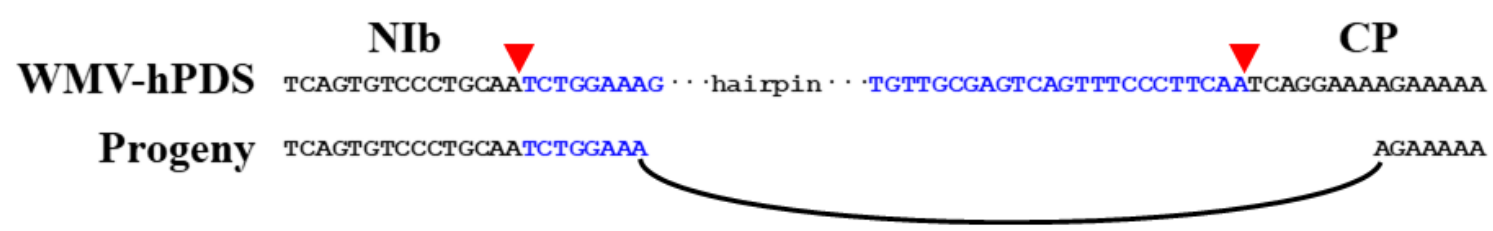

Fig. 4. Consensus sequence at the $\mathrm{NIb} / \mathrm{CP}$ intercistronic site in the progeny of a representative plant infected with WMV-hPDS. RNA was purified from upper non-inoculated leaves at $21 \mathrm{dpi}$ and subjected to RT-PCR amplification. The amplification product was purified and sequenced.

Finally, RT-quantitative PCR (qPCR) analysis of PDS mRNA at 28 dpi confirmed gene silencing in systemic tissues of plants infected with WMV-sPDS, WMV-aPDS, and WMVhPDS, in contrast to those mock-inoculated or infected with WMV-Vera (Fig. 5A). These results indicate that the Vera isolate of WMV can be used as a vector for gene function analyses in melon. To confirm these results, we targeted another melon gene using the WMV VIGS vector. We chose Magnesium chelatase subunit I (CHLI). Magnesium chelatase is a threecomponent enzyme (CHLI, CHLD, and $\mathrm{CHLH}$ ) that catalyzes the insertion of $\mathrm{Mg} 2+$ into protoporphyrin IX, in the first committed and key regulatory step of chlorophyll biosynthesis (Stenbaek and Jensen 2010). Silencing of CHLI can be easily tracked by a foliar decoloration phenotype, as a consequence of deficient chlorophyll accumulation. Since we previously obtained significant silencing in all three assayed modalities (sense, antisense, and hairpin) (Fig. 5A), we built the VIGS vector pGWMV-sCHLI (Supplementary Fig. S1) to express the CHLI ORF 5' $201 \mathrm{nt}$ only in a sense orientation. 

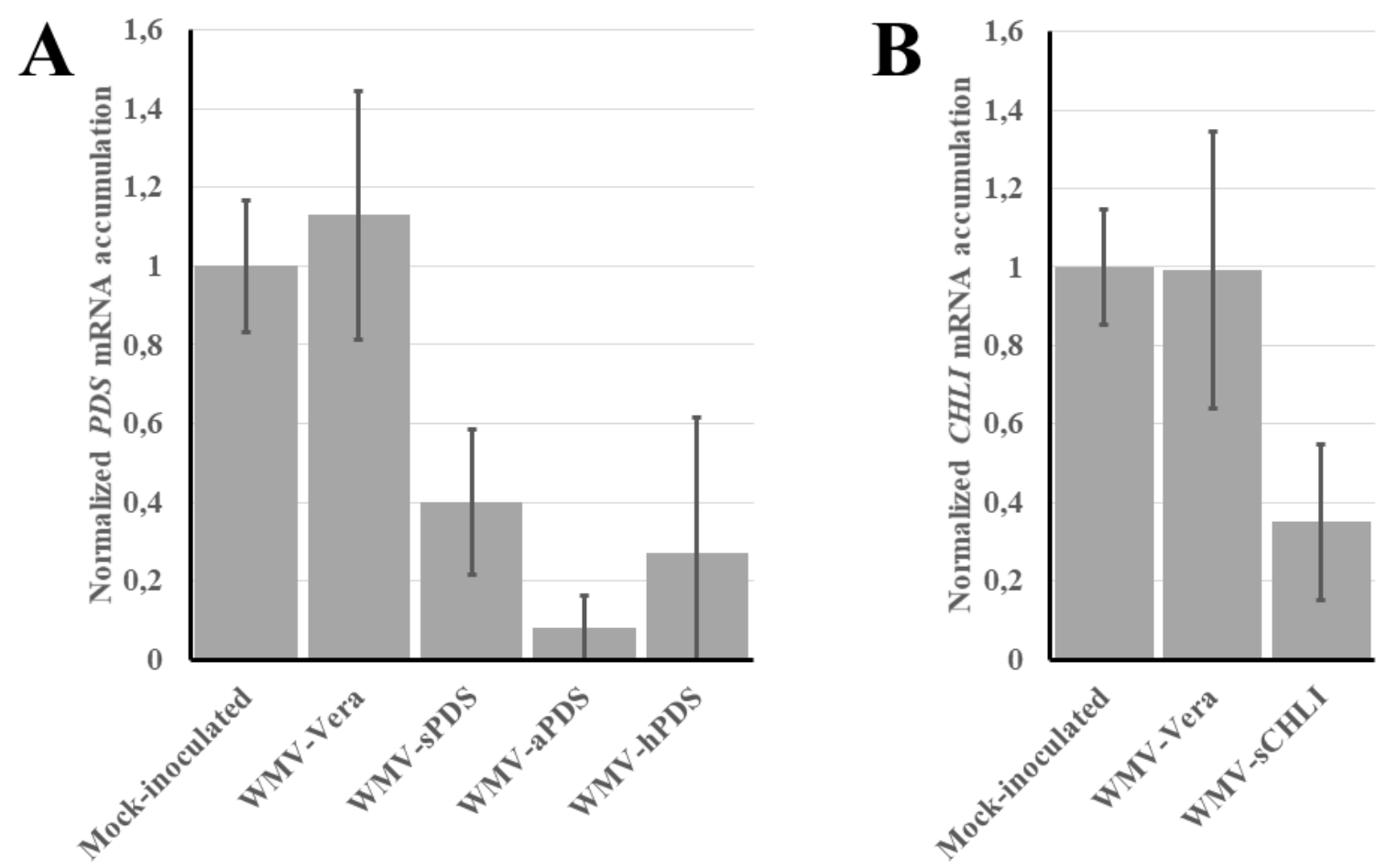

Fig. 5. RT-qPCR analysis of (A) $P D S$ and (B) CHLI mRNAs. Columns represent the normalized average mRNA accumulation in three independent plants (two technical replicates per plant). The average PDS and $C H L I$ mRNA accumulations in the mock-inoculated plants were used for normalization in (A) and (B), respectively.

The melon plants were agroinoculated with A. tumefaciens bearing the empty plasmid pG35Z, pGWMV-Vera, or pGWMV-sCHLI. Again, two weeks after inoculation, we detected symptoms of infection in plants inoculated with the wild-type virus and WMV-sCHLI. Interestingly, systemic tissues of plants infected with this second virus exhibited decolored spots, suggesting CHLI silencing (Fig. 6A). RT-qPCR analysis of RNA preparations from systemic leaf samples from these plants at 28 dpi confirmed the presence of the inserted fragment of exogenous RNA in the viral progeny (Fig. 6B), indicating CHLI silencing (Fig. $5 B)$. 

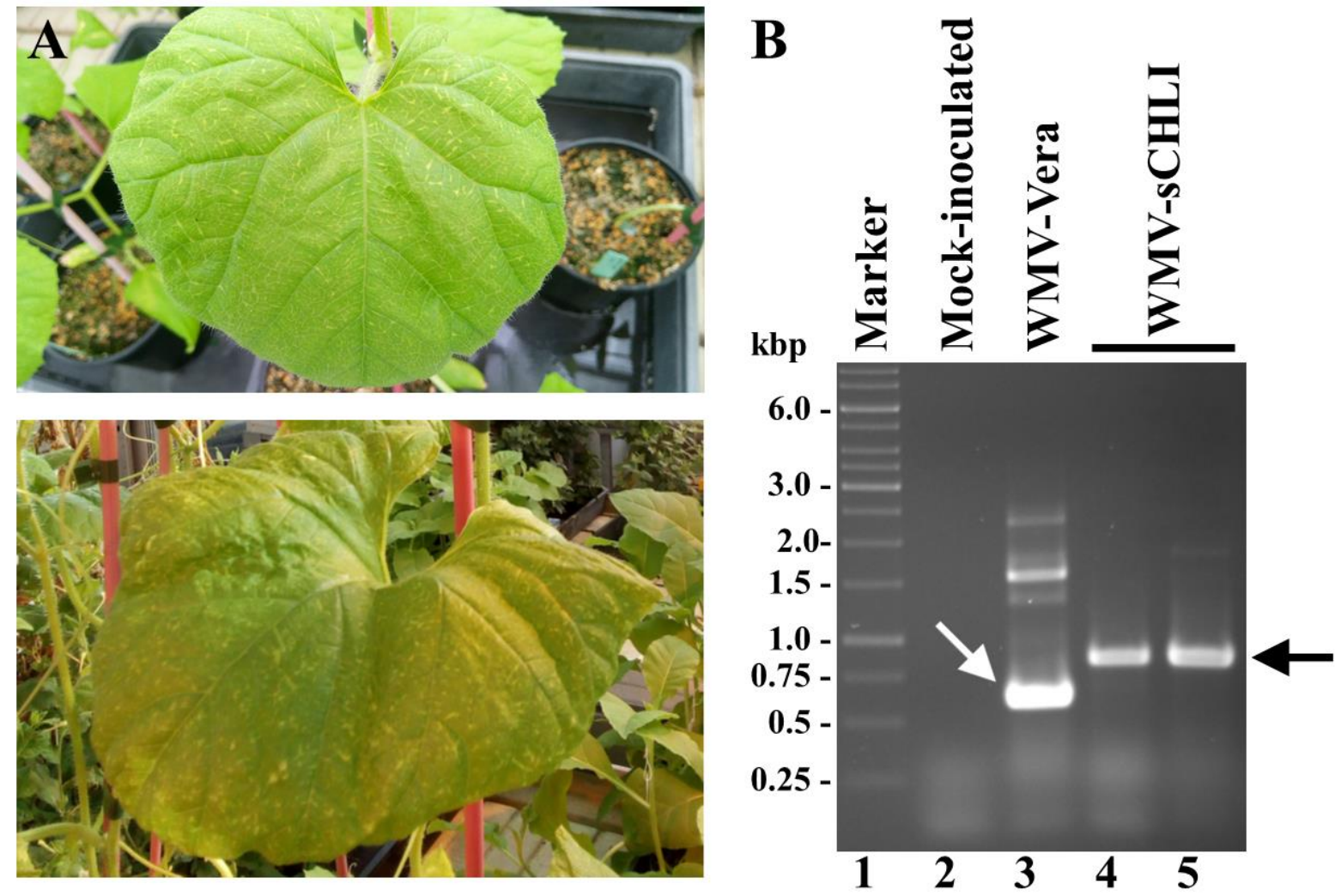

Fig. 6. Analyses of melon plants inoculated with WMV-sCHLI. (A) Photographs taken at 28 dpi of representative plants agroinoculated with WMV-sCHLI. (B) RT-PCR analysis of the inserted exogenous sequence at $21 \mathrm{dpi}$, as indicated in the legend to Fig. 3B. Lane 1, DNA marker with the sizes (in $\mathrm{kbp}$ ) of some of the standards on the left; lanes 2 and 3, single representative plants mock-inoculated and inoculated with WMV-Vera; lanes 4 and 5, two representative plants inoculated with WMV-sCHLI.

\section{Construction of a WMV-based VIGS vector for easy cloning}

Finally, to facilitate the use of this novel VIGS vector among the research community interested in cucurbit gene function analysis, we built a new binary plasmid containing the full-length WMV-Vera infectious clone, with the rearranged artificial NIaPro cleavage site between NIb and $\mathrm{CP}$ and with a unique $M l u \mathrm{I}$ cleavage site to facilitate plasmid linearization and the insertion of the foreign gene fragment in a single Gibson assembly step. This plasmid, named pGWMVVIGS (Supplementary Fig. S1), was deposited in Addgene (accession number pending). 


\section{Discussion}

Our results show that an infectious clone of a mild isolate of WMV (Aragonés et al. 2019) can be used as a VIGS vector to study gene function in melon. This new system adds to those previously reported for VIGS in melon and other cucurbits, based on Apple latent spherical virus (ALSV, genus Cheravirus, family Secoviridae) (Igarashi et al. 2009), Tobacco rattle virus (TRV, genus Tobravirus, family Virgaviridae) (Zhao et al. 2016), and-in particularCucumber green mottle mosaic virus (CGMMV; genus Tobamovirus, family Virgaviridae). The latter has been recently shown to induce a long-lasting silencing of PDS in watermelon, melon, cucumber, and bottle gourd (Liu et al. 2020). Although we have only performed experiments on melon, because WMV presents a broad host range-160 dicotyledonous species of 23 families (Desbiez and Lecoq 2004; Ouibrahim et al. 2014; Peláez et al. 2020) we expect this new system to be useful in other cucurbits, as well as species outside this family that also host the virus. The vector is based on a single binary plasmid carrying kanamycin resistance, as well as two origins of replication in E. coli and A. tumefaciens. The exogenous sequence fragment homologous to the gene selected for silencing can be inserted between the two parts of a rearranged artificial NIaPro cleavage site at the NIb/CP intercistronic position, after a simple MluI digestion of the vector and an assembly reaction (Gibson et al. 2009). The two parts of the artificial NIaPro cleavage site complement the split NIb/CP cleavage site, facilitating $\mathrm{NIb} /$ heterologous protein and heterologous protein/CP proteolytic cleavages (Fig. 1). In this way, the translation product corresponding to the exogenous sequence is efficiently released from the viral polyprotein, likely reducing the impact on virus viability. However, the exogenous sequence must be inserted in a way that does not change the reading frame of the large viral polyprotein. The plasmid vector, named pGWMV-VIGS, has been deposited in Addgene (accession number pending) to facilitate exchange and to promote its use by the research community interested in cucurbit genetics. Because pGWMV-VIGS ultimately derives from pCLEAN-G181 (Aragonés et al. 2019c), this plasmid requires a pSOUP-series helper for replication in A. tumefaciens (Thole et al. 2007).

WMV belongs to the genus Potyvirus, the largest group of RNA viruses that infect plants (Revers and García 2015; Wylie et al. 2017). Relatively few VIGS vectors have been derived to date from this large group of viruses, whose diversity remains mostly underutilized for reverse genetic analyses. This is likely a consequence of the strong RNA silencing suppressor 
activity of potyviral HC-Pro (Kasschau and Carrington 1998; Valli et al. 2018), which is reinforced by that of the viral protein genome-linked (VPg) (Rajamäki and Valkonen 2009). The combined activities of HC-Pro and VPg efficiently cancel the host RNA-based antiviral response. For this reason, viruses with weak and mild RNA silencing suppressors are typically preferred as VIGS vectors (Baulcombe 1999). Our results demonstrate that particular potyvirus isolates - such as WMV-Vera (Aragonés et al. 2019) —which induce mild symptoms and, presumably, must harbor mild silencing suppressors, can be used as vectors for efficient VIGS. In addition to exploring natural variation, potyvirus infectious clones may also be mutagenized to reduce the activity of their RNA silencing suppressors, in order to be used as efficient VIGS vectors (Torres-Barceló et al. 2008, 2010; Wu et al. 2010).

The second constraint of potyviruses as vectors for VIGS is their particular genome organization, which contains an almost genome-long polyprotein (Revers and García 2015). It is unlikely that the exogenous sequences can be inserted in the viral 5' or 3' UTRs without dramatically affecting virus infectivity. Potyvirus 5' UTRs are highly structured and contain cap-independent regulatory translation elements (Niepel and Gallie 1999; Zeenko and Gallie 2005). 3' UTRs, together with the final part of CP cistrons, fold in a complex secondary structure involved in viral genome amplification (Haldeman-Cahill et al. 1998). As an alternative, the exogenous gene fragment can be inserted into an intercistronic position. An NIb relocation analysis showed that the only permitted intercistronic positions in Tobacco etch virus (TEV; genus Potyvirus) were in front of P1, P1/HC-Pro, and NIb/CP. NIb insertion in the other intercistronic positions generated non-viable viruses (Majer et al. 2014). However, a different study using Turnip mosaic virus (TuMV; genus Potyvirus) reported tolerance to inserting foreign sequences also at $\mathrm{HC}-\mathrm{Pro} / \mathrm{P} 3,6 \mathrm{~K} 1 / \mathrm{CI}$, and NIaPro/NIb intercistronic sites (Chen et al. 2007). In our experiments, we exclusively explored the NIb/CP intercistronic site, which is a classic position for inserting heterologous sequences in potyvirus-based vectors (Choi et al. 2000), although other positions may be equally well-suited.

To gain insight into potyvirus-based VIGS, we explored the silencing efficiency and vector stability that resulted from expressing exogenous sequences under different modalities: sense, antisense, and hairpin. All three constructs produced a significant reduction of the PDS mRNA (Fig. 5A). Although the antisense modality had the largest effect on average, the differences were not statistically significant. However, while the sense and antisense constructs remained stable in the viral progeny, the hairpin was rapidly lost (Fig. 3B and Fig. 4). Remarkably, it still 
triggered a gene silencing effect of the same intensity as the sense and antisense counterparts that remained in the progeny (Fig. 5A). This indicates that, once unleashed, the plant silencing machinery amplifies and transitorily maintains the silencing signal in the absence of the trigger. Since no significant differences were observed between the sense, antisense, and hairpin constructs, we preferred the sense modality for further assays (Fig. 5B) because maintaining the viral ORF is straightforward in this case.

In our hairpin construct, we used a group-I self-splicing intron from the rRNA of T. thermophila as an alternative to a plant intron processed by the spliceosome, which is typically used to express hairpin constructs in plants (Smith et al. 2000). Efficient self-splicing of the T. thermophila group-I intron is indicated by the high infectivity of WMV-hPDS, comparable to that of WMV-sPDS and WMV-aPDS (Fig. 3A). Some spliceosomal introns - typically intron2 from the Piruvate orthophosphate dikinase (Pdk) gene of Flaveria trinervia (Westhoff 1995; Smith et al. 2000) - are frequently used to express hairpin constructs in plants and have demonstrated broad functionality in many plant species. Nevertheless, we believe that a selfsplicing intron, such as that used in our study, must be universally applied because it only requires a guanosine nucleoside for processing (Zaug and Cech 1986). In this way, the use of this self-splicing intron allows the correct formation of the hairpin motif-not only in plants but also in species belonging to other domains (Ortolá et al. 2021). This technique can even be applied in vitro if more complex experimental strategies require it.

In conclusion, we have developed a new VIGS vector, based on a mild isolate of WMV, that we expect to be useful in reverse genetics analyses particularly in melon and other cucurbits. In addition, we contribute new techniques, such as the use of mild isolates and the insertion of inframe sense fragments of the exogenous genes, which may facilitate the incorporation of many more potyviruses into VIGS technology.

\section{Acknowledgements}

This research was supported by grants BIO2017-83184-R, AGL2017-85563-C2-1-R and RTA2017-00061-C03-03 from Ministerio de Ciencia e Innovación (Spain), through Agencia Estatal de Investigación (cofinanced European Regional Development Fund). 


\section{References}

Aragonés V, Pérez-de-Castro A, Cordero T, Cebolla-Cornejo J, López C, Picó B, Daròs JA (2019) A Watermelon mosaic virus clone tagged with the yellow visual maker phytoene synthase facilitates scoring infectivity in melon breeding programs. Eur J Plant Pathol $153: 317-323$

Baulcombe DC (1999) Fast forward genetics based on virus-induced gene silencing. Curr Opin Plant Biol 2:109-113

Bertin S, Manglli A, McLeish M, Tomassoli L (2020) Genetic variability of watermelon mosaic virus isolates infecting cucurbit crops in Italy. Arch Virol 165:937-946

Burch-Smith TM, Schiff M, Liu Y, Dinesh-Kumar SP (2006) Efficient virus-induced gene silencing in Arabidopsis. Plant Physiol 142:21-7

Chen CC, Chen TC, Raja JA, Chang CA, Chen LW, Lin SS, Yeh SD (2007) Effectiveness and stability of heterologous proteins expressed in plants by Turnip mosaic virus vector at five different insertion sites. Virus Res 130:210-227

Choi IR, Stenger DC, Morris TJ, French R (2000) A plant virus vector for systemic expression of foreign genes in cereals. Plant J 23:547-555

Chomicki G, Schaefer H, Renner SS (2020) Origin and domestication of Cucurbitaceae crops: insights from phylogenies, genomics and archaeology. New Phytol. 226:1240-1255

Cordero T, Cerdan L, Carbonell A, Katsarou K, Kalantidis K, Daròs JA (2017) Dicer-like 4 is involved in restricting the systemic movement of zucchini yellow mosaic virus in nicotiana benthamiana. Mol Plant-Microbe Interact 30:63-71

Courdavault V, Besseau S, Oudin A, Papon N, O'Connor SE (2020) Virus-Induced Gene Silencing: Hush Genes to Make Them Talk. Trends Plant Sci. 25:714-715

Csorba T, Kontra L, Burgyàn J (2015) Viral silencing suppressors: tools forged to fine-tune host-pathogen coexistence. Virology 479-480:85-103

Desbiez C, Lecoq H (2004) The nucleotide sequence of Watermelon mosaic virus (WMV, Potyvirus) reveals interspecific recombination between two related potyviruses in the 5 , part of the genome. Arch Virol 149:1619-1632

Desbiez C, Wipf-Scheibel C, Millot P, Berthier K, Girardot G, Gognalons P, Hirsch J, Moury B, Nozeran K, Piry S, Schoeny A, Verdin E (2020) Distribution and evolution of the major viruses infecting cucurbitaceous and solanaceous crops in the French Mediterranean area. Virus Res 286:198042 
Dommes AB, Gross T, Herbert DB, Kivivirta KI, Becker A (2019) Virus-induced gene silencing: Empowering genetics in non-model organisms. J Exp Bot 70:817-833

Fofana IBF, Sangaré A, Collier R, Taylor C, Fauquet CM (2004) A geminivirus-induced gene silencing system for gene function validation in cassava. Plant Mol Biol 56:613-624

Gammelgård E, Mohan M, Valkonen JPT (2007) Potyvirus-induced gene silencing: The dynamic process of systemic silencing and silencing suppression. J Gen Virol 88:23372346

Gibson DG, Young L, Chuang RY, Venter JC, Hutchison 3rd CA, Smith HO (2009) Enzymatic assembly of DNA molecules up to several hundred kilobases. Nat Methods 6:343-345

Gonzalez-Ibeas D, Blanca J, Roig C, González-To M, Picó B, Truniger V, Gómez P, Deleu W, Caño-Delgado A, Arús P, Nuez F, Garcia-Mas J, Puigdomènech P, Aranda MA (2007) MELOGEN: An EST database for melon functional genomics. BMC Genomics 8:306

Haldeman-Cahill R, Daròs J-A, Carrington JC (1998) Secondary Structures in the Capsid Protein Coding Sequence and 3' Nontranslated Region Involved in Amplification of the Tobacco Etch Virus Genome. J Virol 72:4072-4079

Holzberg S, Brosio P, Gross C, Pogue GP (2002) Barley stripe mosaic virus-induced gene silencing in a monocot plant. Plant J 30:315-327

Igarashi A, Yamagata K, Sugai T, Takahashi Y, Sugawara E, Tamura A, Yaegashi H, Yamagishi N, Takahashi T, Isogai M, Takahashi H, Yoshikawa N (2009) Apple latent spherical virus vectors for reliable and effective virus-induced gene silencing among a broad range of plants including tobacco, tomato, Arabidopsis thaliana, cucurbits, and legumes. Virology 386:407-416

Jones AL, Thomas CL, Maule AJ (1998) De novo methylation and co-suppression induced by a cytoplasmically replicating plant RNA virus. EMBO J 17:6385-6393

Kant R, Dasgupta I (2019) Gene silencing approaches through virus-based vectors: speeding up functional genomics in monocots. Plant Mol. Biol. 100:3-18

Kasschau KD, Carrington JC (1998) A counterdefensive strategy of plant viruses: suppression of posttranscriptional gene silencing. Cell 95:461-470

Kjemtrup S, Sampson KS, Peele CG, Nguyen L V., Conkling MA, Thompson WF, Robertson D (1998) Gene silencing from plant DNA carried by a Geminivirus. Plant J 14:91-100

Kumagai MH, Donson J, della-Cioppa G, Harvey D, Hanley K, Grill LK (1995) Cytoplasmic inhibition of carotenoid biosynthesis with virus-derived RNA. Proc Natl Acad Sci USA 92:1679-1683 
Lai PJ, Lim CT, Le HP, Katayama T, Leach DRF, Furukohri A, Maki H (2016) Long inverted repeat transiently stalls DNA replication by forming hairpin structures on both leading and lagging strands. Genes to Cells 21:136-145

Lindbo JA, Silva-Rosales L, Proebsting WM, Dougherty WG (1993) Induction of a highly specific antiviral state in transgenic plants: Implications for regulation of gene expression and virus resistance. Plant Cell 5:1749-1759

Liu M, Liang Z, Aranda MA, Hong N, Liu L, Kang B, Gu Q (2020) A cucumber green mottle mosaic virus vector for virus-induced gene silencing in cucurbit plants. Plant Methods $16: 9$

Liu Y, Schiff M, Dinesh-Kumar SP (2002a) Virus-induced gene silencing in tomato. Plant J $31: 777-786$

Liu Y, Schiff M, Marathe R, Dinesh-Kumar SP (2002b) Tobacco Rar1, EDS1 and NPR1/NIM1 like genes are required for $\mathrm{N}$-mediated resistance to tobacco mosaic virus. Plant J 30:415429

Livak KJ, Schmittgen TD (2001) Analysis of relative gene expression data using real-time quantitative PCR and the 2- $\Delta \Delta C T$ method. Methods 25:402-408

Majer E, Salvador Z, Zwart MP, Willemsen A, Elena SF, Daros J-A (2014) Relocation of the $\mathrm{NIb}$ Gene in the Tobacco Etch Potyvirus Genome. J Virol 88:4586-4590

Niepel M, Gallie DR (1999) Identification and characterization of the functional elements within the tobacco etch virus 5 ' leader required for cap-independent translation. J Virol 73:9080-9088

Olspert A, Carr JP, Firth AE (2016) Mutational analysis of the Potyviridae transcriptional slippage site utilized for expression of the P3N-PIPO and P1N-PISPO proteins. Nucleic Acids Res 44:7618-7629

Ortolá B, Cordero T, Hu X, Daròs J-A (2021) Intron-assisted, viroid-based production of insecticidal circular double-stranded RNA in Escherichia coli. RNA Biol. https://doi.org/10.1080/15476286.2021.1872962

Ouibrahim L, Mazier M, Estevan J, Pagny G, Decroocq V, Desbiez C, Moretti A, Gallois JL, Caranta C (2014) Cloning of the Arabidopsisrwm1 gene for resistance to Watermelon mosaic virus points to a new function for natural virus resistance genes. Plant J 79:705716

Peláez A, McLeish MJ, Paswan RR, Dubay B, Fraile A, García-Arenal F (2020) Ecological fitting is the forerunner to diversification in a plant virus with broad host range. J Evol Biol jeb.13672 
Rajamäki ML, Valkonen JP (2009) Control of nuclear and nucleolar localization of nuclear inclusion protein a of picorna-like Potato virus A in Nicotiana species. Plant Cell 21:2485-2502

Revers F, García JA (2015) Molecular biology of potyviruses. Adv Virus Res 92:101-199

Rosche E, Westhoff P (1995) Genomic structure and expression of the pyruvate, orthophosphate dikinase gene of the dicotyledonous $\mathrm{C} 4$ plant Flaveria trinervia (Asteraceae). Plant Mol Biol 29:663-678

Smith NA, Singh SP, Wang MB, Stoutjesdijk PA, Green AG, Waterhouse PM (2000) Total silencing by intron-spliced hairpin RNAs. Nature 407:319-320

Stenbaek A, Jensen PE (2010) Redox regulation of chlorophyll biosynthesis. Phytochemistry $71: 853-859$

Teresa Ruiz M, Voinnet O, Baulcombe DC (1998) Initiation and maintenance of virus-induced gene silencing. Plant Cell 10:937-946

Thole V, Worland B, Snape JW, Vain P (2007) The pCLEAN dual binary vector system for Agrobacterium-mediated plant transformation. Plant Physiol 145:1211-1219

Torres-Barceló C, Daròs JA, Elena SF (2010) HC-Pro hypo- and hypersuppressor mutants: Differences in viral siRNA accumulation in vivo and siRNA binding activity in vitro. Arch Virol 155:251-254

Torres-Barceló C, Martín S, Daròs JA, Elena SF (2008) From hypo- to hypersuppression: Effect of amino acid substitutions on the RNA-silencing suppressor activity of the Tobacco etch potyvirus HC-pro. Genetics 180:1039-1049

Valli AA, Gallo A, Rodamilans B, Lopez-Moya JJ, Garcia JA (2018) The HCPro from the Potyviridae family: an enviable multitasking Helper Component that every virus would like to have. Mol Plant Pathol 19:744-763

Weng Y, Garcia-Mas J, Levi A, Luan F (2020) Editorial: Translational Research for Cucurbit Molecular Breeding: Traits, Markers, and Genes. Front Plant Sci 11:615346

Wu HW, Lin SS, Chen KC, Yeh SD, Chua NH (2010) Discriminating mutations of HC-Pro of Zucchini yellow mosaic virus with differential effects on small RNA pathways involved in viral pathogenicity and symptom development. Mol Plant-Microbe Interact 23:17-28 Wylie SJ, Adams M, Chalam C, Kreuze J, López-Moya JJ, Ohshima K, Praveen S, Rabenstein F, Stenger D, Wang A, Zerbini FM, Ictv Report C, Lopez-Moya JJ, Ohshima K, Praveen S, Rabenstein F, Stenger D, Wang A, Murilo Zerbini F, Ictv Report C (2017) ICTV Virus Taxonomy Profile: Potyviridae. J Gen Virol 98:352-354 
Zaug AJ, Cech TR (1986) The intervening sequence RNA of Tetrahymena is an enzyme. Science (80- ) 231:470-475

Zeenko V, Gallie DR (2005) Cap-independent translation of tobacco etch virus is conferred by an RNA pseudoknot in the 5'-leader. J Biol Chem 280:26813-26824

Zhao F, Lim S, Igori D, Yoo RH, Kwon SY, Moon JS (2016) Development of tobacco ringspot virus-based vectors for foreign gene expression and virus-induced gene silencing in a variety of plants. Virology 492:166-178

\section{Supplementary material}

Fig. S1. Nucleotide sequences of plasmids pGWMV-Vera, pMWMV-Z, pGWMV-sPDS, pGWMV-aPDS, pGWMV-hPDS, pGWMV-sCHLI, and pGWMV-VIGS.

>pGWMV-Vera (13 $290 \mathrm{bp})$

GCGGCCGCGATTCCATTGCCCAGCTATCTGTCACTTTATTGTGAAGATAGTGGAAAAGGAAGGTGGCTCCTACAA ATGCCATCATTGCGATAAAGGAAAGGCCATCGTTGAAGATGCCTCTGCCGACAGTGGTCCCAAAGATGGACCCCC ACCCACGAGGAGCATCGTGGAAAAAGAAGACGTTCCAACCACGTCTTCAAAGCAAGTGGATTGATGTGATATCTC CACTGACGTAAGGGATGACGCACAATCCCACTATCCTTCGCAAGACCCTTCCTCTATATAAGGAAGTTCATTTCA TTTGGAGAGGAAATTAAAACAACTCATAAAGACATCAAACAAAACAAACGCAAACAAACTCTCAAGTTTTCAAGC TATTTCAAGCAATTTACATCTTCACCATTCACAAGTTTACGATTCATCAATATCAACAACAACACAAATGGCAAC AATTATGTTTGGAGATTTCGCTGTGCAGCTGAAGCATAGCACTGTTACAGAAAAGAGAAAGCGAGTGGTTGAGAC CACTAAGCTTGTGCAAGAAGTGCATATGGATACTGTTTATGAGCAAGTTATGGAGAGCATCACTGTAGGATGCAC AGAAAGGTGCGCGGGCCTGAGCGCATATACAAAATCGTCCCTCAGGAGAGCAATCAAAGAGGGAGATCTCAGTGC ATCTGGAGGGTGCAACTACTGTGGTCTCCGAGCACTAGTGGGTGAGGGTCGCGAGAGGGTGATTTCTGTACCCAG AACAGTGGCACAGCAGAAGGAGGTAGTTGTCACCAAGGAAGTTCCTCATATCTATGAAGAAGAATATGAGGTGGA AGTGCCACACCCAACCTCTGAAATGGTGTTGCCAACTGGAGGTAATGTCTGTGGAACTGCTGTGCAGACAAAAGT GGCGAAGAATATCGTCACCAAAGAGATGATGGCAAAATCTGAGCCGTCATTAAAACAAGCGAGCCGATCTCTTGT CTTGGCTGGTAGAAAGGAAATTGGTAATTATGATCTGGCAATTAAAAAGATGGATGAGGCAATGAAGCATGATCC TGCGCTTCAACGAAGACTTTTCATTCAACAGCAAAGCACCATTAAGCAGCTACCTAAAGGAGCTGTTCAGTTGAG GTTATGCTCGTATGAACAAGCAAAGAAGCGTGCAGAATTGGAGCACAAGAGGAAACAGGAGGAGGAAGATTTCCT CAATGGTAAATATGAACAGCAAGCCTACATTGGAACAACTGCTGTTAATACTATGAAATCCGCAGGAGGGAGCAT GGGTTTCAGAACAATTCACTGGAGATCAACTCCAAAGCAAAACAAGACAAAGCGCGTCAAGAAACAGTGTGACAA GCCCATACATGTTCTAGAAGGAGTTCTTTCCTTAGCTGCGAAAAGTGGAAAGCCAGTCGAATTCATAACAAAACG TAAAAGGAAAAACTTCAAAGTTAACTATGTGCGGAAGTATGGAGCTGTTATACCAAAATTTACTCTCCCACATGA AGAAGGCAAATACGTACATCAAGAGCTTCAATACGCAAACATATGTGAATTTCTTCCATATATTTGTATGTTTGC AAAATACAAAGCTGTACGTGCAGATGATTTGACTCATGGAGATAGTGGTTTACTGTTTGATGAACGATCTTCAAT TACTTCAGAACACACTACACTACCATATTTTGTGGTGCGAGGTAGAAAGAATGGAAAGCTCGTTAGTGCCTTTGG AGAGTTCAAAGAGATAGGAGATATTCAACACTATTCCCACATCCCAGAAGTTCAATTTTTCCTAGGCTGGAAGAA GGTGTTTGATAAGATGCAACCACGAATTGATGCTCACGAATGCACAATTGATTTTACAAATGAACAATGTGGTGA ATTGGCAGCAGCAATTAGTCAATCGATCTTTCCAGTTAAGAAACTATCTTGCAAACACTGCAGGCGACACATAAA GGATCTTAGTTGGGAGGAGTACAAGCAATTTCTTCTGACTCATATGGGTTGCTCTGAAACCACATGGGCGGATGT TCGGAAAGTTGAGGGTGTAGAGCATGTGAAGAAATTAATTGAAAGATCAACTGCGGAGAATCTGAGCTTACAAAC GTCAATGGAAATTGTCAGGTTGACACAGAATTACAAGAGCACACATATGCTGCAGATACAGGACATTAATAAGGC TCTCATGAAAGGTTCATCGGTGACACAAGATGAACTGGAGCAAGCTTCCAAGCAGCTTCTTGCCATGACACAGTG GTGGAAGAATCACATGACCTTGACTGATGAAGATGCACTTAAAGTGTTTAGAAATAAGCGATCTTCCAAAGCATT GCTTAATCCAAGTTTGCTCTGTGATAATCAGTTGGACAAGAATGGAAATTTTATTTGGGGTGAGCGTGGTAAGCA TTCAAAGCGGTTTTTCGCAAATTATTTTGAAGAGGTGATTCCTTCCGAAGGATATAGTAAATATGTCATTAGGAA AAACCCAAATGGACAGAGAGAATTAGCAATTGGGTCGCTCATTGTACCATTGGACTTCGAGCGTGCACGCATGGC ATTGCAAGGCAAAAGCATAGCAAGGGAACCAATTACAATGGCGTGTATTTCAAGGCAGGATGGTAACTTTGTATA CCCTTGTTGCTGTGTCACACATGATGATGGGAAGGCCTTCTATTCTGAACTTAAAAGTCCTACAAAACGTCATTT GGTTATTGGGACATCTGGTGATCCGAAATATATTGACCTCCCAGCCACGGAAACAGATCGCATGTACATAGCAAA GGAAGGATATTGCTATCTCAACATTTTTTTAGCAATGTTAGTTAACGTCAATGAGGATGAAGCCAAGGATTTCAC 
CAAAATGGTCAGAGATGTCATTGTACCAAAGCTTGGGCAATGGCCGACAATGTTTGATGTGGCTACAGCTGTGTA TATGTTGACAGTTTTTCATCCTGAAACTAGAAATGCTGAACTTCCACGTATTTTGGTTGACCATGCATGTCAGAC TATGCACGTTATAGACTCTTTTGGTTCTCTGACAGTTGGATACCATGTACTAAAAGCTGGCACAGTGAATCAACT TATTCAATTCGCATCGAACGATCTGCAAAGCGAGATGAAGTTTTATAGGGTTGGTGGTGTAGCGCAACAAAGGAT GAAGTGTGAAACGGCATTAATCACAAGCATCTTTAAACCCAAAAGGATGATTCAAATTCTTGAAGAAGATCCGTA TATACTCCTTATGGGTTTGATATCACCATCCATTTTAATCCACATGTATCGCATGAGACACTTTGAGAAAGGAAT TGAAATGTGGATAAATAAGGAGCATAGCGTTGCAAAAATTTTCATAATCATGGAGCAACTCACTAAAAAGATTGC GGCAAATGATCTGTTACTTGAACAGCTTGATATAATTGCAGGAACTTCTCATAAGCTCATGGATGTTTTGGAGGA TTGTCCACAATCAGCACATTCATACAAAACGGTTAAGGATCTTTTGGCTATGTATATAGAGAGGAAAGCATCCAA CAACCAGCTAGTTGAGAACGGATTTGTGGATATGAATGATCAATTGTACGTGATGCATGAAAAAATCTATGTGGA TCGTTTAAAGCAGGAATGGCGCGCTTTAAGTTGGTTGGAAAAATCTTCTATAACATGGCAATTGAAAAGGTTTAC TCCACATACGGAGCAATGTTTGACAAAGAGAGTTGTAGAAGAAAGCAGCGCATATTCAAGAAACTTTGTGAGCGC GTGCTTTATGAATGCTCAGTCACACCTCAAAAACGTCAGAAATACATTTTTCCGAAAGTGTGACCAAGCTTGGAC TGCATCAGTGCGAGGTTTTGTCAGATTTATCATATCAACGCTACACAAGTGTTACAGTGACATAGTGTACCTAGT CAACATTTGTTTAATATTTTCATTATTGATTCAAATGGCTAGCGTATTACAAGGTATTGTGAGCACAGCAAAGAA AGACAAAGCGTTCGTACACATGCATAAGAGAAATGAGGATGAGCAAGCTGTGGTGCATTTGTATGAGATGTGTGA GAAGATAGGAAACAAGCATCCAAGCGTTGAAGAATTCTTAAGTCATGTTAAGAAAGTTAGGCCTGAATTGCTTCC 0 . z\&CGTAGCAATGAGCATGACAGGACAATCGGAAGATGTTTCTGCGCAAGCTAAAACAGCCACGCAACTGCAAC TTGAGAAGATTGTCGCATTTATGGCTTTATTGACTATGTGCATTGATAATGAAAGAAGTGATGCTGTTTTCAAGA TACTAAGCAAATTGAAAACGTTCTTTGGCACAATGGGTGAGGAAGTTAAAGTGCAGAGTCTAGATGAGATCCAGA ACATTGATGAAGACAAAAAGCTCACAATTGACTTTGACCTTGAGACAAGCAAAGAACCCTCCAGTGTTTCCTTTG ATGTCAAATTCGAGGACTGGTGGCACAGGCAGTTGCAACAGAACAGAGTCATTCCACATTATAGGTCAACAGGTG AGTTCTTGGAATTTTCACGAGAGACAGCAGCTAAGATTGCAAATTTGATAGCAACCTCAAGTCATACAGAGTTTT TGATTAGAGGAGCAGTCGGATCGGGAAAATCAACAGGTCTGCCACATCATTTATCAAAGAAAGGCAAAGTTTTGC TATTGGAACCAACGAGACCATTAGCAGAGAATGTTAGCAAGCAGTTAGGCCTCGAGCCTTTCTATCACAACGTGA CATTGAGGATGAGAGGGTTAAGCAAGTTTGGATCGAGCAACATAGTTGTTATGACGAGTGGATTCGCATTCCATT ATTATGTCAATAATCCACACCAACTGTCCGACTTCGATTTCATTATCATAGATGAGTGTCATGTGCAGGATAGTC ACACAATAGCGTTTAATTGTGCACTTAAAGAATTTGAGTTCAGTGGCAAGCTCTTGAAAGTGTCTGCAACTCCTC CAGGGCGAGAGTGTGAGTTCACAACACAACACCCAGTCAAATTGAAGATCGAGGACCATCTCTCATTTCAAAATT TCGTACAAGCTCAAGGAACGGGCTCAAACGCCGATATGCTTCAACATGGGAACAACTTACTTGTGTATGTTGCAA GCTACAATGAGGTTGACCAGTTATCACGACTTCTTACTGAGAAGCACTACAAAGTGACAAAGGTTGATGGTAGAA CTATGCAGATGGGTAATGTTGAGATTACCACAACGGGCACAGAAGGAAAACCACACTTCATAGTTGCAACAAACA TCATTGAAAATGGAGTGACACTGGATATAGACTGTGTGATTGACTTTGGACTTAAGGTTGTGGCAGTTTTGGACA CAGACAATCGGTGTGTTCGTTACAATAAACAATCAGTTTCGTATGGCGAGAGGATTCAGAGACTTGGTAGAGTGG GGAGACATAAACCAGGATTTGCGCTGAGAGTGGGGCACACGGAGAAAGGAATTGAGGAAGTTCCAGAGTTTATAG CAACTGAAGCGGCTTTTCTATCTTTTGCGTACGGATTGCCAGTCACAACACAGAGTGTATCCACTAATATACTCT CTCGTTGTACGGTCAAGCAAGCACGAGTCGCTTTGAATTTTGAGTTGACACCСTTCTTCACCATCAATTTCATTA AATATGATGGCGGTATGCACCCAGAAATCCACAGGTTACTTAAACCGTATAAGTTGAGAGAATCAGAAATGATGC TACACAAGTTAGCCATACCACATCAGTTTGTCGGGCAGTGGATATCAGTGAAAGAATACAATCGGCAAGGAATTC ACСTTAATTGCCCAGAAACAGTTAAAGTACCGTTCTATGTTAATGGCATACCTGATAAGCTATATGAATCATTGT GGGATGCGGTATGCAACTATAAGTGTGATGCAGGTTTTGGCTCAATAAGAAGTGTGAATGCGTCAAAAATAAGTT ACACTCTGAGCACAGACCCAACAGCAATACCCCGAACACTCGTCATTTTGGATCATTTACTCAGTGAAGAGATGA CTAAGAAAAGCCATTTTGATACAATTGGCTCTTCTGTTACTGGTTATTCTTTTTCTCTTGCGGGTATAGCTGATG GATTCAGGAAGAGGTACTTAAGAGACTACACGCAGCAAAATATAGCAATCCTGCAACAGGCAAAAGCACAGCTGC TAGAATTTGACTGTACCAAAGTCGATATTAACAACCTCCAAAGTGTTGAAGGTATTGGCATTCTTAACGCAGTGC AGCTGCAAAGCAAACATGAGGTCAGCAAGTTCTTGCAATTAAAAGGAAAGTGGGATGGAAAGAAGTTCATGAACG ACGCTATTGTGGCAATCTTTGCTTTGATTGGTGGTGGTTGGATGCTGTGGGACTACTTCACAAGAATGATACGTG AGCCAGTCACAACTCAAGGAAAGAAAAGACAGATACAGAAGCTGAAATTCAGAGATGCCTTTGACAGGAAAGTAG GACGTGAAGTGTATGCTGATGATTACACCATGGAACATACTTTTGGAGAAGCGTACACTAAGAAAGGAAAGCAAA AAGGAAGCACTAAAACAAAAGGAATGGGTCGCAAATCACGGAATTTTATACACATGTATGGAGTTGAGCCAGAGA ATTATAGCATGATTCGTTTTGTTGATCCACTAACTGGACACACGATGGATGAAAGTACAAGAGTGGATATCAGGC TGGTGCAACAGGAATTTGGGGAAATCAGAGAGGAGATGATTGGGGCGGATGAGCTAGACCCACAGAAGGTGTACC ATAGTCCTGGAATACAAGCATATTTTATGGGAAAGAATGCAGAGGAAGCTCTTAAGGTTGATCTCACACCACATA TACCAACACTTTTGTGCCAAAACACCAATGCCATTTCAGGTTTTCCAGAAAGAGAGGGCGAGTTGCGACAAACAG GCTTGCCACAAATTGTTTCTAAGGCTGATGTGCCAAGAGCTAAGGAGCGAGTGGAGGTTGAGAGCAAGTCTGTGT ACAAGGGACTCAGAGATTATAGTGGCATTTCTACTTTGATTTGCCAACTCACGAACTCTTCAGATGGTCACAAGG AGACAATGTTTGGAGTTGGGTACGGTTCTTTCATTATCACCAATGGGCACTTATTTAGAAGAAACAATGGAATAC TCACAGTTAAAACATGGCATGGTGAATTTGTTATACATAACACCACACAACTGAGAATCCATTTTATTCAAGGGA AAGATGCAATCTTGATTCGCATGCCAAAGGATTTTCCTCCATTTGCAAAGCGCAACTTCTTTAGACAGCCAAAAC GTGAAGAACGGGTTTGCATGGTTGGAACAAATTTTCAAGAAAAGAGTTTACGCGCAACAGTCTCAGAGTCTTCCA TCATTCTACCTGAAGGGAAGGGATCTTTCTGGATACATTGGATAACGACTCAGGATGGTTTTTGTGGGTTACCTC 
TTGTGTCTGTCAATGACGGACATGTTGTTGGTATACATGGATTAACATCTAATGACTCAGAGAAGAATTTCTTTG TTCCATTCACTGATGGGTTCGAGAAGGAGTATTTGGACAACGCTGATAACTTATCGTGGGATAAACATTGGTTTT GGGAACCAAGCAAGATTGCGTGGGGCTCTTTGAACTTAGTGGAAGAACAGCCAAAGGAAGAGTTTAAGATATCAA AACTTGTATCTGATCTCTTTGGTAACACAGTAGCAGTGCAGAGTAGAAAGGAGAGATGGGTTTTGGATGCCATGG AAGGGAATTTGGTTGCTTGTGGGCAAGCTGACAGCGCGCTAGTGACAAAGCATGTGGTTAAAGGAAAATGCCCTT ATTTTTCACAATATCTCTCATTGCACAATGAAGCAAAACAGTTCTTTGAGCCATTGATGGGGGCATACCAGCCAA GCCGGTTAAATAAAGACGCTTTCAAGAAAGATTTCTTTAAATACAACAAACCGGTAGTTTTGAATGAAGTTGATT TTAACGCTTTCGAGAAAGCAGTTGAGGGAGTGATAACAATGATGGTTGACTTTGAATTCGCAGAATGCTTGTTTG TAACTGATCCTGATGAAATTTATGGATCCCTGAACATGAAAGCCGCTGTTGGTGCTCAATACAAAGGAAAGAAAC AGGATTACTTTTCTGGCATGGATAGTTTTGATAAGGAGCGCCTGTTGTACCTTAGCTGTGAGAGGCTGTTCAATG GAGAGAAGGGAATTTGGAATGGTTCTCTAAAGGCGGAGTTGAGACCAATTGAGAAAGTGCAGGCAAACAAAACTA GAACATTTACAGCAGCACCGATTGACACATTACTTGGAGCCAAAGTTTGCGTTGATGACTTCAATAATCAATTCT ACAGCTTCAACTTAAAATGTCCATGGACAGTTGGCATGACTAAGTTTTATGGGGGTTGGGATAAGCTAATGAGGA GTTTACCTGATGGTTGGACATATTGCCATGCAGATGGTTCACAGTTCGACAGTTCTTTAACTCCСTTGTTGTTGA ATGCTGTCCTCAGTATTAGATGTTGCTTCATGGAAGATTGGTGGGTTGGAAAGGAAATGCTTGAAAACCTTTACG CTGAAATAGTTTACACACCAATCTTAGCGCCTGATGGCACAATTTTCAAAAAGTTCAGAGGGAACAACAGTGGAC AGCCATCTACAGTCGTTGACAATACGCTTATGGTTGTCATTGCTATGTATTATTCGTGCTGTAAACAAGGTTGGT CAGAGGAGGACATTGAAAGGAGGCTGGTGTTCTTTGCCAATGGTGATGATATTATCCTGGCAGTTAGGGATGAGG ATGTGTGGCTGTATGACACTCTGAGTGCTTCATTTGCTGAGCTTGGCCTGAATTACAATTTTGATGAGCGAACAA AGAAAAGAGAGGAACTGTGGTTCATGTCACACCAAGCCATGCTAGTTGATGGGATATACATCCCAAAGCTTGAAC CTGAAAGGATAGTTTCCATCTTAGAATGGGATAGGAGCAAGGAAATTATGCACCGCACTGAGGCAATTTGTGCAG CCATGATTGAAGCGTGGGGATACACTGAGCTTTTACAAGAAATTCGCAAATTTTATTTGTGGCTTCTGAGCAAAG ATGAATTTAAGGAACTCGCAGCGTCTGGAAAAGCCCCATACATAGCTGAGACAGCGTTAAAGAAGCTCTACACAG ATGTCAACACACAACCAAGTGAATTGCAAAGATACCTTGAAGTTCTGGATTTCAGCCATACTGATGGTTGCTGCG AATCAGTGTCCCTGCAATCAGGAAAAGAAAAAGAAACGGTGGAAAATTTGGATGCAGGAAAGGACTCGAAGAAAG ACACCAGTGGCAAAGGTGATAAGCCGCAAAACTCGCAAACTGGGCAGGGTAGCAAGGAACAGATAAAAGCCGGCA CAGTCAGCAAGGATGTAAATGTTGGATCAAAAGGAAAAGAAGTCCCACGACTGCAAAAGATAACAAAGAAAATGA ACСTTCCAACAGTTGGTGGGAAAATCATTCTTAGCTTAGACCACTTGCTTGAGTACAAACCTAATCAAGTCGATC TGTTTAACACTCGAGCAACAAAAACACAGTTTGAATCATGGTACAGCGCAGTTAAAGTTGAATATGATCTTAATG ATGAGCAAATGGGTGTGATTATGAATGGTTTTATGGTTTGGTGCATCGATAACGGTACATCTCCAGATGTTAATG GAGTGTGGGTGATGATGGATGGGGAAGAGCAAGTTGAATACCCACTAAAGCCAATTGTCGAAAATGCAAAGCCAA CTTTGAGACAAATCATGCACCATTTCTCAGACGCAGCAGAAGCGTATATTGAAATGAGAAACTCTGAAAGTCCGT ATATGCCTAGATACGGATTACTAAGAAATTTAAGAGATAGGGAATTAGCACGCTATGCTTTTGACTTCTATGAAG TTACTTCCAAAACACCAAATAGGGCAAGAGAAGCAATAGCACAAATGAAGGCCGCAGCTCTCGCGGGAATGAACA GCAGGTTATTTGGACTTGATGGTAATATCTCGACCAATTCCGAAAATACTGAGAGGCACACTGCAAGGGACGTAA ATCAGAATATGCATACTTTGTTGGGTATGGGTCCACCGCAGTAAAGACTAGGTAAACTGGTCACAGTTAGCATTT CGGGTCGTTATAAGTTTTCTATAATATAATATGTAGCACTTTACTTAAGTATAGTGTGATTTCATCACCTTTGTA CTGTTTATGTTAGCGTGGTTTCACCACCTTAGTGTGCTTTATATTATAGTTTATGCGTAGCAGGGAGAACCATTA CAATGCCGGAGTTGTTTGTAGTGTGATTTCATCACGTTTAATAGCCGAGGTACGGTAATGTTTGTTGTCCTAAAA AAAAAAAAAAAAAAAAAAAAAAAAAAAAAAAAAAAAAAAAAAAAAACGCTGAAATCACCAGTCTCTCTCTACAAA TCTATCTCTCTCTATTTTCTCCATAAATAATGTGTGAGTAGTTTCCCGATAAGGGAAATTAGGGTTCTTATAGGG TTTCGCTCATGTGTTGAGCATATAAGAAACCCTTAGTATGTATTTGTATTTGTAAAATACTTCTATCAATAAAAT TTСТААТTССТАAАACCAAAATCCAGGGGCCCTCGACGTTCCTTGACAGGATATATTGGCGGGTAAACTAAGTCG CTGTATGTGTTTGTTTGAGATCCTCTAGGGCATGCAAGCTGATCTGGATCTCATGTGAGCAAAAGGCCAGCAAAA GGCCAGGAACCGTAAAAAGGCCGCGTTGCTGGCGTTTTTCCATAGGCTCCGCCCCCCTGACGAGCATCACAAAAA TCGACGCTCAAGTCAGAGGTGGCGAAACCCGACAGGACTATAAAGATACCAGGCGTTTCCCCCTGGAAGCTCCCT CGTGCGCTCTCCTGTTCCGACCCTGCCGCTTACCGGATACCTGTCCGCCTTTCTCCCTTCGGGAAGCGTGGCGCT TTCTCATAGCTCACGCTGTAGGTATCTCAGTTCGGTGTAGGTCGTTCGCTCCAAGCTGGGCTGTGTGCACGAACC CCCCGTTCAGCCCGACCGCTGCGCCTTATCCGGTAACTATCGTCTTGAGTCCAACCCGGTAAGACACGACTTATC GCCACTGGCAGCAGCCACTGGTAACAGGATTAGCAGAGCGAGGTATGTAGGCGGTGCTACAGAGTTCTTGAAGTG GTGGCCTAACTACGGCTACACTAGAAGAACAGTATTTGGTATCTGCGCTCTGCTGAAGCCAGTTACCTTCGGAAG AAGAGTTGGTAGCTCTTGATCCGGCAAACAAACCACCGCTGGTAGCGGTGGTTTTTTTGTTTGCAAGCAGCAGAT TACGCGCAGAAAAAAAGGATCTCAAGAAGATCCTTTGATCTTTTCTACGGGGTCTGACGCTCAGTGGAACGAAAA CTCACGTTAAGGGATTTTGGTCATGAGATTATCAAAAAGGATCTTCACCTAGATCCTTTTAAATTAAAAATGAAG TTTTAAATCAATCTAAAGTATATATGTGTAACATTGGTCTAGTGA TTAGAAAAACTCATCGAGCATCAAATGAAA CTGCAATTTATTCATATCAGGATTATCAATACCATATTTTTGAAAAAGCCGTTTCTGTAATGAAGGAGAAAACTC ACCGAGGCAGTTCCATAGGATGGCAAGATCCTGGTATCGGTCTGCGATTCCGACTCGTCCAACATCAATACAACC TATTAATTTCCССTCGTCAAAAATAAGGTTATCAAGTGAGAAATCACCATGAGTGACGACTGAATCCGGTGAGAA TGGCAAAAGTTTATGCATTTCTTTCCAGACTTGTTCAACAGGCCAGCCATTACGCTCGTCATCAAAATCACTCGC АTCAACCAAACCGTTATTCATTCGTGATTGCGCCTGAGCAAGACGAAATACGCGATCGCT GTTAAAAGGACAATT ACAAACAGGAATCGAATGCAACCGGCGCAGGAACACTGCCAGCGCATCAACAATATTTTCACCTGAATCAGGATA 
TTСTTCTAATACCTGGAATGCTGTTTTCCCTGGGATCGCAGTGGTGAGTAACCATGCATCATCAGGAGTACGGAT AAAATGCTTGATGGTCGGAAGAGGCATAAATTCCGTCAGCCAGTTTAGTCTGACCATCTCATCTGTAACAACATT GGCAACGCTACСTTTGCCATGTTTCAGAAACAACTCTGGCGCATCGGGCTTCCCATACAATCGGTAGATTGTCGC ACCTGATTGCCCGACATTATCGCGAGCCCATTTATACCCATATAAATCAGCATCCATGTTGGAATTTAATCGCGG ССTTGAGCAAGACGTTTCCCGTTGAATATGGCTCATAACACCCCTTGTATTACTGTTTATGTAAGCAGACAGTTT TATTGTTCATGATGATATATTTTTATCTTGGCAATGTAACATCAGAGATTTTGAGACACAACGTGGCTTTGTTG AATAAATCGAACTTTTGCTGAGTTGAAGGATCAGATCACGCATCTTCCCGACAACGCAGACCGTTCCGTGGCAAA GCAAAAGTTCAAAATCACCAACTGGTCCACCTACAACAAAGCTCTCATCAACCGTGGCTCCCTCACTTTCTGGCT GGATGATGGGGCGATTCAGGCGATCCCCATCCAACAGCCCGCCGTCGAGCGGGCTTTTTTATCCCCGGAAGCCTG TGGATAGAGGGTAGTTATCCACGTGAAACCGCTAATGCCCCGCAAAGCCTTGATTCACGGGGCTTTCCGGCCCGC TCCAAAAACTATCCACGTGAAATCGCTAATCAGGGTACGTGAAATCGCTAATCGGAGTACGTGAAATCGCTAATA AGGTCACGTGAAATCGCTAATCAAAAAGGCACGTGAGAACGCTAATAGCCCTTTCAGATCAACAGCTTGCAAACA CCCCTCGCTCCGGCAAGTAGTTACAGCAAGTAGTATGTTCAATTAGCTTTTCAATTATGAATATATATATCAATT ATTGGTCGCCCTTGGCTTGTGGACAATGCGCTACGCGCACCGGCTCCGCCCGTGGACAACCGCAAGCGGTTGCCC ACCGTCGAGCGCCTTTGCCCACAACCCGGCGGCCGGCCGCAACAGATCGTTTTATAAATTTTTTTTTTTGAAAAA GAAAAAGCCCGAAAGGCGGCAACCTCTCGGGCTTCTGGATTTCCGATCCCCGGAATTAGATCCGTTTAAACTACG TAAGATCGATCTTGGCAGGATATATTGTGGTTAAACGTTCCTGCGGCGGTCGAGATGGATCT

GTTCCT

WMV-Vera (GenBank accession number MH469650) in bold. Cistron limit on blue background. NIb/CP cleavage site underlined. Unique site Bpu1102I (=BIpI) on yellow background. Vector in blue. Unique NotI and ApaI sites on yellow background. CaMV 35S promoter in red with the +1 transcription site on yellow background. CaMV 35S terminator in fuchsia with the processing and polyadenylation site underlined. Minimal pUC replication origin on gray background with the replication start doubly underlined. Kanamycin selection marker (reverse complement) on dark gray background with a silent mutation to remove an Esp3I site. pSa replication origina on gray background. RB with overdrive (underlined) on yellow background and double LB on read background.

>PMWMV-Z (3829 bp)

GGTCTCGCTGTATGACACTCTGAGTGCTTCATTTGCTGAGCTTGGCCTGAATTACAATTTTGATGAGCGAACAAA GAAAAGAGAGGAACTGTGGTTCATGTCACACCAAGCCATGCTAGTTGATGGGATATACATCCCAAAGCTTGAACC TGAAAGGATAGTTTCCATCTTAGAATGGGATAGGAGCAAGGAAATTATGCACCGCACTGAGGCAATTTGTGCAGC CATGATTGAAGCGTGGGGATACACTGAGCTTTTACAAGAAATTCGCAAATTTTATTTGTGGCTTCTGAGCAAAGA TGAATTTAAGGAACTCGCAGCGTCTGGAAAAGCCCCATACATAGCTGAGACAGCGTTAAAGAAGCTCTACACAGA TGTCAACACACAACCAAGTGAATTGCAAAGATACCTTGAAGTTCTGGATTTCAGCCATACTGATGGTTGCTGCGA ATCAGTGTCCCTGCAATCTGGAAAGCTAGC CGCGTCCCATTCGCCATTCAGGCTGCGCAACTGTTGGGAAGGGCG ATCGGTGCGGGCCTCTTCGCTATTĀCGCCAGCTGGCGAAAGGGGGATGTGCTGCAAGGCGATTAAGTTGGGTAAC GCCAGGGTTTTCCCAGTCACGACGTTGTAAAACGACGGCCAGTGAGCGCGCGTAATACGACTCACTATAGGGCGA ATTGGGTACCCAGCTTTTGTTCCCTTTAGTGAGGGTTAATTGCGCGCTTGGCGTAATCATGGTCATAGCTGTTTC CTGTGTGAAATTGTTATCCGCTCACAATTCCACACAACATACGAGCCGGAAGCATAAAGTGTAAAGCCTGGGGTG CCTAATGAGTGAGCTAACTCACATTAATTGCGTTGCGCTCACTGCCCGCTTTCACTAGTGTTGCGAGTCAGTTTC

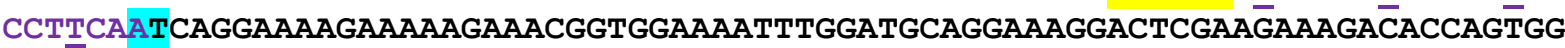
CAĀ̄GGTGATAAGCCGCAAAACTCGCAAACTGGGCAGGGTAGCAAGGAACAGATAAAAGCCGGCACAGTCAGCAA GGATGTAAATGTTGGATCAAAAGGAAAAGAAGTCCCACGACTGCAAAAGATAACAAAGAAAATGAACCTTCCAAC AGTTGGTGGGAAAATCATTCTTAGCTTAGACCACTTGCTTGAGTACAAACCTAATCAAGTCGATCTGTTTAACAC TCGAGCAACAAAAACACAGTTTGAATCATGGTACAGCGCAGTTAAAGTTGAATATGATCTTAATGATGAGCAAAT GGGTGTGATTATGAATGGTTTTATGGTTTGGTGCATCGATAACGGTACATCTCCAGATGTTAATGGAGTGTGGGT GATGATGGATGGGGAAGAGCAAGTTGAATACCCACTAAAGCCAATTGTCGAAAATGCAAAGCCAACTTTGAGACA AATCATGCACCATTTCTCAGACGCAGCAGAAGCGTATATTGAAATGAGAAACTCTGAAAGTCCGTATATGCCTAG ATACGGATTACTAAGAAATTTAAGAGATAGGGAATTAGCACGCTATGCTTTTGACTTCTATGAAGTTACTTCCAA AACACCAAATAGGGCAAGAGAAGCAATAGCACAAATGAAGGCCGCAGCTCTCGCGGGAATGAACAGCAGGTTATT TGGACTTGATGGTAATATCTCGACCAATTCCGAAAATACTGAGAGGCACACTGCAAGGGACGTAAATCAGAATAT GCATACTTTGTTGGGTATGGGTCCACCGCAGTAAAGACTAGGTAAACTGGTCACAGTTAGCATTTCGGGTCGTTA TAAGTTTTCTATAATATAATATGTAGCACTTTACTTAAGTATAGTGTGATTTCATCACCTTTGTACTGTTTATGT TAGCGTGGTTTCACCACCTTAGTGTGCTTTATATTATAGTTTATGCGTAGCAGGGAGAACCATTACAATGCCGGA GTTGTTTGTAGTGTGATTTCATCACGTTTAATAGCCGAGGTACGGTAATGTTTGTTGTCCTAAAAAAAAAAAAAA AAAAAAAAAAAAAAAAAAAAAAAAAAAAAAAAAAAACGCTGAAATCACCAGTCTCTCTCTACAАATCTATCTCTC TCTATTTTCTCCATAAATAATGTGTGAGTAGTTTCCCGATAAGGGAAATTAGGGTTCTTATAGGGTTTCGCTCAT 
GCTTAATCAGTGAGGCACCTATCTCAGCGATCTGTCTATTTCGTTCATCCATAGTTGCCTGACTCCCCGTCGTGT AGATAACTACGATACGGGAGGGCTTACCATCTGGCCCCAGTGCTGCAATGATACCGCGAGAGCCACGCTCACCGG CTCCAGATTTATCAGCAATAAACCAGCCAGCCGGAAGGGCCGAGCGCAGAAGTGGTCCTGCAACTTTATCCGCCT CCATCCAGTCTATTAATTGTTGCCGGGAAGCTAGAGTAAGTAGTTCGCCAGTTAATAGTTTGCGCAACGTTGTTG CCATTGCTACAGGCATCGTGGTGTCACGCTCGTCGTTTGGTATGGCTTCATTCAGCTCCGGTTCCCAACGATCAA GGCGAGTTACATGATCCCCCATGTTGTGCAAAAAAGCGGTTAGCTCCTTCGGTCCTCCGATCGTTGTCAGAAGTA AGTTGGCCGCAGTGTTATCACTCATGGTTATGGCAGCACTGCATAATTCTCTTACTGTCATGCCATCCGTAAGAT GCTTTTCTGTGACTGGTGAGTACTCAACCAAGTCATTCTGAGAATAGTGTATGCGGCGACCGAGTTGCTCTTGCC CGGCGTCAATACGGGATAATACCGCGCCACATAGCAGAACTTTAAAAGTGCTCATCATTGGAAAACGTTCTTCGG GGCGAAAACTCTCAAGGATCTTACCGCTGTTGAGATCCAGTTCGATGTAACCCACTCGTGCACCCAACTGATCTT CAGCATCTTTTACTTTCACCAGCGTTTCTGGGTGAGCAAAAACAGGAAGGCAAAATGCCGCAAAAAAGGGAATAA GGGCGACACGGAAATGTTGAATACTCATACTCTTCCTTTTTCAATATTATTGAAGCATTTATCAGGGTTATTGTC TCAT

pGWMV-Vera fragment flanked by two BsaI sites (cleavage sites underlined). Rearranged artificial WMV NIaPro cleavage site (in purple; silent mutations underlined) inserted between NIb and CP cistrons, with a NheI-LacZ-SpeI polylinker. LacZ (blue and italics) in reverse orientation. Unique sites BlpI=Bpu1102I and ApaI on yellow background. pUC replication origin in gray and ampicillin resistance marker (reverse orientation) on gray background (promotor on dark gray).

>PGWMV-sPDS (insert between positions 9238 and 9239 of pGWMV-Vera) TCTGGAAAGATGTCACTATGTGGGTCTGTCTCTGCTCTGAACTTGAGGTGGGGAAAAGGTATTCCAAAAGTAACC TCGAGATGCTGTTCTCCATTAAGTTGTGAGAAAAGCAATGGTTTAGCGTTTTGGGGTAGTGAGATTGTGGGCGAT GGGTTGAAAGTATCTGGCAGACATGTTAGTAGGAAACTGTATAAGGGAGCTTTACCACTGTGTTGCGAGTCAGTT TCCCTTCAA

>pGWMV-aPDS (insert between positions 9238 and 9239 of pGWMV-Vera) TCTGGAAAGAGTGGTAAAGCTCCСTTATACAGTTTCCTACTAACATGTCTGCCAGATACTTTCAACCCATCGCCC

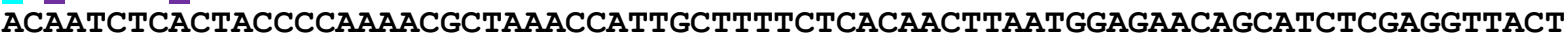
TTTGGAATACCTTTTCCCCACCTCAAGTTCAGAGCAGAGACAGACCCACATAGTGACATTTGTTGCGAGTCAGTT TCCСTTCAA

>pGWMV-hPDS (insert between positions 9238 and 9239 of pGWMV-Vera; $T$. thermophila rRNA exons in blue and intron in bold blue)

TCTGGAAAGATGTCACTATGTGGGTCTGTCTCTGCTCTGAACTTGAGGTGGGGAAAAGGTATTCCAAAAGTAACC TCGAGATGC̄TGTCTCCATTAAGTTGTGAGAAAAGCTATGACTCTCTAAATAGCAATATTTACCTTTGGAGGGAA AAGTTATCAGGCATGCACCTGGTAGCTAGTCTTTAAACCAATAGATTGCATCGGTTTAAAAGGCAAGACCGTCAA ATTGCGGGAAAGGGGTCAACAGCCGTTCAGTACCAAGTCTCAGGGGAAACTTTGAGATGGCCTTGCAAAGGGTAT GGTAATAAGCTGACGGACATGGTCCTAACCACGCAGCCAAGTCCTAAGTCAACAGATCTTCTGTTGATATGGATG CAGTTCACAGACTAAATGTCGGTCGGGGAAGATGTATTCTTCTCATAAGATATAGTCGGACCTCTCCTTAATGGG AGCTAGCGGATGAAGTGATGCAACACTGGAGCCGCTGGGAACTAATTTGTATGCGAAAGTATATTGATTAGTTTT GGAGTACTCGTAAGGTAGCCСTTTTCTCACAACTTAATGGAGAACAGCATCTCGAGGTTACTTTTGGAATACCTT TTCCCCACCTCAAGTTCAGAGCAGAGACAGACCCACATAGTGACATTTGTTGCGAGTCAGTTTCCCTTCAA

>pGWMV-sCHLI (insert between positions 9238 and 9239 of pGWMV-Vera) TCTGGAAAGGCTGTGAATATCTCAAAAGAGAGTCAGAGGCCAGTTTATCCTTTTGCTGCTATAGTAGGGCAGGAT GAGATGAĀ̄CTATGTCTTCTACTGAACGTTATTGACCCAAAAATCGGAGGTGTCATGATCATGGGTGATAGAGGA ACAGGAAAATCAACCACAGTTAGGTCTTTGGTTGATTTGCTTCCTGAAATCAGGGTTGTGTGTTGCGAGTCAGTT TCCCTTCAA 
>pGWMV-VIGS (insert between positions 9238 and 9239 of pGWMV-Vera; unique MluI site on yellow background; note that this artificial NIaPro cleavage site contains two different silent mutations, in italics)

TTCTGG TAAACGCGTGTTGCGAGTCAGTTTCCCTTCAA

Fig. S2. In frame protein translation of the hairpin construct residue after intron self-cleavage.

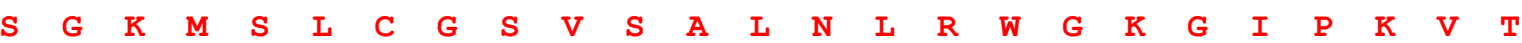
TCTGGAAAGATGTCACTATGTGGGTCTGTCTCTGCTCTGAACTTGAGGTGGGGAAAAGGTATTCCAAAAGTAACC

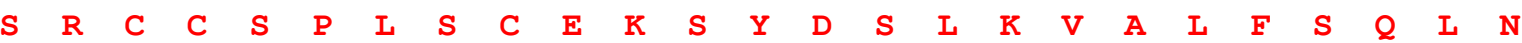
TCGAGATGCTGTTCTCCATTAAGTTGTGAGAAAAGCTATGACTCTCTTAAGGTAGCCCTTTTCTCACAACTTAAT

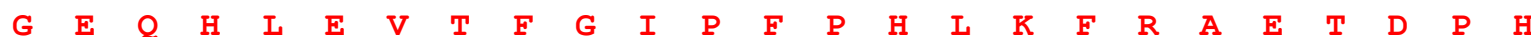
GGAGAACAGCATCTCGAGGTTACTTTTGGAATACCTTTTCCCCACCTCAAGTTCAGAGCAGAGACAGACCCACAT

$\begin{array}{lllllllllllllll}S & D & I & C & C & E & S & V & S & L & Q\end{array}$

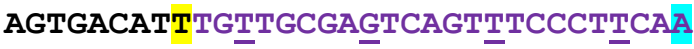

Table S1. Oligodeoxynucleotide primers used to create the different constructs.

\begin{tabular}{|c|c|c|}
\hline Primer & Sequence (5'-3') & Purpose \\
\hline $\mathrm{P} 1$ & tatcagggttattgtctcatGGTCTCGCTGTATGACACTCTGAGT & \multirow{2}{*}{$\begin{array}{l}\text { Amplification of } B s a \mathrm{I} \text {-flanked pGWMV-Vera } \\
\text { fragment }\end{array}$} \\
\hline $\mathrm{P} 2$ & $\begin{array}{l}\text { tggaaaaacgccagcaacgcGGTCTCCATATATCCTGTCAAGGAA } \\
\text { CGTCGAGGGCCCCTGGATTTTGGT }\end{array}$ & \\
\hline P3 & GCTAGCTTTCCAGATTGCAGGGACAC & \multirow{2}{*}{$\begin{array}{l}\text { Linearization WMV-Vera fragment at the } \\
\text { NIb/CP intercistronic site }\end{array}$} \\
\hline $\mathrm{P} 4$ & ACTAGTGTTGCGAGTCAGTTTCCCTT & \\
\hline P5 & tgtccctgcaatctggaaagATGTCACTATGTGGGTCTG & \multirow{2}{*}{ Amplification sense PDS fragment } \\
\hline P6 & agggaaactgactcgcaacaCAGTGGTAAAGCTCCCTTATAC & \\
\hline $\mathrm{P} 7$ & tgtccctgcaatctggaaagAGTGGTAAAGCTCCCTTATAC & \multirow{2}{*}{ Amplification antisense $P D S$ fragment } \\
\hline P8 & agggaaactgactcgcaacaAATGTCACTATGTGGGTCTG & \\
\hline P9 & tgtccctgcaatctggaaagATGTCACTATGTGGGTCTG & \multirow{2}{*}{$\begin{array}{l}\text { Amplification sense strand for hairpin } P D S \\
\text { construct }\end{array}$} \\
\hline $\mathrm{P} 10$ & gagagtcataGCTTTTCTCACAACTTAATGG & \\
\hline P11 & tgagaaaagcTATGACTCTCTAAATAGCAATATTTAC & \multirow{2}{*}{$\begin{array}{l}\text { Amplification } T \text {. thermophila rRNA group-I } \\
\text { intron plus exons }\end{array}$} \\
\hline P12 & gtgagaaaagGGCTACCTTACGAGTACTCC & \\
\hline $\mathrm{P} 13$ & taaggtagссСтTTTCTCACAACTTAATGGAG & \multirow{2}{*}{$\begin{array}{l}\text { Amplification antisense strand for hairpin } P D S \\
\text { construct }\end{array}$} \\
\hline P14 & agggaaactgactcgcaacaAATGTCACTATGTGGGTCTG & \\
\hline $\mathrm{P} 15$ & tgtccctgcaatctggaaagGCTGTGAATATCTCAAAAGA & \multirow{2}{*}{ Amplification sense $C H L I$ fragment } \\
\hline P16 & agggaaactgactcgcaacaCACAACCCTGATTTCAGGAAGC & \\
\hline P17 & cacgcgtttaCCAGATTGCAGGGACACTG & \multirow{2}{*}{ Construction pGWMV-VIGS } \\
\hline P18 & tgcaatctggtaaacgcgTGTTGCGAGTCAGTTTCC & \\
\hline P19 & AGGACAACAAACATTACCGTACCTC & RT for WMV diagnosis \\
\hline $\mathrm{P} 20$ & TCAGGAAAAGAAAAAGAAACGGTG & \multirow{2}{*}{ Amplification WMV CP cistron } \\
\hline $\mathrm{P} 21$ & CTGCGGTGGACCCATACCCAAC & \\
\hline $\mathrm{P} 22$ & СTGCGGTGGACCCATACCCAAC & RT for NIb/CP intercistronic analysis \\
\hline $\mathrm{P} 23$ & GCTGAGACAGCGTTAAAGAAGC & \multirow{2}{*}{ Amplification WMV NIb/CP intercistronic site } \\
\hline P24 & СTTTTATCTGTTCCTTGCTACCCTG & \\
\hline $\mathrm{P} 25$ & GTGGAAAGGTAGCAGCTTGG & \multirow{2}{*}{$P D S$ mRNA qPCR analysis } \\
\hline P26 & GGTGCAGGAAGTTTTTCAGG & \\
\hline $\mathrm{P} 27$ & GGAAAGTCTGGGGAAAGGAG & \multirow{2}{*}{ CHLI mRNA qPCR analysis } \\
\hline $\mathrm{P} 28$ & GCCGAATCCAGTAGGACATC & \\
\hline $\mathrm{P} 29$ & \begin{tabular}{|l} 
CGATGTGGAAATTGACGGAA \\
\end{tabular} & \multirow{2}{*}{ CYP7 mRNA qPCR analysis } \\
\hline P30 & CGGTGCATAATGCTCGGAA & \\
\hline
\end{tabular}



CHAPTER II 


\title{
CHAPTER II
}

\section{Carotenoid and tocopherol fortification of zucchini fruits using a viral RNA vector}

\author{
Fakhreddine Houhou ${ }^{1}$, Teresa Cordero ${ }^{1}$, Verónica Aragonés ${ }^{1}$, Maricarmen Martí1 ${ }^{1}$, Jaime \\ Cebolla-Cornejo $^{2}$, Ana Pérez de Castro $^{2}$, Manuel Rodríguez-Concepción ${ }^{1}$, Belén Picó $^{2}$ and \\ José-Antonio Daròs ${ }^{1}$
}

${ }^{1}$ Instituto de Biología Molecular y Celular de Plantas (Consejo Superior de Investigaciones Científicas-Universitat Politècnica de València), 46022 Valencia, Spain

${ }^{2}$ Instituto de Conservación y Mejora de la Agrodiversidad Valenciana, Universitat Politècnica de València, 46022 Valencia, Spain 


\section{Summary}

Carotenoids and tocopherols are health-promoting metabolites in livestock and human diets. Some important crops have been genetically modified to increase their content. Although the usefulness of transgenic plants to alleviate nutritional deficiencies is obvious, their social acceptance has been controversial. Here, we demonstrate an alternative biotechnological strategy for carotenoid and tocopherol fortification of edible fruits in which no transgenic DNA is involved. A viral RNA vector derived from Zucchini yellow mosaic virus (ZYMV) was modified to express a bacterial phytoene synthase (crtB)

and inoculated in zucchini (Cucurbita pepo L.) leaves nurturing pollinated flowers. After the viral vector moved to the developing fruit and expressed $\operatorname{crt} B$, the rind and flesh of the fruits developed yellow-orange rather than green color. Metabolite analyses showed a substantial enrichment in health-promoting carotenoids, such as $\alpha$ - and $\beta$-carotene (pro-vitamin A), lutein and phytoene, in both rind and flesh. Considerably higher accumulation of $\alpha$ - and $\gamma$-tocopherol was also detected, particularly in fruit rind. Although this strategy is perhaps not free from controversy due to the use of genetically modified viral RNA, our work does demonstrate the possibility of metabolically fortifying edible fruits using an approach in which no transgenes are involved.

\section{Introduction}

Plants produce a vast number of secondary metabolites, many of them of great interest in food, pharmaceutical and industrial applications. However, valuable plant metabolites are not infrequently produced in limited amounts or without the desired chemical properties. The ability to manipulate endogenous metabolic pathways or to deploy novel pathways in plants via biotechnological metabolic engineering approaches should contribute to overcoming these issues and successfully establishing these autotrophic organisms as "green factories" able to sustainably provide most of the molecules required by humankind. In contrast to other systems, production in plants is cheap, easily scalable, mainly fueled by sunlight, and, if properly managed, free of human pathogens.

In fact, plants are currently being used as platforms to produce recombinant proteins and peptides in both stable genetic transformation or transient expression approaches (Fischer and 
Buyel, 2020; Margolin et al., 2020). Stable genetic transformation of plants is a labor-intensive and time-consuming process that frequently leads to results with undesired variability. By contrast, transient expression systems, such as those that employ Agrobacterium tumefaciens, viral vectors, or a combination of both, offer a rapid alternative for reaching some biotechnological goals. We have recently showed that plant virus-derived vectors can be used not only to produce recombinant proteins, but also to engineer plant metabolism in cases in which the expressed proteins are regulatory factors or biosynthetic enzymes that interact with the natural host plant metabolism. Virus-based expression of transcription factors Delila and, particularly, Rosea1 from Antirrhinum majus has been shown to lead to massive accumulation of anthocyanins in plant tissues (Bedoya et al., 2010; Cordero et al., 2017). Similarly, virusbased expression of Pantoea ananatis phytoene synthase (crtB), the enzyme catalyzing the first step of carotenoid biosynthesis in this soil bacterium, has been demonstrated to lead to a substantial accumulation of phytoene and other carotenoids in plant tissues (Llorente et al., 2020; Majer et al., 2017). Virus-based co-expression of crtB and a Crocus sativus carotenoid cleavage dioxygenase (CCD2L) induced large accumulation in $N$. benthamiana leaves of the apocarotenoid crocins and picrocrocin, which naturally accumulate in saffron stigma and are main constituents of the valued spice (Martí et al., 2020). However, these achievements were mainly produced in model plants, such as Nicotiana tabacum, N. benthamiana or Arabidopsis thaliana. Our goal here was to translate this ability to produce health-promoting metabolites such as carotenoids to edible tissues, particularly edible fruits. Generally, animals do not biosynthesize carotenoids, which are essential nutrients that must be acquired from diet (Zheng et al., 2020). Consequently, highly relevant projects aimed to the carotenoid fortification of important crops have been undertaken in last two decades (Diretto et al., 2007; Wang et al., 2014; Ye et al., 2000; Zhu et al., 2008). To this end, we investigated a strategy to induce accumulation of carotenoids in edible zucchini (Cucurbita pepo L.) fruits using an RNA-based viral vector derived from Zucchini yellow mosaic virus (ZYMV; genus Potyvirus, family Potyviridae) that expresses the bacterial biosynthetic enzyme crtB.

\section{Materials and Methods}

\section{Virus inoculum}

One-month old zucchini plants (MU-CU-16, COMAV accession BGV004370) were infiltrated (Bedoya and Daròs, 2010) with A. tumefaciens C58C1 co-transformed with the helper plasmid 
pCLEAN-S48 (Thole et al., 2007) and pGZYMV-crtB (Majer et al., 2017), which contains an infectious ZYMV cDNA (GenBank accession number KX499498) in which the cDNA of $P$. ananatis crtB) (Cunningham Jr. et al., 1993) was inserted between the NIb and CP cistrons, flanked by sequences that complement the viral NIaPro cleavage sites (Majer et al., 2017) . In pGZYMV-crtB, the cDNA of the recombinant virus is under control of Cauliflower mosaic virus (CaMV) 35S promoter and terminator. Plants were kept in a greenhouse at $25^{\circ} \mathrm{C}$ with a 16/8 h day/night cycle. Ten dpi, symptomatic tissue was harvested, cut into pieces approximately $50 \mathrm{mg}$, and stored at $-80^{\circ} \mathrm{C}$. For mechanical inoculation of zucchini plants, one of tissue piece $(50 \mathrm{mg}$ ) was ground using a 4-mm steel ball in a 2-ml Eppendorf tube in a bead beater (VWR) for $1 \mathrm{~min}$ at 30 revolutions $\cdot \mathrm{s}^{-1}$. Powder was brought to the bottom of the tube by a brief centrifugation, after which $1 \mathrm{ml}$ of inoculation buffer $(50 \mathrm{mM}$ potassium phosphate, $\mathrm{pH}$ $8.0,1 \%$ polyvinylpyrrolidone-10, $1 \%$ polyethylene glycol-6000, $10 \mathrm{mM}$ 2-mercaptoethanol) was added and the mixture thoroughly vortexed.

\section{Plant inoculation}

A10 $\mu 1$ drop of $10 \%$ carborundum in inoculation buffer was deposited on the abaxial side of a fully expanded leaf of a zucchini plant. A cotton swab soaked in virus inoculum was smoothly rubbed on the leaf surface. Plants were kept in a greenhouse at $25^{\circ} \mathrm{C}$ with a $16 / 8 \mathrm{~h}$ day/night cycle.

\section{Virus diagnosis}

RNA was purified using silica gel columns (Zymo Research) from pieces of zucchini fruits. Aliquots of the RNA preparations were subjected to RT with primer PI (5'AGGCTTGCAAACGGAGTCTAA-3') and RevertAid reverse transcriptase (Thermo Scientific). RT products were amplified by PCR with Thermus thermophilus DNA polymerase (Biotools) using primers PII (5'-TCAGGCACTCAGCCAACTGTGG-3') and PIII (5'CTGCATTGTATTCACACCTAGT-3'). PCR products were separated by electrophoresis in a $1 \%$ agarose gel in TAE buffer (40 mM Tris, $20 \mathrm{mM}$ sodium acetate, $1 \mathrm{mM}$ EDTA, pH 7.2), and the gel was stained in a solution of $0.5 \mu \mathrm{g} / \mathrm{ml}$ ethidium bromide. 


\section{Carotenoid and tocopherol analyses}

Fruit pieces $(0.3 \mathrm{~g})$ were homogenized and subjected to extraction with $10 \mathrm{ml}$ hexane:acetone:methanol (50:25:25) for $30 \mathrm{~min}$ at $4^{\circ} \mathrm{C}$ with continuous gentle shaking. Then, $1 \mathrm{ml}$ of water was added and samples were centrifuged for $5 \mathrm{~min}$. The organic layer was recovered and dried in a speedvac. The solid residue was then resuspended in ethyl acetate:acetone:methanol (20:60:20), filtered, and frozen $\left(-80^{\circ} \mathrm{C}\right)$ until analysis. Carotenoids were quantified in an Agilent 1200 series HPLC system (Agilent Technologies, Waldbronn) using a Kinetex-XB C18 fused core column (150 mm length x $4.6 \mathrm{~mm}$ internal diameter, and $2.6 \mu \mathrm{m}$ particle size) from Phenomenex (Torrance) following a published procedure (GarcíaPlazaola and Becerril, 1999), with minor modifications. Briefly, $10 \mu$ aliquots of the samples were injected and separated using a mobile phase with two components, solvent A (acetonitrile:methanol:water, 84:9:7 v:v:v) and solvent B (methanol:ethyl acetate, 68:32 v:v). The sample was eluted using a linear gradient from $100 \%$ solvent A to $100 \%$ solvent B for 12 min; an isocratic elution of $100 \% \mathrm{~B}$ was then maintained for $7 \mathrm{~min}$. Afterwards, a linear gradient to $100 \%$ solvent A was applied for $1 \mathrm{~min}$, followed by an isocratic elution for 4 min to allow the column to re-equilibrate. Each sample was analyzed in duplicate. $\alpha$-carotene, $\beta$-carotene, and lutein absorbance were measured at $445 \mathrm{~nm}$, and phytoene absorbance at $295 \mathrm{~nm}$. Tocopherols were determined in the same extract obtained for carotenoid analysis and using the same separation methodology, but in this case, detection was performed using a fluorimetric detector that worked at an excitation $\lambda=290 \mathrm{~nm}$ and emission $\lambda=330 \mathrm{~nm}$ (Kulczynski and Gramza-Michałowska, 2019).

\section{Results and Discussion}

Inoculation of zucchini plants with ZYMV-crtB at the right developmental stage induces yelloworange fruits

We previously observed that inoculation of zucchini plants with a ZYMV-based vector that expressed P. ananatis crtB (ZYMV-crtB) caused infected leaves to turn bright yellow (Majer et al., 2017). We have, more recently, understood that this phenotype is a consequence of the heterologous crtB enzyme inducing phytoene accumulation beyond a threshold that triggers 
transformation of leaf chloroplasts into chromoplasts, which is accompanied by the accumulation of high levels of downstream carotenoids (Llorente et al., 2020). To test whether we could trigger the chloroplast-to-chromoplast transformation in fruits, with concomitant carotenoid overaccumulation, we grew seedlings of a zucchini cultivar (MU-CU-16) (Esteras et al., 2012; Montero-Pau et al., 2018), which produces marketable dark green uniformly cylindrical fruits, and mechanically inoculated the plants $(n=3)$ with ZYMV-crtB at one-week intervals (Figure 1A). These intervals corresponded to five different developmental stages (Figure 1B): plants with $\left(1^{\text {st }}\right)$ male buds, $\left(2^{\text {nd }}\right)$ female buds, $\left(3^{\text {rd }}\right)$ male flowers at anthesis, $\left(4^{\text {th }}\right)$ female flowers at anthesis, and $\left(5^{\text {th }}\right)$ female flowers one week after the anthesis, with fruits of approximately $20 \mathrm{~cm}$.

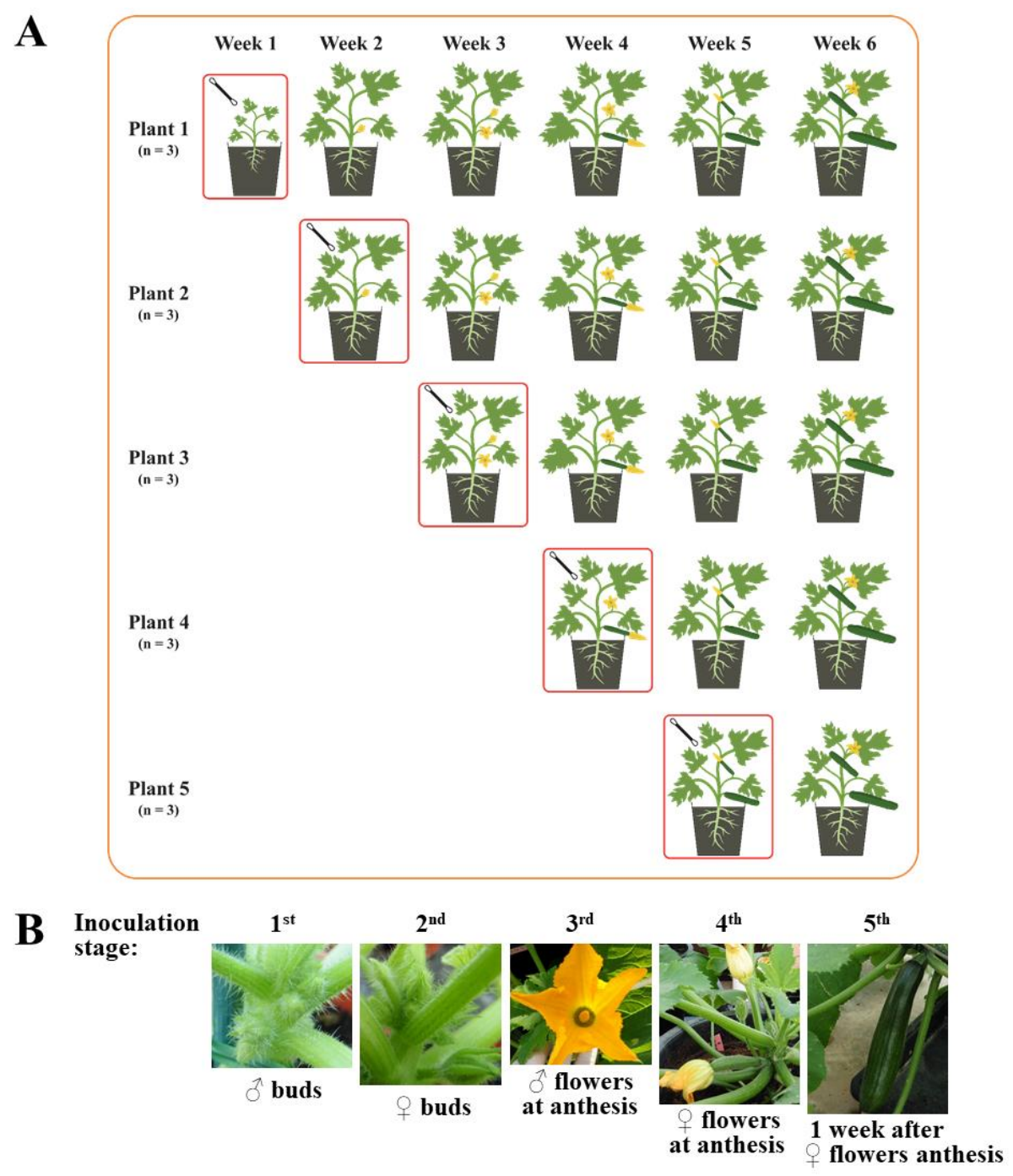

Figure 1. Zucchini plant inoculation process with viral vector ZYMV-crtB. (A) Plants, in groups of three, were mechanically inoculated (red rounded rectangle) at one-week intervals, such that each group became infected at a different developmental stage. (B) Pictures of flower and fruit developmental stages at which plants were inoculated. 
All inoculated plants showed the first symptoms of infection at approximately 7 days postinoculation (dpi) and symptomatic tissue turned yellow during the following days (Figure 2A), as previously reported (Majer et al., 2017). Interestingly, the development of flowers and fruits of infected plants was very different depending of plant developmental stage at inoculation time. Plants inoculated at the male bud stage $\left(1^{\text {st }}\right)$ did not develop female flowers. In contrast, those inoculated at the female bud stage $\left(2^{\text {nd }}\right)$ resulted in completely yellow female buds (Figure 2B), although flowers stopped growing before reaching anthesis. Zucchini plants inoculated at the male flower anthesis ( $3^{\text {rd }}$ stage) completed flower development and female flowers reached anthesis (Figure 2C). However, fruits did not continue growing after pollination (Figure 2D). Despite immature, these plants produced different types of fruits. Those below the inoculated leaves showed less yellow pigmentation than those above the inoculated leaf (Figure 2E). Interestingly, plants inoculated having female flowers at anthesis $\left(4^{\text {th }}\right.$ stage $)$ developed fruits after pollination, which displayed different degrees of green to yellow-orange color in their rinds (Figure 2F), having a uniformly orange flesh (Figure 2G). Plants inoculated one week after female flower anthesis $\left(5^{\text {th }}\right.$ stage) developed fruits of commercial size. These fruits remain with dark green rinds or developed orange speckles (Figure $2 \mathrm{H}$ ), but remarkably they exhibited a uniformly orange flesh (Figure 2I). Taken together, these results suggest that a viral RNA vector can be used to specifically express a phytoene synthase, such as the bacterial crtB, in the fruits of adult zucchini plants to transform their color from green to yellow-orange. Importantly, although pigment accumulation is achieved at different developmental stages, plants with female flowers at or after the anthesis must be inoculated to produce fruit of commercial size with orange flesh. 

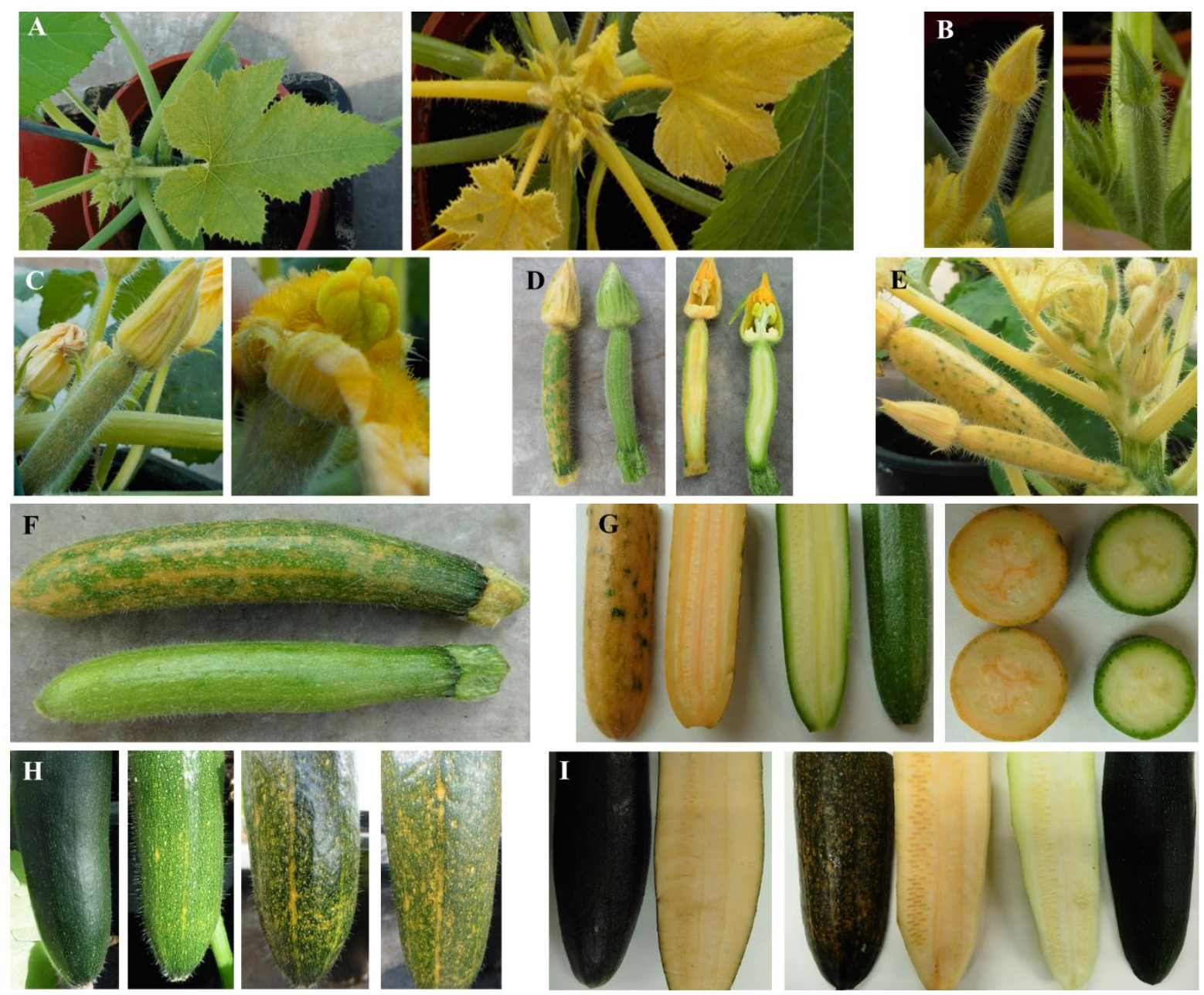

Figure 2. Photographs of zucchini plants inoculated with ZYMV-crtB. (A) Plants inoculated at $1^{\text {st }}$ stage (male buds) that exhibit the first symptoms of infection and a bright yellow pigmentation at 7 and 14 dpi, respectively. (B) Yellow and green female buds from plants inoculated at $2^{\text {nd }}$ stage (female buds) and a non-inoculated control, respectively. (C) Female flowers with yellow speckles at preanthesis (left) and anthesis (right) from plants inoculated at $3^{\text {rd }}$ stage (male flowers at anthesis). (D) Preanthesis female flower from a plant inoculated at $3^{\text {rd }}$ stage (left), compared to a non-inoculated control (right). Longitudinal sections of the same flowers are also shown. (E) Female flowers from a plant inoculated at $3^{\text {rd }}$ stage, developed over the inoculated leaf, exhibiting intense yellow pigmentation. (F) Fruit (upper) from a plant inoculated at $4^{\text {th }}$ stage (female flowers at anthesis), compared to a non-inoculated control (lower) at 14 dpi. (G) Details of the uniformly orange flesh of a fruit from an inoculated plant (left) compared to a control (right), at 14 dpi. (H) Fruits of commercial size from plants inoculated at $5^{\text {th }}$ stage (one week after anthesis of female flowers). From left to right, non-inoculated control and fruits exhibiting different degrees of yellow-orange speckles at 5, 10 and 15 dpi. (I) Longitudinal sections of fruits from inoculated plants (left) that exhibited orange flesh compared to a control (right). 
If pigmentation of zucchini fruits from inoculated plants results from viral vector-based expression of the bacterial crtB, these fruits, in contrast to green zucchinis from non-inoculated controls, must contain the recombinant virus ZYMV-crtB. To confirm this prediction, we purified RNA from fruit samples of three predominantly yellow and three speckled zucchinis, each of them harvested from a different inoculated plant. As a control, we also purified RNA from three green zucchinis from three independent non-inoculated plants. Reverse transcription (RT)-polymerase chain reaction (PCR) amplification of a cDNA corresponding to ZYMV coat protein cistron using specific primers demonstrated the presence of the virus in both the speckled and yellow zucchinis, but not in the green non-inoculated controls (Figure 3).

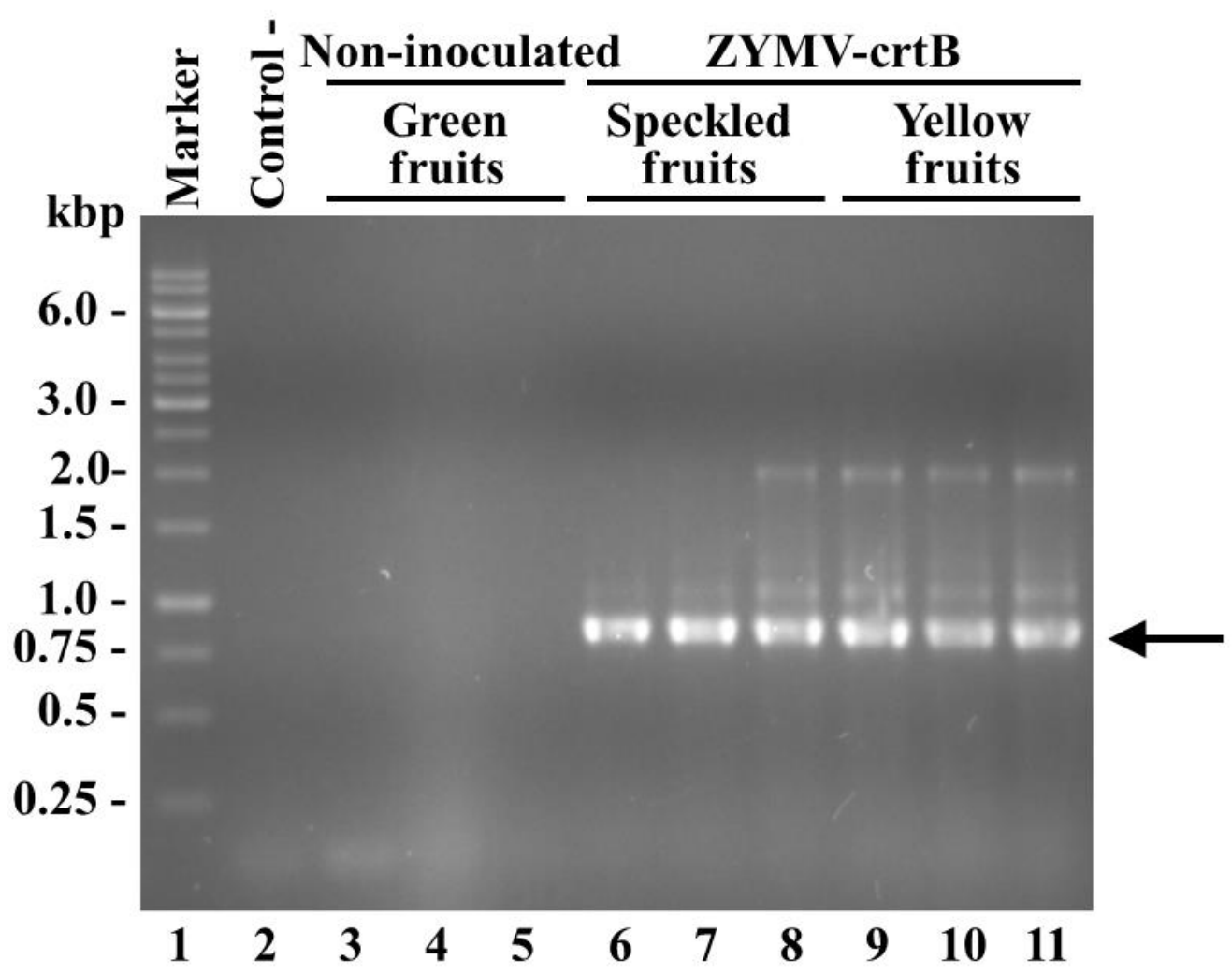

Figure 3. Diagnosis of ZYMV-crtB in zucchini fruits. RNA was purified and the ZYMV CP cistron amplified by RT-PCR. Products were separated by electrophoresis in a $1 \%$ agarose gel that was stained with ethidium bromide. Lane 1, DNA marker with some sizes (in kbp) on the left; lane 2, RT-PCR control with no RNA added; lanes 3 to 5, amplification products from green fruits harvested from noninoculated plants; lanes 6 to 8 and 9 to 11 , amplification products from speckled (lanes 6 to 8 ) and fully yellow fruits (lanes 9 to 11) harvested from ZYMV-crtB-inoculated plants. Band corresponding to ZYMV CP cistron is indicated by an arrow on the right. 
Another prediction was that the pigmented fruits produced by inoculation with ZYMV-crtB exhibited an increase in carotenoid accumulation. To confirm this, we extracted carotenoids from green and pigmented fruits harvested, respectively, from non-inoculated and ZYMV-crtBinoculated plants and quantified them after separation by high performance liquid chromatography (HPLC). Analysis was performed at the fruit commercial ripening stage, but also at two earlier developmental stages: fruit at post-anthesis (medium size) and fruit at preanthesis (small size), sampled respectively from plants inoculated at $5^{\text {th }}, 4^{\text {th }}$ and $3^{\text {rd }}$ stages. Four representative carotenoids were quantified, namely phytoene, $\alpha$ - and $\beta$-carotene, and lutein. Remarkably, compared to the green controls from non-inoculated plants, pigmented fruits from ZYMV-crtB-inoculated plants, at all three developmental stages, exhibited a dramatically increased accumulation of the four analyzed carotenoids in whole fruits, as well as in rind and flesh tissues (Figure 4 and Table 1). Carotenoids provide some of the most important nutritional benefits of consuming squash. More specifically, $\beta$-carotene and lutein are the most abundant carotenoids in the fruits of $C$. pepo, although these carotenoids are only abundant in those fruits with yellow-orange flesh that are consumed when fully mature (Azevedo-Meleiro and Rodriguez-Amaya, 2007; Martínez-Valdivieso et al., 2014). Zucchini fruits are consumed immature and naturally contain low amounts of these two carotenoids.

Fruits from ZYMV-crtB-inoculated plants exhibited up to 12-fold increase in $\beta$-carotene content relative to control fruits. At the commercial ripening stage, pigmented whole fruits contained 6-fold higher levels of the provitamin A carotenoid compared to controls. Although $\beta$-carotene amounts were higher in rinds (peel), increases were more important in flesh (pulp), as that of control fruits accumulate insignificant amounts of this pigment. Besides being the main precursor of vitamin A, $\beta$-carotene displays antioxidant activity that inhibits DNA damage and enhances immune system (Rodriguez-Concepcion et al., 2018). Conversely, lutein amounts were nearly doubled in whole fruits from inoculated plants at commercial ripening stage, mostly caused by a similar increase in the edible fruit rind (Figure 4 and Table 1). Lutein is a nonprovitamin A carotenoid involved in the macular pigment of the human retina and intake decreases the risk of macular degeneration and other ocular diseases (Eisenhauer et al., 2017). In addition to these two main carotenoids, accumulation of phytoene and $\alpha$-carotene in fruits of inoculated plants was particularly relevant, since content of these two carotenoids in control fruits was negligible (Figure 4 and Table 1). Phytoene is a health-promoting carotenoid 
normally absent from green fruits and vegetables, and $\alpha$-carotene has provitamin A activity (although only half that of $\beta$-carotene) (Rodriguez-Concepcion et al., 2018). Taken together, these results indicate that zucchini fruits from ZYMV-crtB-inoculated plants not only develop an attractive yellow-orange color, but are highly enriched in healthy carotenoids.

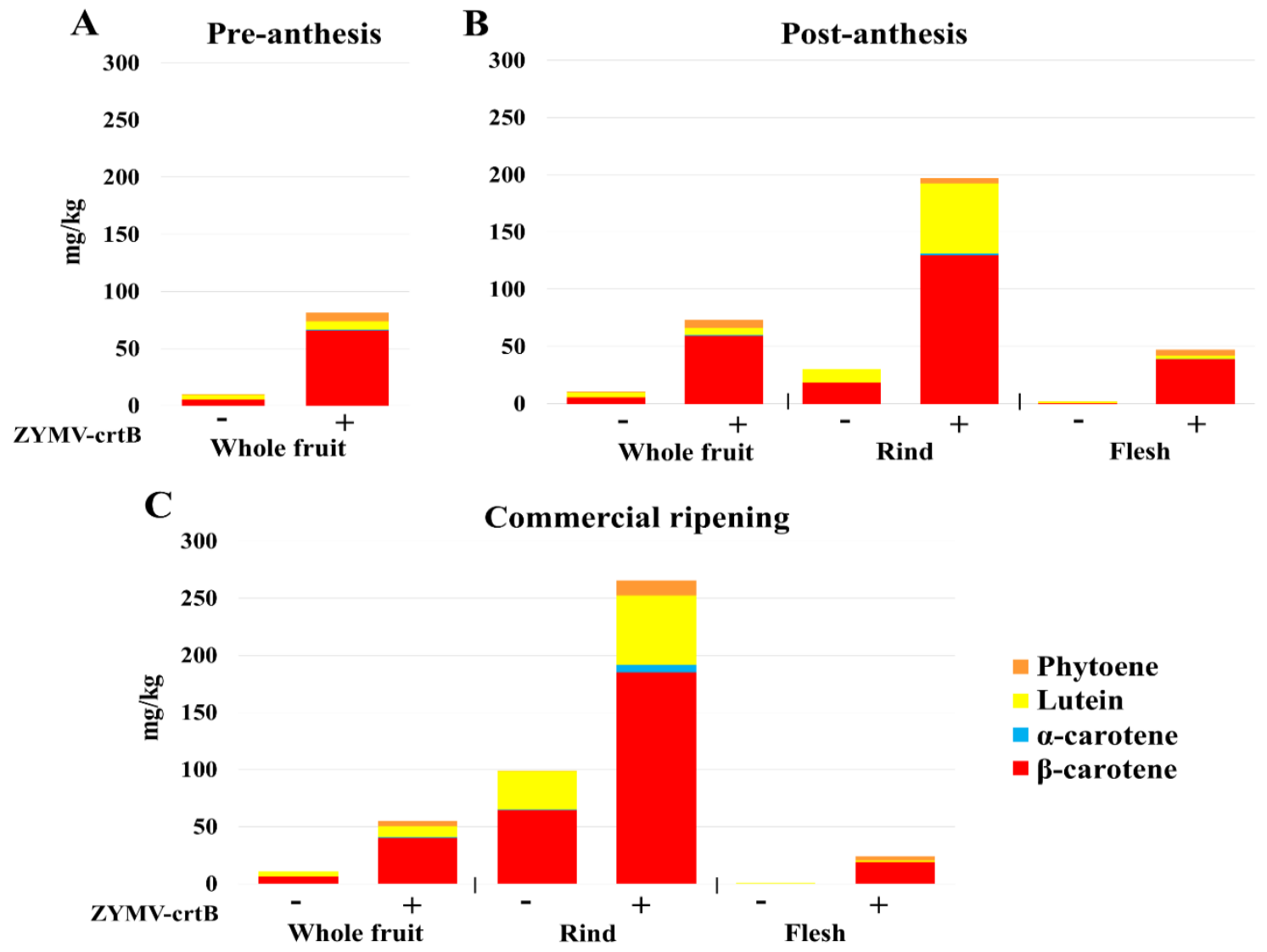

Figure 4. Accumulation of some representative carotenoids in whole fruit, rind, and flesh (as indicated) of green and yellow-orange zucchini fruits harvested from non-inoculated (-) and ZYMV-crtBinoculated (+) plants, respectively, at three developmental stages: (A) pre-anthesis, (B) post-anthesis, and $(C)$ commercial ripening. Bars represent average accumulation in three fruits harvested from three different plants. Numerical quantifications with standard deviations are in Table 1. 
Table 1. Carotenoid content $\left(\mathrm{mg} \cdot \mathrm{kg}^{-1}\right.$ fresh weight; mean \pm standard deviation, $\mathrm{n}=3$ ) of zucchini fruits at different stages of development in non-inoculated controls and ZYMV-crtB-inoculated plants. For the commercial ripening and post-anthesis fruit sizes, peel and pulp were also separately analyzed.

\begin{tabular}{|c|c|c|c|c|c|c|}
\hline Fruit size & \multicolumn{2}{|c|}{ Pre-anthesis (small size) } & & & & \\
\hline Tissue & \multicolumn{2}{|c|}{ Whole fruit } & & & & \\
\hline Treatment & Control & Inoculated & & & & \\
\hline$\beta$-carotene & $5.41 \pm 0.71$ & $65.75 \pm 2.52$ & & & & \\
\hline$\alpha$-carotene & $0.00 \pm 0.00$ & $0.99 \pm 0.08$ & & & & \\
\hline Lutein & $4.27 \pm 0.59$ & $7.03 \pm 0.32$ & & & & \\
\hline Phytoene & $0.02 \pm 0.03$ & $7.73 \pm 0.34$ & & & & \\
\hline Fruit size & \multicolumn{6}{|c|}{ Post-anthesis (medium size) } \\
\hline Tissue & \multicolumn{2}{|c|}{ Whole fruit } & \multicolumn{2}{|c|}{ Rind } & \multicolumn{2}{|c|}{ Flesh } \\
\hline Treatment & Control & Inoculated & Control & Inoculated & Control & Inoculated \\
\hline$\beta$-carotene & $5.67 \pm 0.61$ & $58.97 \pm 3.60$ & $18.23 \pm 1.98$ & $129.63 \pm 0.50$ & $0.13 \pm 0.08$ & $38.67 \pm 6.15$ \\
\hline$\alpha$-carotene & $0.00 \pm 0.00$ & $0.82 \pm 0.11$ & $0.00 \pm 0.00$ & $1.83 \pm 0.02$ & $0.00 \pm 0.00$ & $0.32 \pm 0.08$ \\
\hline Lutein & $4.30 \pm 0.60$ & $6.26 \pm 1.28$ & $11.82 \pm 0.93$ & $60.64 \pm 0.20$ & $1.44 \pm 0.20$ & $2.69 \pm 0.39$ \\
\hline Phytoene & $0.07 \pm 0.01$ & $7.08 \pm 0.56$ & $0.00 \pm 0.00$ & $5.05 \pm 0.00$ & $0.15 \pm 0.04$ & $5.29 \pm 1.53$ \\
\hline Fruit size & \multicolumn{6}{|c|}{ Commercial ripening } \\
\hline Tissue & \multicolumn{2}{|c|}{ Whole fruit } & \multicolumn{2}{|c|}{ Rind } & \multicolumn{2}{|c|}{ Flesh } \\
\hline Treatment & Control & Inoculated & Control & Inoculated & Control & Inoculated \\
\hline$\beta$-carotene & $6.35 \pm 2.11$ & $39.78 \pm 5.17$ & $64.54 \pm 34.92$ & $184.93 \pm 59.03$ & $0.05 \pm 0.09$ & $18.83 \pm 1.35$ \\
\hline$\alpha$-carotene & $0.00 \pm 0.00$ & $1.26 \pm 0.15$ & $0.32 \pm 0.37$ & $6.89 \pm 2.59$ & $0.00 \pm 0.00$ & $0.21 \pm 0.03$ \\
\hline Lutein & $4.54 \pm 1.00$ & $9.51 \pm 1.41$ & $33.56 \pm 16.94$ & $60.35 \pm 31.04$ & $0.99 \pm 0.08$ & $1.22 \pm 0.05$ \\
\hline Phytoene & $0.00 \pm 0.00$ & $4.44 \pm 0.15$ & $0.04 \pm 0.05$ & $13.37 \pm 4.14$ & $0.00 \pm 0.00$ & $3.71 \pm 0.96$ \\
\hline
\end{tabular}

Pigmented fruits from inoculated plants exhibit increased tocopherol accumulation

Carotenoids are synthesized from geranylgeranyl diphosphate (GGPP), a precursor that is also used for the production of phytol for chlorophylls, but also for other nutritionally relevant plastidial isoprenoids such as tocopherols (vitamin E) (Gutbrod et al., 2019; Muñoz and MunnéBosch, 2019; Rodriguez-Concepcion et al., 2018) . The crtB enzyme is known to convert GGPP into phytoene, the first committed step of the carotenoid pathway. To test whether increased diversion of GGPP towards the carotenoid pathway might negatively impact tocopherol accumulation, the levels of these isoprenoids were also determined in the rind and whole fruit at the commercial ripening stage. ZYMV-crtB-inoculated plants exhibited not a drop but a clear increase in $\alpha$ - and $\gamma$-tocopherol contents, especially in the rind of the fruits (Figure 5 and Table 
2). By contrast, chlorophylls levels were slightly decreased in pigmented fruits. Chlorophyll degradation is normally associated to viral infection and it has also been observed upon virusbased expression of crtB in tobacco leaves (Majer et al., 2017). It is therefore possible that the phytol released upon chlorophyll breakage might be recycled to produce tocopherols in the zucchini fruits of virus-inoculated plants. As a result, vitamin E levels are enriched 5-fold in whole fruits and 6-fold in the rind. Some zucchini yellow cultivars have been obtained introgressing the $B$ gene, which affects plastogenesis, bypassing the proplastid to chloroplast transition and preventing the accumulation of chlorophylls. However, these cultivars exhibit a compromised tocopherol accumulation (Tadmor et al., 2005).

Taken together, these analyses demonstrate that yellow-orange zucchinis harvested from ZYMV-crtB-inoculated plants provide nutritional benefits compared to those from market cultivars, including a substantial accumulation of highly valuable dietary isoprenoids, such as the carotenoids phytoene, lutein and others with provitamin A activity ( $\beta$-carotene and $\alpha$ carotene), as well as the vitamin $\mathrm{E} \alpha$ - and $\gamma$-tocopherol. Also, these results show that the use of genetically modified RNA viruses as vectors is a viable strategy for metabolically fortifying the edible tissues of non-transgenic plants. As long as biosecurity issues related to the use of manipulated viruses are properly managed (Brewer et al., 2018), this novel process presents strong potential to bring new metabolically fortified products to the market. 


\section{0}

\section{Commercial ripening}

\section{5}

40

35

-tocopherol

$\begin{array}{ll}\text { opd } & 30 \\ \text { 我 } & 25\end{array}$

a-tocopherol

20

15

10

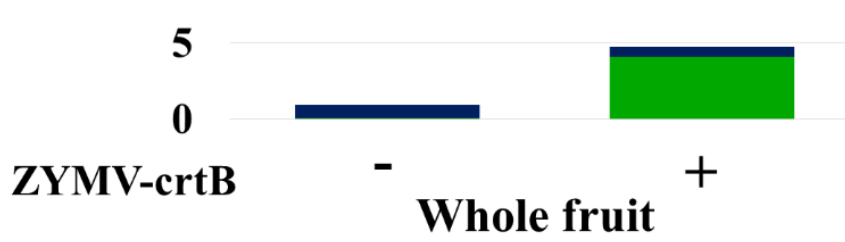

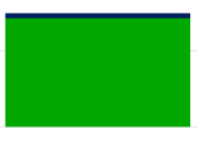

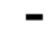

Figure 5. Accumulation of $\alpha$ - and $\gamma$-tocopherol in whole fruit and rind (as indicated) of green and yellow-orange zucchini fruits harvested from non-inoculated (-) and ZYMV-crtB-inoculated (+) plants, respectively, at commercial ripening stage. Bars represent average accumulation in three fruits harvested from three different plants. Numerical quantifications with standard deviations are in Table 2.

Table 2. Tocopherol content $\left(\mathrm{mg} \cdot \mathrm{kg}^{-1}\right.$ fresh weight; mean \pm standard deviation, $\mathrm{n}=3$ ) of zucchini fruits at commercial ripening development in non-inoculated controls and ZYMV-crtB-inoculated plants. Rind was also separately analyzed.

\begin{tabular}{|c|c|c|c|c|}
\hline Fruit size & \multicolumn{3}{|c|}{ Commercial ripening } \\
\hline Tissue & \multicolumn{2}{|c|}{ Whole fruit } & \multicolumn{2}{c|}{ Rind } \\
\hline Treatment & Control & Inoculated & Control & Inoculated \\
\hline $\boldsymbol{\gamma}$-tocopherol & $0.04 \pm 0.07$ & $4.06 \pm 0.08$ & $7.13 \pm 4.92$ & $41.63 \pm 5.32$ \\
\hline $\boldsymbol{\alpha}$-tocopherol & $0.89 \pm 0.14$ & $0.67 \pm 0.48$ & $0.31 \pm 0.44$ & $1.92 \pm 0.42$ \\
\hline
\end{tabular}

\section{Conclusion}

Metabolically fortified zucchini fruits of a visually attractive yellow-orange color can be produced by using a viral RNA vector to trigger carotenoid and tocopherol overaccumulation in fruits, with no manipulation of the plant genome. This strategy is easier and faster than both 
classic breeding and conventional genetic engineering. The use of engineered RNA viruses in metabolic fortification of edible plant organs, subject to appropriate regulation, may contribute to bringing new products to the food, animal feed, and pharma industries.

\section{Acknowledgements}

This research was supported by grants BIO2017-83184-R, BIO2017-84041-P, BIO201790877-REDT and AGL2017-85563-C2-1-R from Ministerio de Ciencia e Innovación (Spain), through Agencia Estatal de Investigación (cofinanced European Regional Development Fund) M.M. is the recipient of a predoctoral fellowship (FPU16/05294) from Ministerio de Educación, Cultura y Deporte (Spain). We also thank the genebank from Instituto Universitario de Conservación y Mejora de la Agrodiversidad Valenciana (COMAV), Universistat Politècnica de València.

\section{References}

Azevedo-Meleiro, C.H. and Rodriguez-Amaya, D.B. (2007) Qualitative and Quantitative Differences in Carotenoid Composition Among Cucurbita moschata, Cucurbita maxima, and Cucurbita pepo. J. Agric. Food Chem., 55, 4027-4033.

Bedoya, L., Martínez, F., Rubio, L., and Daròs, J.A. (2010) Simultaneous equimolar expression of multiple proteins in plants from a disarmed potyvirus vector. J. Biotechnol., 150, 268 275.

Bedoya, L.C. and Daròs, J.A. (2010) Stability of Tobacco etch virus infectious clones in plasmid vectors. Virus Res., 149.

Brewer, H.C., Hird, D.L., Bailey, A.M., Seal, S.E., and Foster, G.D. (2018) A guide to the contained use of plant virus infectious clones. Plant Biotechnol. J., 16, 832-843.

Cordero, T., Mohamed, M.A., López-Moya, J.J., and Daròs, J.A. (2017) A recombinant Potato virus Y infectious clone tagged with the Rosea1 visual marker (PVY-Ros1) facilitates the analysis of viral infectivity and allows the production of large amounts of anthocyanins in plants. Front. Microbiol., 8, 611.

Cunningham Jr., F.X., Chamovitz, D., Misawa, N., Gantt, E., and Hirschberg, J. (1993) Cloning and functional expression in Escherichia coli of a cyanobacterial gene for lycopene 
cyclase, the enzyme that catalyzes the biosynthesis of b-carotene. FEBS Lett., 328, 130138.

Diretto, G., Al-Babili, S., Tavazza, R., Papacchioli, V., Beyer, P., and Giuliano, G. (2007) Metabolic engineering of potato carotenoid content through tuber-specific overexpression of a bacterial mini-pathway. PLoS One, 2, e350.

Eisenhauer, B., Natoli, S., Liew, G., and Flood, V.M. (2017) Lutein and zeaxanthin — Food sources, bioavailability and dietary variety in age-related macular degeneration protection. Nutrients, 9 .

Esteras, C., Gómez, P., Monforte, A.J., Blanca, J., Vicente-Dólera, N., Roig, C., et al. (2012) High-throughput SNP genotyping in Cucurbita pepo for map construction and quantitative trait loci mapping. BMC Genomics, 13, 80.

Fischer, R. and Buyel, J.F. (2020) Molecular farming - The slope of enlightenment. Biotechnol. Adv., 40.

García-Plazaola, J.I. and Becerril, J.M. (1999) A rapid high-performance liquid chromatography method to measure lipophilic antioxidants in stressed plants: Simultaneous determination of carotenoids and tocopherols. Phytochem. Anal., 10, 307313.

Gutbrod, K., Romer, J., and Dörmann, P. (2019) Phytol metabolism in plants. Prog. Lipid Res., $74,1-17$.

Kulczynski, B. and Gramza-Michałowska, A. (2019) The profile of secondary metabolites and other bioactive compounds in cucurbita Pepo L. And cucurbita moschata pumpkin cultivars. Molecules, 24.

Llorente, B., Torres-Montilla, S., Morelli, L., Florez-Sarasa, I., Matus, J.T., Ezquerro, M., et al. (2020) Synthetic conversion of leaf chloroplasts into carotenoid-rich plastids reveals mechanistic basis of natural chromoplast development. Proc. Natl. Acad. Sci., 202004405.

Majer, E., Llorente, B., Rodríguez-Concepción, M., and Daròs, J.A. (2017) Rewiring carotenoid biosynthesis in plants using a viral vector. Sci. Rep., 7, 41645.

Margolin, E.A., Strasser, R., Chapman, R., Williamson, A.L., Rybicki, E.P., and Meyers, A.E. (2020) Engineering the Plant Secretory Pathway for the Production of Next-Generation Pharmaceuticals. Trends Biotechnol., 38, 1034-1044.

Martí, M., Diretto, G., Aragonés, V., Frusciante, S., Ahrazem, O., Gómez-Gómez, L., and Daròs, J.A. (2020) Efficient production of saffron crocins and picrocrocin in Nicotiana benthamiana using a virus-driven system. Metab. Eng., 61, 238-250. 
Martínez-Valdivieso, D., Font, R., Blanco-Díaz, M.T., Moreno-Rojas, J.M., Gómez, P., Alonso-Moraga, Á., and Del Río-Celestino, M. (2014) Application of near-infrared reflectance spectroscopy for predicting carotenoid content in summer squash fruit. Comput. Electron. Agric., 108, 71-79.

Montero-Pau, J., Blanca, J., Bombarely, A., Ziarsolo, P., Esteras, C., Martí-Gómez, C., et al. (2018) De novo assembly of the zucchini genome reveals a whole-genome duplication associated with the origin of the Cucurbita genus. Plant Biotechnol. J., 16, 1161-1171.

Muñoz, P. and Munné-Bosch, S. (2019) Vitamin E in Plants: Biosynthesis, Transport, and Function. Trends Plant Sci., 24, 1040-1051.

Rodriguez-Concepcion, M., Avalos, J., Bonet, M.L., Boronat, A., Gomez-Gomez, L., HorneroMendez, D., et al. (2018) A global perspective on carotenoids: Metabolism, biotechnology, and benefits for nutrition and health. Prog. Lipid Res., 70, 62-93.

Tadmor, Y., Paris, H.S., Meir, A., Schaffer, A.A., and Lewinsohn, E. (2005) Dual role of the pigmentation gene B in affecting carotenoid and vitamin E content in squash (Cucurbita pepo) mesocarp. J. Agric. Food Chem., 53, 9759-9763.

Thole, V., Worland, B., Snape, J.W., and Vain, P. (2007) The pCLEAN dual binary vector system for Agrobacterium-mediated plant transformation. Plant Physiol., 145, 12111219.

Wang, C., Zeng, J., Li, Y., Hu, W., Chen, L., Miao, Y., et al. (2014) Enrichment of provitamin A content in wheat (Triticum aestivum L.) by introduction of the bacterial carotenoid biosynthetic genes CrtB and CrtI. J. Exp. Bot., 65, 2545-2556.

Ye, X., Al-Babili, S., Klöti, A., Zhang, J., Lucca, P., Beyer, P., and Potrykus, I. (2000) Engineering the provitamin A (b-carotene) biosynthetic pathway into (carotenoid-free) rice endosperm. Science (80-. )., 287, 303-305.

Zheng, X., Giuliano, G., and Al-Babili, S. (2020) Carotenoid biofortification in crop plants: citius, altius, fortius. Biochim. Biophys. Acta - Mol. Cell Biol. Lipids, 1865, 158664.

Zhu, C., Naqvi, S., Breitenbach, J., Sandmann, G., Christou, P., and Capell, T. (2008) Combinatorial genetic transformation generates a library of metabolic phenotypes for the carotenoid pathway in maize. Proc. Natl. Acad. Sci. U. S. A., 105, 18232-18237. 


\section{Supplementary Material}

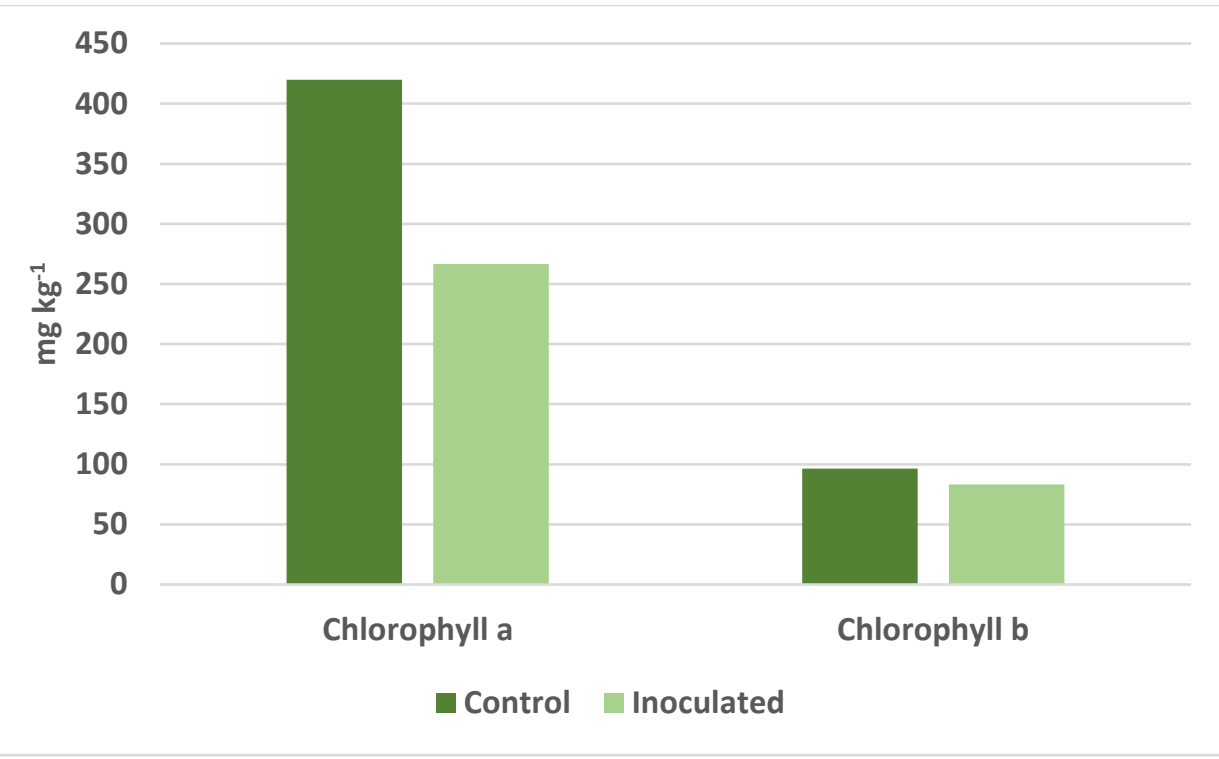

Fig. S1. Accumulation of chlorophylls at commercial ripening stage in zucchini rinds from noninoculated (-) and ZYMV-crtB-inoculated (+) plants. Bars represent average accumulation in three fruits harvested from three different plants. Numerical quantifications with standard deviations are in Suppl. Table 2.

Suppl. Table 2. Chlorophylls accumulation $\left(\mathrm{mg} \cdot \mathrm{kg}^{-1}\right.$ fresh weight; mean \pm standard deviation, $\mathrm{n}=3$ ) in rinds of zucchini fruits at commercial ripening development in non-inoculated controls and ZYMV-crtB-inoculated plants.

\begin{tabular}{|c|c|c|c|}
\hline \multicolumn{3}{|c|}{ Commercial ripening } \\
\hline \multicolumn{2}{|c|}{ Chlorophyll a } & \multicolumn{2}{c|}{ Chlorophyll b } \\
\hline Non-inoculated & ZYMV-crtB & Non-inoculated & ZYMV-crtB \\
\hline $419.9 \pm 162.0$ & $266.5 \pm 163.7$ & $96,3 \pm 33$ & $83,3 \pm 45$ \\
\hline
\end{tabular}



GENERAL DISCUSSION 


\section{GENERAL DISCUSSION}

Plants use energy descended utterly from the sun and transform $\mathrm{CO}_{2}$ to organic carbon that will genuinely generate carbohydrates in fruits and oxygen to other living organisms. The urge to improve plant production, plant defense or plant metabolic pathways has been constantly present in both conventional breeding and modern genetic engineering for the ultimate benefit of humans (Frailie and Innes, 2021; Lau et al., 2014). The pharmaceutical sector has also found in plants a great alternative to produce and over express health promoting molecules in a rapid and cost-effective manner. For that purpose, plant virus were used as transient expression vectors in a sophisticated method used to confront the challenges of low production and contamination found in microbial or mammalian cell-based expression (Pogue et al., 2010).

In this context, the perception of plant virus has changed radically from obligate parasite that drains their host and cause severe epidemical ravages and heavy economic losses on crops, to a helpful accomplice with valuable attributes for the great cause of molecular biology advances, thanks to their ability to produce high amount of viral proteins, which triggered the interest of scientists. Thus, several plants viruses have successfully been implied in vector constructs to overexpress heterologous proteins (Gleba et al., 2007; Lico et al., 2008; Pogue et al., 2002). Regardless of the small genome of plant virus, their manipulation needs adequate knowledge of virus biology and virus organization to avoid a misuse of this technology, whereas a single insertion of cDNA can be complicated to achieve.

In the first part of this work, we studied the ability of a potyviruses to be used in reverse genetic analysis. WMV is a well-known virus attacking mainly cucurbits with a large range of plant hosts. We used an infectious clone of a mild isolate of WMV to learn more about potyvirusbased VIGS. We investigated the effect of the insert on the performance of silencing and the stability of the vector under different configurations in viral organization: sense, antisense and hairpin; the inserted gene fragment corresponded to the second enzyme in the carotenoids biosynthesis pathway (PDS), easily observed as a photobleach phenotype. Our purpose in this study was to point out the efficiency of potyvirus vectors, taking advantages of their host diversity and their facility to be inoculated in plants. Potyviruses express well-known RNA silencing suppressors: potyviral HC-Pro, and viral protein genome-linked (VPg); which can be 
alleviated by using mild isolates like that used in our study, which is an infectious clone of a mild isolate of WMV(Aragonés et al., 2019).

Nonetheless, although potyviruses have a restrictive genome organization made up of a series of viral polyproteins, letting small possibilities for insert positions. Yet, plausible insert sites were studied and validated to express foreign genes in HC-Pro/P3, 6K1/CI, NIaPro/NIb, P1/HC-Pro and NIb/CP (Chen et al., 2007; Majer et al., 2014). In our study for potyviral VIGS in melon, we chose to investigate $\mathrm{NIb} / \mathrm{CP}$ intercistronic site, as it is the typical positions used to insert heterologous sequences in potyvirus-based vectors. Though, other insert sites might be adapted as well.

The study permitted to compare the best options, for an application of potyvirus based vector in melon and possibly other species. For the three constructs, no significant difference was found in the reduction of PDS mRNA; however, as a visual observation the effect was largely more apparent on antisense construct. Thus, both sense and antisense constructs allowed a stable expression on the inoculated plants; the third construct in hairpin configuration was quickly lost, but still could stimulate a phenotype of similar intensity to thoes of sense and antisense constructs, which were maintained in the progeny. This indicated that, even when the trigger dissapears, the plant silencing machinery could expand the silencing signals temporarily. As for the suitability of the construct modalities analyzed, the sense-oriented construct seems to be the best choice considering the convenience in maintaining the viral ORF in a straightforward position, which is preferable for further experimentations.

The second part of this work was about plant fortification of important molecules, such as carotenoids, which are essential in human diet for their health-related benefits(Llorente et al., 2017; Rodriguez-Concepcion et al., 2018). As it was reported (Llorente et al., 2020; Majer et al., 2017), zucchini plants infected by ZYMV-crtB vector colored infected leaves bright yellow. In continuation, we wanted to extend the finding to other organs of the plants, where this time the focus was on the fruit and its content in carotenoids in comparison to non-infected plants. The analyses demonstrated that ZYMV-crtB-inoculated plants had accumulated high amount of certain carotenoids, such as phytoene and provitamin A carotenoids ( $\beta$-carotene and $\alpha$ carotene) and lutein that was find at a concentration four time higher than a commercial yellow zucchini providing an overall added nutritional values to the product. Therefore, this results show the effectiveness of this technique as a fruit fortification method with valuable proteins, 
using genetically modified RNA viruses, without engendering transgenic transformations on the plant itself; only the RNA virus vector was meticulously modified to express the desired heterologous protein on the plant fruits in a safe and rapid approach, opening doors to a new alternative to metabolically fortify edible fruits in non-transgenic plants for food, livestock and pharmaceutical industries.

On the cellular level, carotenoids accumulation was found to be brought forth from the induced expression of heterologous crtB enzyme that trigger the production of phytoene, which is the interim of the carotenoid pathway, prompts the shift of chloroplast cells to chromoplasts, leading to cancellation of chloroplasts cells and an enhancement of carotenoids storage capacity in chloroplasts (Llorente et al., 2020). This was confirmed in our work in dark green zucchini plants

From the conducted assays, we can declare that potyviruses are valuable in reverse genetics and deserve to be used in VIGS systems, for their functionalities and broad possibilities to be inoculated in a large number of plant hosts. Potyviruses permit a better understanding of plant silencing machinery in front of the constraints caused by suppressor's factors, highly present in plant viruses, but still could be defeated and muted by a synthesized expression of heterologous genes. Whether the aim was to produce valued proteins, such as carotenoids to enhance fruit metabolic properties, or to trigger silencing of a specific endogenous trait in plant, with the overall help of a designed viral construct. Potyviruses keep intriguing and uncover hidden mechanisms deployed by the plant, when it is alarmed by a viral attack. In addition to the bio production of valuable proteins in a transient approach in a rapid and cost-effective way leading to a great demand of this natural bio factories as an attractive alternative for various industries for a better production chain system and great valued products. 

CONCLUSIONS 


\section{CONCLUSIONS}

An infectious clone of a mild isolate of Watermelon mosaic virus (WMV) has successfully proven to be an efficient virus-induced gene silencing (VIGS) vector to study gene function in melon by expressing fragments of Phytoene desaturase (PDS) mRNA between the WMV nuclear inclusion $b(\mathrm{NIb})$ and coat protein $(\mathrm{CP})$ cistrons.

We were able to build a new binary plasmid named pGWMV-VIGS that contains the full-length WMV-Vera infectious clone with the rearranged artificial NIaPro cleavage site between NIb and $\mathrm{CP}$ and with a unique $M l u \mathrm{I}$ cleavage site that allows plasmid linearization and insertion of the foreign gene fragment in a single Gibson assembly step.

Vector stability and the effect of the insert on gene silencing was verified, by testing three different modalities; and has revealed a stable expression of the PDS insert in both sense and antisense, though sense modality is preferred for its facility to keep viral open reading frame (ORF).

The hairpin modality has failed to maintain the insert in the progeny; beyond that, interestingly it has exhibited amplification and transitory maintenance of the silencing signals even without the presence of the trigger.

We have demonstrated that potyviruses isolates such as WMV-Vera that induces mild symptoms can be efficiently used for VIGS.

A viral RNA vector has shown to be efficient to express crtB-encoding sequences in the fruits of adult zucchini plants; inoculation of leaves that directly nurture the developing flower has displayed fully yellow-orange colored fruits.

Zucchini fruits from plants inoculation with ZYMV-crtB exhibited an increase in carotenoid accumulation in in all three developmental stages analyzed (ripening stage, post-anthesis, preanthesis) showing a significant raise in the accumulation of four carotenoids (phytoene, $\alpha$ - and $\beta$-carotene, and lutein) and $\alpha$ - and $\gamma$-tocopherol in whole fruits, as well as in rind and flesh tissues. 
We exploited the possibilities of potyvius-based vectors as an alternative to metabolically fortify edible fruits of non-transgenic plants, always considering biosafety regulation for a proper manipulation of viral clones. 



\section{BIBILIOGRAPHY}




\section{BIBILIOGRAPHY}

Aragonés, V., Pérez-de-Castro, A., Cordero, T., Cebolla-Cornejo, J., López, C., Picó, B., and Daròs, J.A. (2019) A Watermelon mosaic virus clone tagged with the yellow visual maker phytoene synthase facilitates scoring infectivity in melon breeding programs. Eur. J. Plant Pathol., 153, 317-323.

Arazi, T., Moshe Shiboleth, Y., Lee Huang, P., Huang, P.L., Zhang, L., Lee-Huang, S., and Gal-On, A. (2002) Production of antiviral and antitumor proteins MAP30 and GAP31 in cucurbits using the plant virus vector ZYMV-AGII. Biochem. Biophys. Res. Commun., 292, $441-448$.

Arazi, T., Slutsky, S.G., Shiboleth, Y.M., Wang, Y., Rubinstein, M., Barak, S., et al. (2001) Engineering zucchini yellow mosaic potyvirus as a non-pathogenic vector for expression of heterologous proteins in cucurbits. J. Biotechnol., 87, 67-82.

Bedoya, L., Martínez, F., Rubio, L., and Daròs, J.A. (2010) Simultaneous equimolar expression of multiple proteins in plants from a disarmed potyvirus vector. J. Biotechnol., 150, 268275.

Burch-Smith, T.M., Anderson, J.C., Martin, G.B., and Dinesh-Kumar, S.P. (2004) Applications and advantages of virus-induced gene silencing for gene function studies in plants. Plant J., 39, 734-746.

Canto, T. (2016) Transient Expression Systems in Plants: Potentialities and Constraints. M.C. Vega (ed.), Adv. Technol. Protein Complex Prod. Charact. Adv. Exp. Med. Biol., 287-301.

Carbonell, A., García, J.A., Simón-Mateo, C., and Hernández, C. (2016) Plant Virus RNA Replication. eLS, 1-13.

Carrington, J.C., Haldeman, R., Dolja, V. V, and Restrepo-Hartwig, M.A. (1993) Internal cleavage and trans-proteolytic activities of the VPg-proteinase (NIa) of tobacco etch potyvirus in vivo. J. Virol., 67, 6995-7000.

Chen, C.C., Chen, T.C., Raja, J.A.J., Chang, C.A., Chen, L.W., Lin, S.S., and Yeh, S.D. (2007) Effectiveness and stability of heterologous proteins expressed in plants by Turnip mosaic virus vector at five different insertion sites. Virus Res., 130, 210-227. 
Chen, T.C., Hsu, H.T., Jain, R.K., Huang, C.W., Lin, C.H., Liu, F.L., and Yeh, S.D. (2005) Purification and serological analyses of tospoviral nucleocapsid proteins expressed by Zucchini yellow mosaic virus vector in squash. J. Virol. Methods, 129, 113-124.

Chilton, M.D., Drummond, M.H., Merlo, D.J., Sciaky, D., Montoya, A.L., Gordon, M.P., and Nester, E.W. (1977) Stable incorporation of plasmid DNA into higher plant cells: the molecular basis of crown gall tumorigenesis. Cell, 11, 263-271.

Chung, B.Y.W., Miller, W.A., Atkins, J.F., and Firth, A.E. (2008) An overlapping essential gene in the Potyviridae. Proc. Natl. Acad. Sci. U. S. A., 105, 5897-5902.

Desbiez, C. and Lecoq, H. (2004) The nucleotide sequence of Watermelon mosaic virus (WMV, Potyvirus) reveals interspecific recombination between two related potyviruses in the $5^{\prime}$ part of the genome. Arch. Virol., 149, 1619-1632.

Desbiez, C. and Lecoq, H. (1997) Zucchini yellow mosaic virus. Plant Pathol., 46, 809-829.

Dinesh-Kumar, S.P., Anandalakshmi, R., Marathe, R., Schiff, M., and Liu, Y. (2003) Virusinduced gene silencing. Methods Mol. Biol., 236, 287-294.

Von Dohlen, C.D., Rowe, C.A., and Heie, O.E. (2006) A test of morphological hypotheses for tribal and subtribal relationships of Aphidinae (Insecta: Hemiptera: Aphididae) using DNA sequences. Mol. Phylogenet. Evol., 38, 316-329.

Dolja, V. V., McBride, H.J., and Carrington, J.C. (1992) Tagging of plant potyvirus replication and movement by insertion of $\beta$ - glucuronidase into the viral polyprotein. Proc. Natl. Acad. Sci. U. S. A., 89, 10208-10212.

Dommes, A.B., Gross, T., Herbert, D.B., Kivivirta, K.I., and Becker, A. (2019) Virus-induced gene silencing: Empowering genetics in non-model organisms. J. Exp. Bot., 70, 817-833.

Elena, S.F. and Sanjuán, R. (2007) Virus evolution: Insights from an experimental approach. Annu. Rev. Ecol. Evol. Syst., 38, 27-52.

Faivre-Rampant, O., Gilroy, E.M., Hrubikova, K., Hein, I., Millam, S., Loake, G.J., et al. (2004) Potato virus X-induced gene silencing in leaves and tubers of potato. Plant Physiol., 134, $1308-1316$.

Frailie, T.B. and Innes, R.W. (2021) Engineering healthy crops: molecular strategies for 
enhancing the plant immune system. Curr. Opin. Biotechnol., 70, 151-157.

Fraser, P.D. and Bramley, P.M. (2004) The biosynthesis and nutritional uses of carotenoids. Prog. Lipid Res., 43, 228-265.

Gal-On, A., Antignus, Y., Rosner, A., and Raccah, B. (1992) A zucchini yellow mosaic virus coat protein gene mutation restores aphid transmissibility but has no effect on multiplication. J. Gen. Virol., 73, 2183-2187.

Gammelgård, E., Mohan, M., and Valkonen, J.P.T. (2007) Potyvirus-induced gene silencing: The dynamic process of systemic silencing and silencing suppression. J. Gen. Virol., 88, 2337-2346.

Gibbs, A.J., Ohshima, K., Phillips, M.J., and Gibbs, M.J. (2008) The prehistory of potyviruses: Their initial radiation was during the dawn of agriculture. PLoS One, 3.

Gibson, D.G., Young, L., Chuang, R.Y., Venter, J.C., Hutchison 3rd, C.A., and Smith, H.O. (2009) Enzymatic assembly of DNA molecules up to several hundred kilobases. Nat. Methods, 6, 343-345.

Gleba, Y., Klimyuk, V., and Marillonnet, S. (2007) Viral vectors for the expression of proteins in plants. Curr. Opin. Biotechnol., 18, 134-141.

Grimsley, N., Hohn, B., Hohn, T., and Walden, R. (1986) “Agroinfection,” an alternative route for viral infection of plants by using the Ti plasmid. Proc. Natl. Acad. Sci., 83, 3282-3286.

Grumet, R., Garcia-Mas, J., and Katzir, N. (2017) Cucurbit Genetics and Genomics: A Look to the Future. 409-415.

Guo, D., Rajamäki, M.L., Saarma, M., and Valkonen, J.P.T. (2001) Towards a protein interaction map of potyviruses: Protein interaction matrixes of two potyviruses based on the yeast two-hybrid system. J. Gen. Virol., 82, 935-939.

Hefferon, K.L. (2012) Plant virus expression vectors set the stage as production platforms for biopharmaceutical proteins. Virology, 433, 1-6.

Heinlein, M. (2015) Plant virus replication and movement. Virology, 479-480, 657-671.

Hidalgo, D., Lalaleo, L., Bonfill, M., and Palazon, J. (2018) Biotechnological Production of Pharmaceuticals and Biopharmaceuti-cals in Plant Cell and Organ Cultures. 3577-3596. 
Howell, S.H. and Hull, R. (1978) Replication of cauliflower mosaic virus and transcription of its genome in turnip leaf protoplasts. Virology, 86, 468-481.

Ivanov, K.I., Eskelin, K., Lõhmus, A., and Mäkinen, K. (2014) Molecular and Cellular Mechanisms Underlying Potyvirus Infection.

Johansen, I.E. (1996) Intron insertion facilitates amplification of cloned virus cDNA in Escherichia coli while biological activity is reestablished after transcription in vivo. Proc. Natl. Acad. Sci. U. S. A., 93, 12400-12405.

Johansen, L.. and Carrington, J.. (2001) Silencing on the Spot. Induction and Suppression of RNA Silencing in the. Plant Physiol., 126, 930-938.

Van Kammen, A. (1997) Virus-induced gene silencing in infected and transgenic plants. Trends Plant Sci, 2, 409-410.

Kang, M., Seo, J.K., Choi, H., Choi, H.S., and Kim, K.H. (2016) Establishment of a simple and rapid gene delivery system for cucurbits by using engineered of Zucchini yellow mosaic virus. Plant Pathol. J., 32, 70-76.

Kelloniemi, J., Mäkinen, K., and Valkonen, J.P.T. (2008) Three heterologous proteins simultaneously expressed from a chimeric potyvirus: Infectivity, stability and the correlation of genome and virion lengths. Virus Res., 135, 282-291.

Kumagai, M.H., Donson, J., della-Cioppa, G., Harvey, D., Hanley, K., and Grill, L.K. (1995) Cytoplasmic inhibition of carotenoid biosynthesis with virus-derived RNA. Proc Natl Acad Sci USA, 92, 1679-1683.

Kusnadi, A.R., Nikolov, Z.L., and Howard, J.A. (1997) Production of recombinant proteins in transgenic plants: Practical considerations. Biotechnol. Bioeng., 56, 473-484.

Lau, W., Fischbach, M.A., Osbourn, A., and Sattely, E.S. (2014) Key Applications of Plant Metabolic Engineering. PLoS Biol., 12, 1-5.

Lebeda, A., Widrlechner, M.P., Staub, J., Ezura, H., Zalapa, J., and Křístková, E. (2006) Cucurbits (cucurbitaceae; cucumis spp., cucurbita spp., citrullus spp.). Genet. Resour. Chromosom. Eng. Crop Improv. Veg. Crop., 3, 271-376.

LECOQ, H., PITRAT, M., and CLÉMENT, M. (1981) Identification et caractérisation d'un 
potyvirus provoquant la maladie du rabougrissement jaune du melon. Agronomie, 1, 827834.

Lecoq, H., Wipf-Scheibel, C., Chandeysson, C., Lê Van, A., Fabre, F., and Desbiez, C. (2009) Molecular epidemiology of Zucchini yellow mosaic virus in France: An historical overview. Virus Res., 141, 190-200.

Lico, C., Chen, Q., and Santi, L. (2008) Viral vectors for production of recombinant proteins in plants. J. Cell. Physiol., 216, 366-377.

Liu, M., Liang, Z., Aranda, M.A., Hong, N., Liu, L., Kang, B., and Gu, Q. (2019) A cucumber green mottle mosaic virus vector for virus-induced gene silencing in cucurbit plants. bioRxiv.

Llorente, B., Martinez-Garcia, J.F., Stange, C., and Rodriguez-Concepcion, M. (2017) Illuminating colors: regulation of carotenoid biosynthesis and accumulation by light. Curr. Opin. Plant Biol., 37, 49-55.

Llorente, B., Torres-Montilla, S., Morelli, L., Florez-Sarasa, I., Matus, J.T., Ezquerro, M., et al. (2020) Synthetic conversion of leaf chloroplasts into carotenoid-rich plastids reveals mechanistic basis of natural chromoplast development. Proc. Natl. Acad. Sci. U. S. A., 117, 21796-21803.

Lomonossoff, G.P. and Wege, C. (2018) TMV Particles: The Journey From Fundamental Studies to Bionanotechnology Applications, 1st edn. Elsevier Inc.

Lucas, W.J. (2006) Plant viral movement proteins: Agents for cell-to-cell trafficking of viral genomes. Virology, 344, 169-184.

Majer, E., Llorente, B., Rodríguez-Concepción, M., and Daròs, J.A. (2017) Rewiring carotenoid biosynthesis in plants using a viral vector. Sci. Rep., 7, 1-10.

Majer, E., Navarro, J.A., and Daròs, J.A. (2015) A potyvirus vector efficiently targets recombinant proteins to chloroplasts, mitochondria and nuclei in plant cells when expressed at the amino terminus of the polyprotein. Biotechnol. J., 10, 1792-1802.

Majer, E., Salvador, Z., Zwart, M.P., Willemsen, A., Elena, S.F., and Daros, J.-A. (2014) Relocation of the NIb Gene in the Tobacco Etch Potyvirus Genome. J. Virol., 88, 45864590. 
Mäkinen, K. (2020) Plant susceptibility genes as a source for potyvirus resistance. Ann. Appl. Biol., 176, 122-129.

Martí, M., Diretto, G., Aragonés, V., Frusciante, S., Ahrazem, O., Gómez-Gómez, L., and Daròs, J.A. (2020) Efficient production of saffron crocins and picrocrocin in Nicotiana benthamiana using a virus-driven system. Metab. Eng., 61, 238-250.

Mathur, C., Jimsheena, V.K., Banerjee, S., Makinen, K., Gowda, L.R., and Savithri, H.S. (2012) Functional regulation of PVBV Nuclear Inclusion protein-a protease activity upon interaction with Viral Protein genome-linked and phosphorylation. Virology, 422, 254264.

Meier, S., Tzfadia, O., Vallabhaneni, R., Gehring, C., and Wurtzel, E.T. (2011) A transcriptional analysis of carotenoid, chlorophyll and plastidial isoprenoid biosynthesis genes during development and osmotic stress responses in Arabidopsis thaliana. BMC Syst. Biol., 5.

Mingot, A., Valli, A., Rodamilans, B., San León, D., Baulcombe, D.C., García, J.A., and LópezMoya, J.J. (2016) The PIN-PISPO trans -Frame Gene of Sweet Potato Feathery Mottle Potyvirus Is Produced during Virus Infection and Functions as an RNA Silencing Suppressor . J. Virol., 90, 3543-3557.

Moore, C.J., Sutherland, P.W., Forster, R.L.S., Gardner, R.C., and MacDiarmid, R.M. (2001) Dark green islands in plant virus infection are the result of posttranscriptional gene silencing. Mol. Plant-Microbe Interact., 14, 939-946.

Nigam, D., LaTourrette, K., Souza, P.F.N., and Garcia-Ruiz, H. (2019) Genome-Wide Variation in Potyviruses. Front. Plant Sci., 10, 1-28.

Peyret, H. and Lomonossoff, G.P. (2015) When plant virology met Agrobacterium: The rise of the deconstructed clones. Plant Biotechnol. J., 13, 1121-1135.

Pogue, G.P., Lindbo, J.A., Garger, S.J., and Fitzmaurice, W.P. (2002) Making an ally from an enemy: Plant virology and the new agriculture. Annu. Rev. Phytopathol., 40, 45-74.

Pogue, G.P., Vojdani, F., Palmer, K.E., Hiatt, E., Hume, S., Phelps, J., et al. (2010) Production of pharmaceutical-grade recombinant aprotinin and a monoclonal antibody product using plant-based transient expression systems. 638-654. 
Porta, C. and Lomonossoff, G.P. (2002) Viruses as vectors for the expression of foreign sequences in plants. Biotechnol. Genet. Eng. Rev., 19, 245-292.

Purkayastha, A., Mathur, S., Verma, V., Sharma, S., and Dasgupta, I. (2010) Virus-induced gene silencing in rice using a vector derived from a DNA virus. Planta, 232, 1531-1540.

Renner, S. and Shaefer, H. (2016) Gourds: Bitter, Bottle, Wax, Snake, Sponge and Ridge. 155172.

Revers, F. and García, J.A. (2015) Molecular biology of potyviruses, 1st edn. Elsevier Inc.

Robertson, D. (2004) VIGS Vectors for Gene Silencing: Many targets, many tools. Annu. Rev. Plant Biol., 55, 495-519.

Rodriguez-Concepcion, M., Avalos, J., Bonet, M.L., Boronat, A., Gomez-Gomez, L., HorneroMendez, D., et al. (2018) A global perspective on carotenoids: Metabolism, biotechnology, and benefits for nutrition and health. Prog. Lipid Res., 70, 62-93.

Rolnik, A. and Olas, B. (2020) Vegetables from the Cucurbitaceae family and their products: Positive effect on human health. Nutrition, 78, 110788.

Rybicki, E.P. (2020) Plant molecular farming of virus-like nanoparticles as vaccines and reagents. Wiley Interdiscip. Rev. Nanomedicine Nanobiotechnology, 12, 1-22.

Sanfaçon, H. (2017) Grand challenge in plant virology: Understanding the impact of plant viruses in model plants, in agricultural crops, and in complex ecosystems. Front. Microbiol., 8, 2013-2016.

Schaad, M.C., Haldeman-Cahill, R., Cronin, S., and Carrington, J.C. (1996) Analysis of the VPg-proteinase (NIa) encoded by tobacco etch potyvirus: effects of mutations on subcellular transport, proteolytic processing, and genome amplification. J. Virol., 70, 7039-7048.

Shanmugaraj, B., Bulaon, C.J.I., and Phoolcharoen, W. (2020) Plant molecular farming: A viable platform for recombinant biopharmaceutical production. Plants, 9, 1-19.

Shiboleth, Y.M., Arazi, T., Wang, Y., and Gal-On, A. (2001) A new approach for weed control in a cucurbit field employing an attenuated potyvirus-vector for herbicide resistance. J. Biotechnol., 92, 37-46. 
Simon, A.. and Bujaraski, J.. (1994) RNA-RNA RECOMBINATION AND EVOLUTION IN VIRUS-INFECTED PLANTS A. Annu. Rev. Phytopathol. 1994. 32337-62 Copyr. (C) 1994 by Annu. Rev. Inc. All rights Reserv. Annu., 32:, 337-62.

Szeto, W.W., Hamer, D.H., Carlson, P.S., and Thomas, C.A. (1977) Cloning of Cauliflower Mosaic Virus (CLMV) DNA in Escherichia coli. Science (80-. )., 196, 210-212.

Teresa Ruiz, M., Voinnet, O., and Baulcombe, D.C. (1998) Initiation and maintenance of virusinduced gene silencing. Plant Cell, 10, 937-946.

Vaistij, F.E. and Jones, L. (2009) Compromised virus-induced gene silencing in rdr6-deficient plants. Plant Physiol., 149, 1399-1407.

Valentine, T., Shaw, J., Blok, V.C., Phillips, M.S., Oparka, K.J., and Lacomme, C. (2004) Efficient virus-induced gene silencing in roots using a modified tobacco rattle virus vector. Plant Physiol., 136, 3999-4009.

Vasil, I.K. (2008) A history of plant biotechnology: From the cell theory of Schleiden and Schwann to biotech crops. Plant Cell Rep., 27, 1423-1440.

Wang, M., Gao, S., Zeng, W., Yang, Y., Ma, J., and Wang, Y. (2020) Plant Virology Delivers Diverse Toolsets for Biotechnology. Viruses, 12, 1-16.

Wang, W., Yuan, J., and Jiang, C. (2021) Applications of nanobodies in plant science and biotechnology. Plant Mol. Biol., 105, 43-53.

Wassenegger, M., Heimes, S., Riedel, L., and Sänger, H.L. (1994) RNA-directed de novo methylation of genomic sequences in plants. Cell, 76, 567-576.

Wurtzel, E.T. (2019) Changing form and function through carotenoids and synthetic biology. Plant Physiol., 179, 830-843.

Wylie, S.J., Adams, M., Chalam, C., Kreuze, J., Jos, J., Ohshima, K., et al. (2017) ICTV ICTV Virus Taxonomy Profile: Potyviridae. 352-354.

Xu, J., Dolan, M.C., Medrano, G., Cramer, C.L., and Weathers, P.J. (2012) Green factory: Plants as bioproduction platforms for recombinant proteins. Biotechnol. Adv., 30, 11711184.

Zamora, M., Méndez-López, E., Agirrezabala, X., Cuesta, R., Lavín, J.L., Amelia Sánchez- 
Pina, M., et al. (2017) Potyvirus virion structure shows conserved protein fold and RNA binding site in ssRNA viruses. Sci. Adv., 3, 2-8.

Zhao, F., Lim, S., Igori, D., Yoo, R.H., Kwon, S.Y., and Moon, J.S. (2016) Development of tobacco ringspot virus-based vectors for foreign gene expression and virus-induced gene silencing in a variety of plants. Virology, 492, 166-178. 
